\title{
Physiology of Circadian Entrainment
}

\author{
DIEGO A. GOLOMBEK AND RUTH E. ROSENSTEIN
}

\begin{abstract}
Department of Science and Technology, University of Quilmes/Consejo Nacional de Investigaciones Científicas y Tecnológicas (CONICET), Quilmes; and Department of Human Biochemistry, University of Buenos Aires/ CONICET, Buenos Aires, Argentina
\end{abstract}

$\begin{array}{lr}\text { I. A Brief History of Circadian Time } & 1063 \\ \text { II. Circadian Entrainment: an Adaptive Feature } & 1066 \\ \text { III. Size (of Light) and Time Matters: Effect of Short or Long Light Pulses on Circadian Phase } & 1066 \\ \text { A. Phase response curves } & 1068 \\ \text { IV. There Is Life After Light } & 1069 \\ \text { A. "Unmasking" the effects of light } & 1070 \\ \text { V. Entrainment in the Field } & 1071 \\ \text { VI. Different Superchiasmatic Nuclei Oscillators Responding to Light } & 1071 \\ \text { VII. The Doors of Perception: the Retina as a Circadian Photic Transducer } & 1073 \\ \text { A. Retinal circadian rhythms } & 1073 \\ \text { B. Novel photoreceptors and the circadian biology } & 1074 \\ \text { C. Light is the message } & 1076 \\ \text { VIII. Retinohypothalamic Interactions and Suprachiasmatic Nuclei Neurophysiology } & 1076 \\ \text { IX. Signal Transduction in the Mammalian Suprachiasmatic Nuclei } & 1079 \\ \text { A. Entrainment "alla CREB" } & 1081 \\ \text { B. A MAPK of circadian entrainment } & 1083 \\ \text { C. Lights means NO: the NO-cGMP system in circadian entrainment } & 1084 \\ \text { X. From Light to Genes: Moving the Hands of the Circadian Clock } & 1085 \\ \text { XI. Evolutionary and Clinical Perspectives on Circadian Entrainment } & 1087\end{array}$

Golombek DA, Rosenstein RE. Physiology of Circadian Entrainment. Physiol Rev 90: 1063-1102, 2010; doi:10.1152/physrev.00009.2009.-Mammalian circadian rhythms are controlled by endogenous biological oscillators, including a master clock located in the hypothalamic suprachiasmatic nuclei (SCN). Since the period of this oscillation is of $\sim 24 \mathrm{~h}$, to keep synchrony with the environment, circadian rhythms need to be entrained daily by means of Zeitgeber ("time giver") signals, such as the light-dark cycle. Recent advances in the neurophysiology and molecular biology of circadian rhythmicity allow a better understanding of synchronization. In this review we cover several aspects of the mechanisms for photic entrainment of mammalian circadian rhythms, including retinal sensitivity to light by means of novel photopigments as well as circadian variations in the retina that contribute to the regulation of retinal physiology. Downstream from the retina, we examine retinohypothalamic communication through neurotransmitter (glutamate, aspartate, pituitary adenylate cyclase-activating polypeptide) interaction with SCN receptors and the resulting signal transduction pathways in suprachiasmatic neurons, as well as putative neuron-glia interactions. Finally, we describe and analyze clock gene expression and its importance in entrainment mechanisms, as well as circadian disorders or retinal diseases related to entrainment deficits, including experimental and clinical treatments.

\section{A BRIEF HISTORY OF CIRCADIAN TIME}

Nested deep within the mammalian brain, a tiny pair of nuclei control the times of our lives. Indeed, we, and most creatures, arrive on Earth fully equipped with a brain watch that helps us to cope with the predictable temporal changes in our home: the day and the year.

Notwithstanding, several natural cycles may have been instrumental in the evolutionary acquisition of a (periodic) time sense: not only those directly related to rotation and translation but also tidal movements, geomagnetic influences, food (including prey) availability, and even social interactions have certainly shaped our behavior and physiology in the temporal domain. However, since it is quite obvious that these temporal cues are relatively accurate, a question remains regarding the adaptive value of internal clocks in a predictable, cyclic universe. In other words, why do we need a timing machine when just by sensing the environment we could react quickly to the different needs imposed by the days or the seasons?

There might be several explanations for this apparent paradox. Maybe sometimes Nature is not as reliable as needed, and does not give the adequate temporal cues to 
guide behavior. Indeed, there are situations when most environmental variables are virtually stable, such as what happens in extreme latitudes, including the Arctic and Antarctica. When investigating foraging activity of chinstrap Penguins in the Antarctic South Shetland Islands, one of us reported a clear daily rhythm for the colony even under constant light and temperature conditions (160); there is a certain method in this mad rhythmicity. On the other hand, an hourglass kind of clock that needs to be pushed from time to time by some kind of stimulation does not allow any predictive capabilities, but only passive responses to the environment. One of the main advantages of an inner clockwork mechanism is that of anticipation to predictable changes, thus permitting the organism to be prepared to respond to future challenges in the optimal way. Finally, an endogenous clock might be considered as an orchestral conductor that arranges the rhythm and synchrony of the various components in the body.

Even with classical experiments such as De Mairan's 1729 demonstration of an endogenous rhythm in leaf movement of Mimosa plants (99), among many others, the notion of an inner clock remained quite elusive until the mid 20th century (Table 1). The term circadian was introduced in the 1950s to identify self-sustained rhythms under constant conditions.

A distinct and simple scheme summarized the main features of the circadian system: under natural conditions, diurnal rhythms in most behaviors and physiological variables responded to environmental variables such as the light-dark cycle. However, since in the absence of such cues rhythms persisted, an additional endogenous component was added to the system: "the biological clock." This linear pathway proved quite useful to understand the main features of circadian rhythms: entrainment (synchronization; i.e., driving of endogenous oscillations to external cycles) of circadian clocks by the environment and efferent pathways from this clock that drive rhythmicity throughout the body. For chronobiology made simple, in three boxes and two arrows, see Figure $1 A$.

However, the pathway soon proved to be too simple, since external stimulation could directly affect output variables; indeed, when turning the lights on during the night in an animal room results in a sudden silence, due to the masking of light on behavior. Masking has now been fully described in terms of its neurochemical pathways, and it can also be considered as a driving force for the evolution of circadian rhythms $(44,296,348)$. On the other hand, output variables might also feedback upon the oscillator; such is the case of circadian melatonin secretion by the pineal gland, which in turn might act upon specific receptors on the clock (Fig. $1 B$ ). Even more: input variables might be under circadian control by the biological clock, therefore closing an ouroboros-like creature (the dragon that devours its own tail and forms a circle, representing an eternal cycle) where the output becomes the input. An interesting example is the circadian change in photoreceptor function (as a clock output), which in turn results in a temporal variation in the input pathway to the clock (Fig. 1C).

Going back to the linear model of chronobiology, three main questions stand out right away. 1) Where is the

TABLE 1. A brief history of biological time

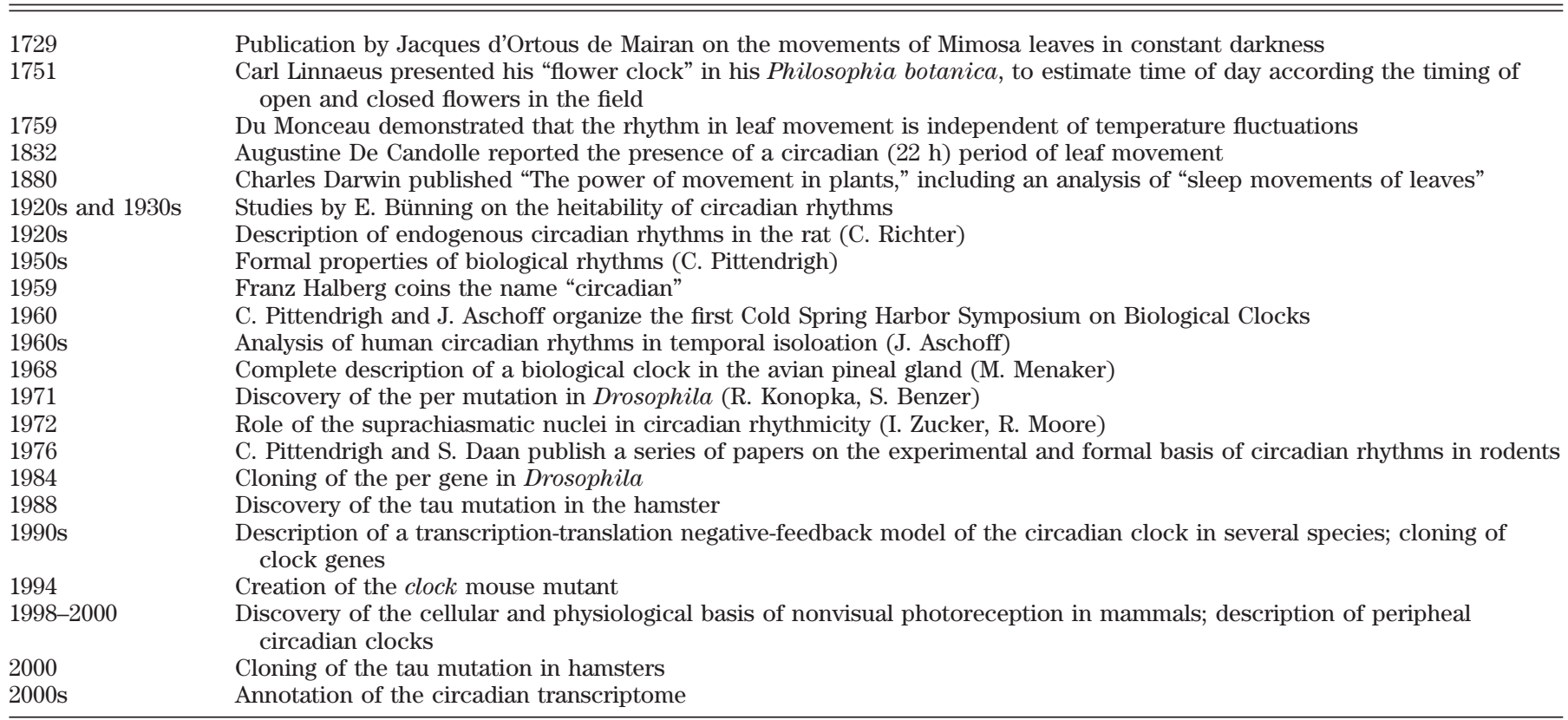

Historical milestones of chronobiology. For additional references and explanation, see Reference 415. 
A

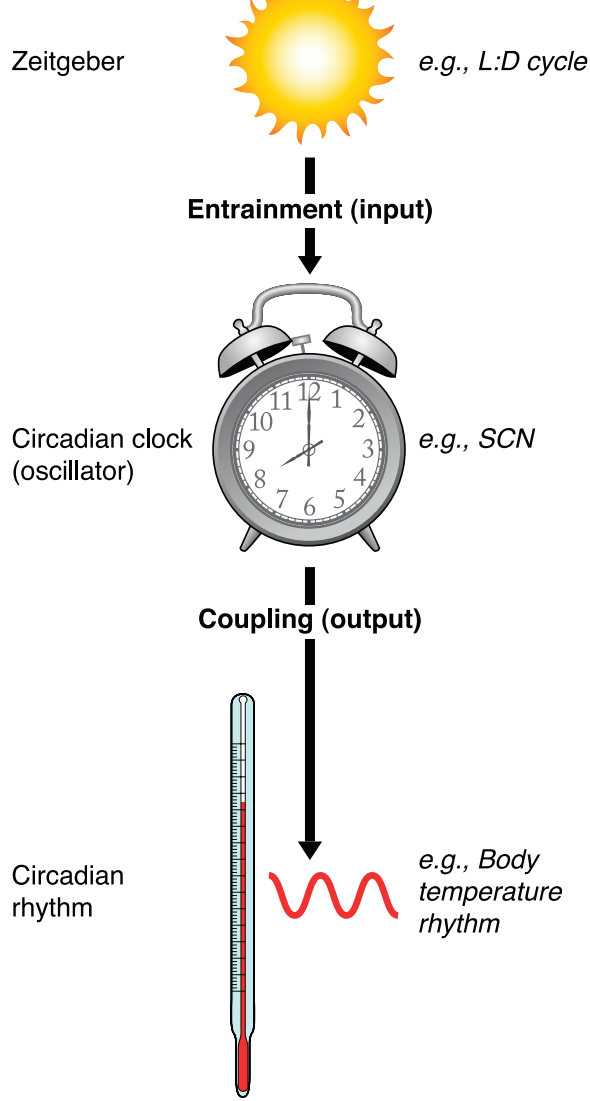

B

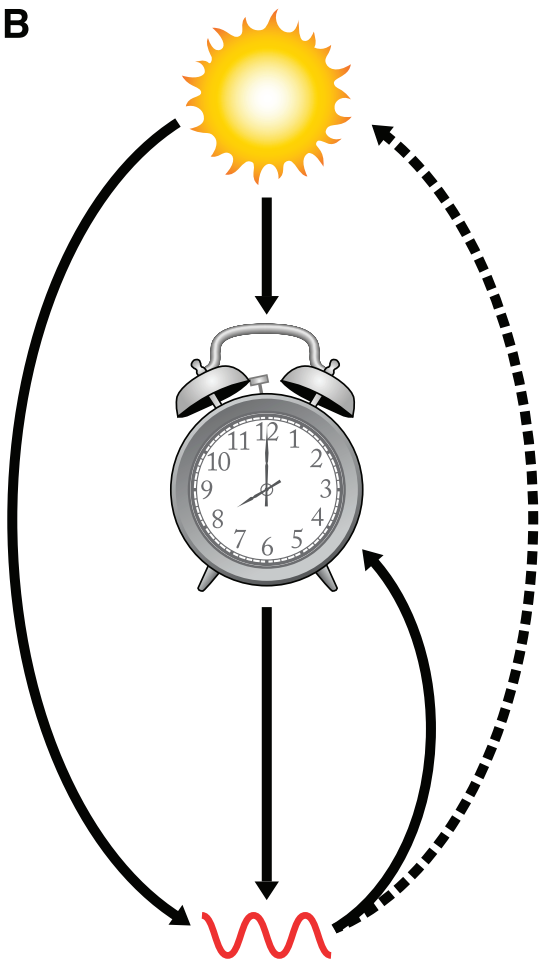

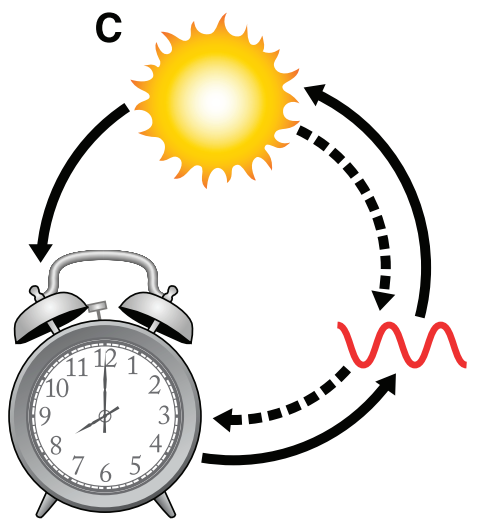

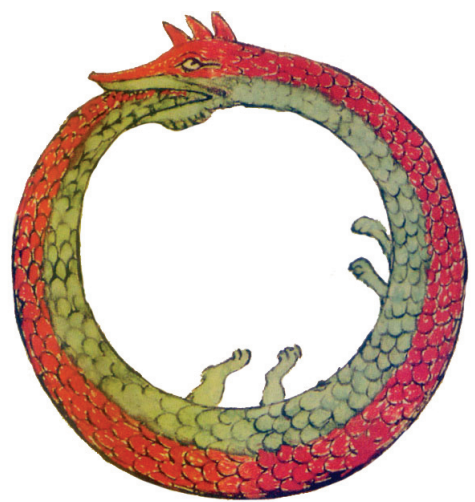

FIG. 1. A simplified scheme of the circadian system. A: a linear model which includes an endogenous oscillator (e.g., the hypothalamic suprachiasmatic nuclei), the environmental entrainment agent (zeitgeber), and the output that governs overt biological rhythms. This 3-box, 2-arrow scheme helps to exemplify the three main questions of chronobiology. 1) The endogenous oscillator: where and how is the endogenous clock organized, and what is the cellular/molecular basis of circadian function? 2) Entrainment: how is the clock entrained to achieve an ecological adaptive role? 3) Output: how does the endogenous clock couple and control temporal synchrony? B: a more complex view based on solid evidence emphasizes a nonlinear relationship between the components of the model. Clock-controlled rhythms often include variables that feedback into the endogenous oscillator, in a similar fashion to physiological homeostatic mechanisms. Moreover, these variables might affect the input pathway (e.g., a clock-controlled circadian rhythm of photoreceptor structures). On the other hand, input signals might directly affect physiological and behavioral variables without the participation of the clock (masking). $C$ : the circadian system as an ouroboros, a self-devouring dragon.

clock located and how does it work? 2) How does it interact with the environment? 3) How does the clock tell time to the rest of the body? The search for the biological circadian clock in mammals remains as one of the finest adventures in structure-function relationship in the central nervous system. Early approaches suggested a hypothalamic location for such an oscillator (339), although its precise neuroanatomical niche remained quite elusive until the 1970s. Being fair, a forerunner of the path to be taken was Argentinean writer Julio Cortázar who, as early as 1960 , wrote that "time enters through the eyes, everybody knows that" (87a). Indeed, although "time" does not enter through the eyes, since light is a well-known stimulus for circadian rhythms, it was tempting to speculate that photic pathways will end in clock-related structures. As we shall see, this was the logic behind the discovery of the retinohypothalamic tract and the suprachiasmatic nuclei (SCN) $(335,336,339,341)$.
In recent years, the notion of "a" circadian clock has been challenged by the discovery of self-sustained oscillations in several tissues throughout the body, which might be particularly relevant for local rhythmic events. Indeed, diverse cell cultures and even cellular lines exhibit circadian rhythmicity, thus challenging the need for a central oscillator structure responsible for driving all periodicities in the organism. Collectively, these structures are referred to as "peripheral oscillators" (although in a very SCN-centered view of the world, peripheral might include from the liver or the lungs to rhythmic nuclei in the central nervous system) $(74,255,301)$. Notably, the search for the molecular components of the clock (both central and peripheral) has been the driving force in chronobiology in recent decades $(205,248,252$, $288,443,451,453,495)$.

This review deals with the second of the main questions in chronobiology (according to the simple scheme of 
Fig. 1): that of the arrow of environmental time cues regulating the mammalian circadian clock, i.e., circadian entrainment. The adaptive value of entrainment is rather obvious: since endogenous rhythms are close to, but not exactly, $24 \mathrm{~h}$, when left to their own free-running properties they will dissociate from the natural cycles unless a specific mechanism keeps them on time on a day-to-day basis.

Several stimuli are capable of entraining the oscillator to their external beat. In this review, we focus on photic entrainment, i.e., the effects of light on the circadian clock, although several other stimuli might be relevant for the correct adaptation of our rhythms to a revolving planet. Among these other synchronizer signals, food availability $(132,312)$, social contacts $(347,352)$ and, depending on the habitats, tides, temperature, or even moonlight $(120,133,378)$ have been reported to be relevant to adjust circadian pacemaking; some shall be mentioned briefly along the way. As for moonlight effects, it is remarkable that primates can respond to the moon phase in their locomotor activity rhythms (133) and that Drosophila pacemaker neurons respond to very dim light illumination patterns, comparable to those of quarter moonlight intensity (30).

In addition, as already stated, in recent years it has become clear that the simple clock-to-rhythms model is inadequate since growing evidence suggests that autonomous biological clocks are distributed throughout the body and might be unevenly entrained by diverse signals (i.e., metabolic entrainment of liver oscillators, reviewed in Ref. 173). However, for the sake of clarity and focus, we will mainly review light-induced entrainment of the SCN, which in turn serves as a body pacemaker and probably couples most, if not all, peripheral oscillators (373).

\section{CIRCADIAN ENTRAINMENT: AN ADAPTIVE FEATURE}

It is clear that circadian entrainment represents an adaptation of organisms to their environment. Indeed, maybe with the exception of caverns, the sea abyss, or certain hot water springs, rhythmic characteristics of all environments in Earth is evident. In this sense, temporal adaptation is fundamental for the survival of species that need to entrain their physiology and behavior and adjust them to the adequate external signals. Coordination of anatomical pathways and physiological mechanisms in a sequential order defines a certain internal economy in which time is one of the main variables involved.

Many of the fundamental concepts related to the temporal relationship between organisms and environment were originally put forward by the pioneering work and foundational hypotheses from Jürgen Aschoff and, especially, Colin Pittendrigh. The latter performed experiments with a variety of animal models and defined the basis of circadian and even seasonal entrainment. In addition, Pittendrigh gave a clear evolutionary framework for his ideas and hypotheses (it should be remembered that his background was, after all, on classical genetics), and many of his predictions proved to be quite right $(88,390)$.

The existence of a biological clock makes a rhythm viable even in the absence of environmental cycles, in a "free-running" situation, thus ensuring that internal functions continue their temporal relationship under constant conditions (for example, the rest-activity cycle in humans is related to body temperature even under isolation conditions; Refs. 24, 28). However, real life usually gives temporal cues that help rhythms to adapt and anticipate to natural periodic changes, including light/dark, temperature, humidity, tides, social activity, and several other cycles. The most studied cycle among these is certainly the alternation between day and night, to which most species are sensitive, and seems to have been the most important pressure factor for the selection of circadian rhythms. Geophysical cycles different from $24 \mathrm{~h}$, e.g., tidal cycles (12:4 h), lunar day (24:8 h), and lunar month (29:53 days, between 2 full moons), seem to have exerted selective pressure in intertidal species. In all cases, the period of the endogenous rhythm, which persists under constant conditions, corresponds approximately to a certain environmental rhythmicity, which can be related both to its evolutionary origin and its functional importance. Therefore, the period of biological rhythms results in an interplay between an endogenous oscillator and the environmental cyclic variable, for which Aschoff proposed the term Zeitgeber ("time giver" in German, Ref. 25).

In the presence of this zeitgeber, the biological clock adjusts its period and phase to the environmental cycle (Fig. 2). This would be equivalent to the daily adjustment of a not very precise wristwatch, which needs to be advanced if its period is smaller than $24 \mathrm{~h}$, and delayed with periods of more than $24 \mathrm{~h}$.

\section{SIZE (OF LIGHT) AND TIME MATTERS: EFFECT OF SHORT OR LONG LIGHT PULSES ON CIRCADIAN PHASE}

As already stated, entrainment is a necessary adjustment of circadian phase to the environment. Even if endogenous period $(\tau)$ is very close to $24 \mathrm{~h}$, say $24.1 \mathrm{~h}$, if left by itself, it will gradually diverge from the outside world until phase differences are inadequate for survival. In our example, the endogenous phase is shifted by $0.1 \mathrm{~h}(6 \mathrm{~min})$ every day, so in 10 days the circadian system of the animal will be $1 \mathrm{~h}$ advanced with respect to a natural cycle. After $\sim 3$ mo, diurnal animals would have become nocturnal, and vice versa. Light can exert different effects on the circadian clock. Short light pulses have been extensively tested in the lab, inducing phasic or "nonparametric" 


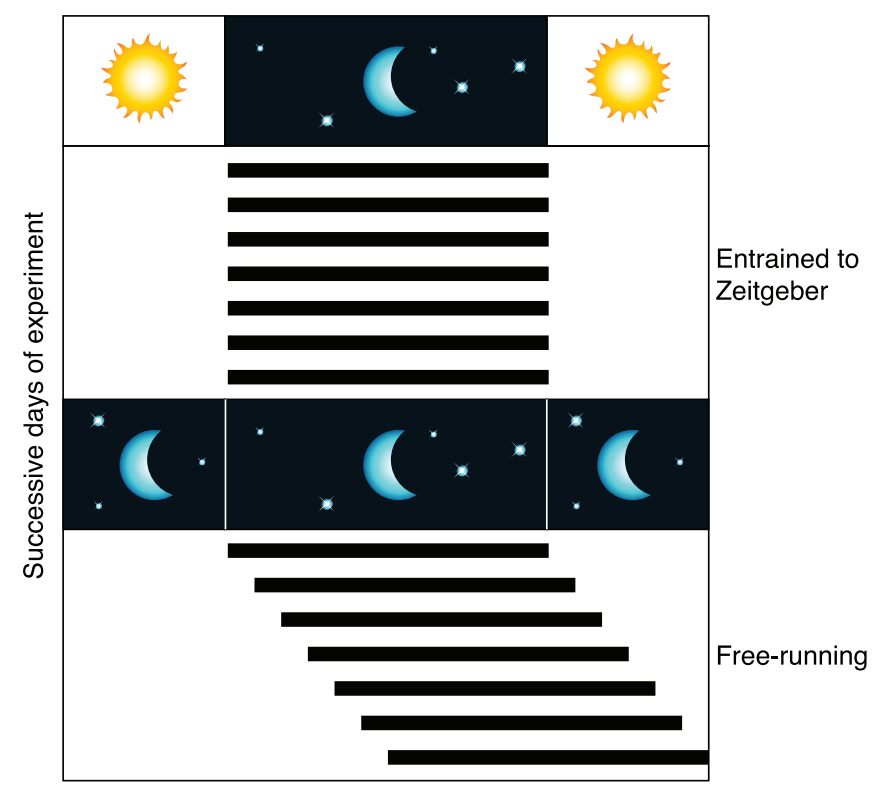

Time of day (clock time or circadian hours)

FIG. 2. Entrainment of a circadian rhythm to light. Under entrained conditions, circadian rhythms adjust their endogenous period $(\tau)$ to that of the zeitgeber (T). In the figure, the actogram represents a rhythm of locomotor activity initially entrained to a 24-h light-dark cycle. Upon transfer to constant dark conditions (represented by the black bar in the center of the actogram), circadian rhythm resume with their endogenous period. Note that the onset of locomotor activity after DD is coincident with the previous onset under $\mathrm{LD}$ conditions, indicating that the Zeitgeber was indeed entraining the circadian oscillation.

entrainment of rhythms, while longer light durations (or even constant light stimulation) tonically affect the frequency of the clock through a "parametric" synchronization $(89,414)$. We can exemplify parametric entrainment with a nocturnal animal whose ecological niche is strictly restricted to the dark hours. If, for whatever reason, the animal wakes up early and leaves its burrow during the late hours of the day, the dangers of meeting a predator (or not finding food, or a mate) are high. The circadian system responds to such stimulation with a phase delay so that the following days the phase of the rhythm will return to normal, later, hours. On the contrary, if the animal stays in the wild for too long, the system will sense the first moments of daylight (also potentially risky for survival) and will respond with a phase advance as from the next day. Light at other times of the day is virtually ineffective in moving the hands of the circadian clock, defining a phase response curve (PRC) that indicates the times at which light can induce phase delays, phase advances, or no change at all (120, 231, 232). The PRC, which in practice serves as a mechanism for transforming $\tau$ (the intrinsic circadian period) to $\mathrm{T}$ (the frequency of the environmental zeitgeber) is one of the main tools to study sensitivity of the circadian system not only to light but to many other stimuli potentially capable of resetting the clock (Fig. 3).
An interesting paradox, again for nocturnal animals, is how could light affect behavior and induce an exactly 24-h period if the organism restricts itself to the dark period of the day. An early hypothesis was put forward and demonstrated by Patricia DeCoursey (102), who stated that nocturnal animals might be able to sample light with brief incursions out of their burrows. In fact, by means of a clever experimental scheme, she demonstrated that animals under a light-dark cycle actually behave as in constant conditions, interrupted by periodic phase shifts that relocated locomotor activity to its natural dark framework (see Fig. 5).

Under natural conditions, then, the PRC regions in which the largest phase shifts can occur, start and end of the subjective night, are coincident with twilight hours. Indeed, with only one or two light pulses under laboratory conditions, i.e., a "skeleton" photoperiod, stable entrainment can be easily achieved $(242,393)$. The temporal difference between the two pulses will delimit the boundaries of the subjective day and night of the animals.

The PRC, its shape and amplitude, is an intrinsic property of the circadian oscillator and is characteristic for each species, including humans (243, 321), that also respond to relatively low intensities of light (503). Indeed, it is also the basis for the design of treatments in abnormal entrainment situations, such as jetlag, shift work, or circadian-related sleep disruption (130, 167, 338, 460).

Parametric entrainment is related to the circadian photosensitivity to long-duration light stimuli, from a regular photoperiod (with usually more than $8 \mathrm{~h}$ of light per day) to constant illumination (LL). The manipulation of photic parameters (intensity, spectral composition) can modify circadian period through its continuous action on the photoreceptor pathway leading to the clock. However, the physiological, neurochemical, and molecular basis of this type of entrainment are not well understood (see Refs. 77, 82).

In addition, constant light is able to disrupt circadian rhythmicity, depending on the intensity of light, and exhibiting a continuum of responses that ranges from reduced locomotion and an increase in $\tau$ to complete arrhythmicity (392). However, although constant light is able to desynchronize SCN cells, it does not stop the intracellular clock; circadian changes in the expression of clock genes persist (372). Therefore, light might be able to elicit two different kinds of effects on the clock: 1) brief light pulses are transduced into changes in the expression of clock genes that phase advance or delay the clock, and 2) chronic light affects the intercellular coupling between SCN neurons by yet unidentified mechanisms.

In addition, a recent study by Chen et al. (82) examined what happens when, after chronic LL treatment, animals are put back in constant darkness. They found that upon transfer to constant darkness (DD), circadian rhythms in behavior and gene expression are very quickly regained and start from a specific phase, suggesting again 

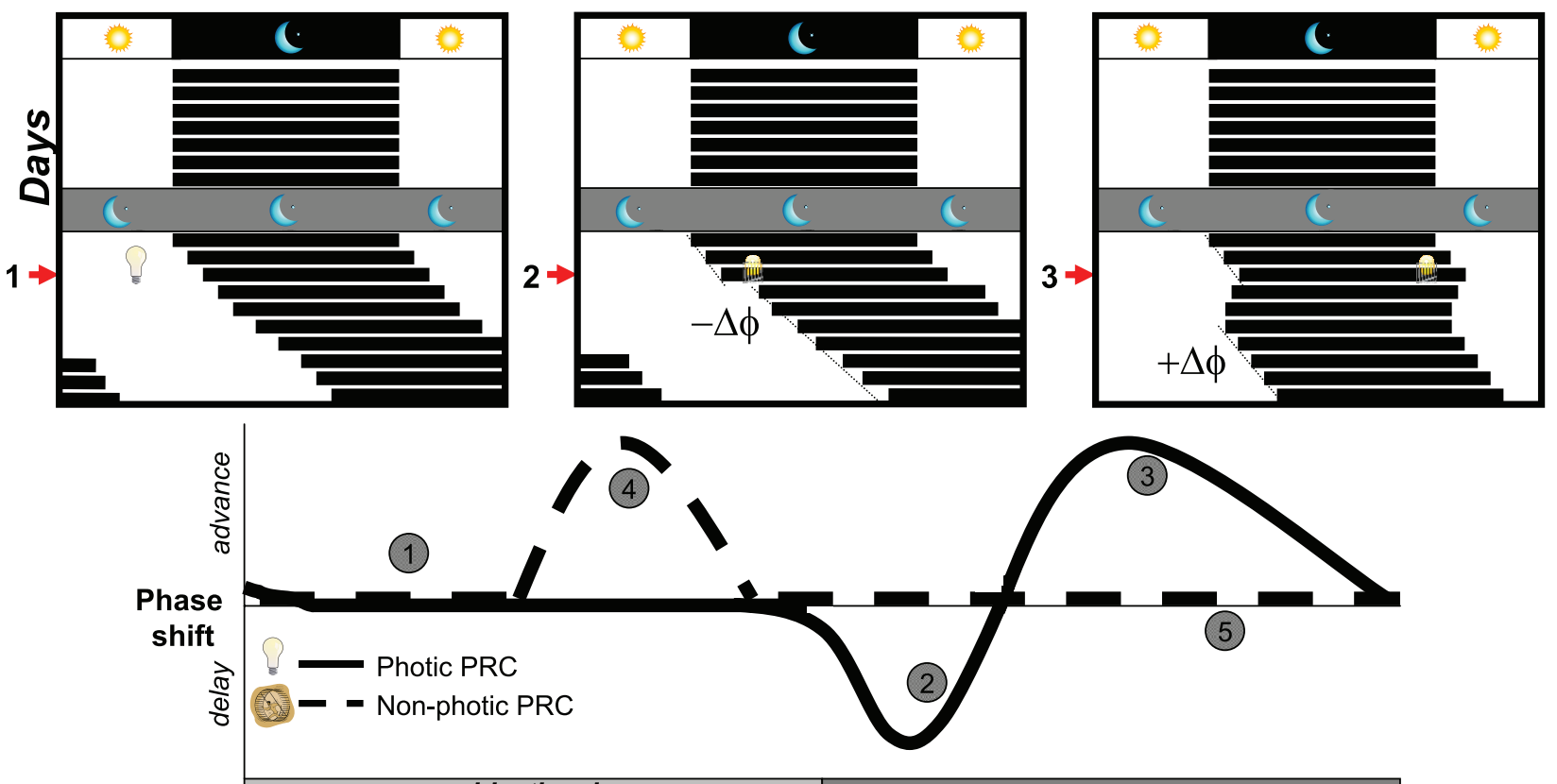

subjective day
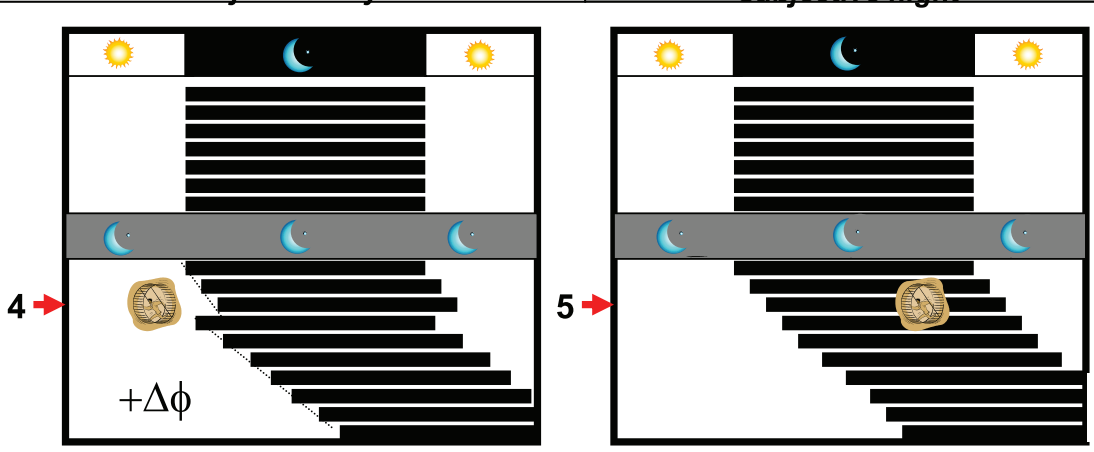

FIG. 3. Phase response curves of circadian rhythms. In the top panel, actograms represent the response of locomotor activity rhythms to a light pulse during 1) the subjective day, 2) the early subjective night (inducing a phase delay of the rhythm), and 3) the late subjective night (inducing a phase advance). The bottom panel represents a nonphotic stimulus (such as a novel running wheel) presented 4) in the middle of the subjective day (inducing a phase advance of the rhythm) or 5) during the subjective night (no response). The central graph is a representation of both phase response curves, a PRC to light (solid line), and a PRC to a nonphotic stimulus (dashed line), indicating the numbers of the manipulations shown in the corresponding actograms. By convention, phase advances are plotted as positive values and phase delays as negative values. Photic PRCs are typically biphasic, with phase delays at the beginning of the subjective night and phase advances at the end of that period, while nophotic PRCs exhibit clear phase advances during the subjective day and little, if any, responses during the subjective night. The shape and amplitude of PRCs is species specific.

that the clock output was masked by the constant light treatment. Moreover, after several days in LL, these authors were able to induce 12-h phase shifts in locomotor activity, suggesting that light manipulation might be a fundamental tool when coping with circadian disorders such as shift work or jetlag.

\section{A. Phase Response Curves}

As stated before, one of the most powerful tools for dissecting entrainment and, in particular, temporal gating for zeitgeber effects, is the construction of PRCs, i.e., the effect of the same stimuli at different times of the day. PRCs are the graphic representation of the dynamics of a certain variable (e.g., locomotor activity) under the control of the circadian oscillator, when subjected to an acute stimulation at different circadian times (231). Although quite variable in terms of amplitude and timing, PRCs usually fall into two categories. Curves that show phase shifts during the subjective night (usually phase delays, $-\Delta \varphi$, in the first half and phase advances, $+\Delta \varphi$, in the second half), such as those for light stimulation and other signals, are called "photic PRCs" (91, 420). Curves with phase advances during the subjective day are called "nonphotic PRCs," such as those in response to forced locomotion, social stimuli, and others $(328,352,411)$ (Fig. 3).

PRCs are further classified depending on their strength in terms of phase shifting $(156,512)$. Type 0 
(weak) PRCs show maximal phase shifts on the order of a few hours and gradual transition between phase advances and delays, while type 1 PRCs have larger maximal phase shifts, of up to $12 \mathrm{~h}$, and the transition between delays and advances is quite abrupt and discontinuous (Fig. 4).

PRCs are species specific, dependent on the type and strength of the stimulus, and quite relevant for the elucidation of the underlying entraining mechanism.

\section{THERE IS LIFE AFTER LIGHT}

As mentioned before, circadian rhythms can be entrained by a variety of stimuli, of which light appears to be the main but not only means of adjusting $\tau$ to T. As we shall see, photic entrainment is transduced by a specific pathway and transcriptional mechanism that can be mimicked by pharmacological manipulations. In addition, as already mentioned, there is another group of stimuli that are able to entrain the clock with a different PRC than that for light (synchronization called nonphotic entrainment). Although not the focus of the review, we will mention that early recordings of blind human subjects suggested a role for social stimuli in circadian entrainment (Lund 1974, cited in Ref. 511). However, the real basis for nonphotic entrainment came from a series of elegant experiments performed by Nicholas Mrosovsky and co-workers, triggered in response to the claim that the short-acting benzodiazepine triazolam acted directly on the suprachiasmatic clock (479). However, Mrosovsky and co-workers $(353,354)$ clearly demonstrated that this effect was mediated by triazolam-induced increase in locomotor activity, without which (e.g., by blocking running wheels) entrainment did not occur. In addition, this kind

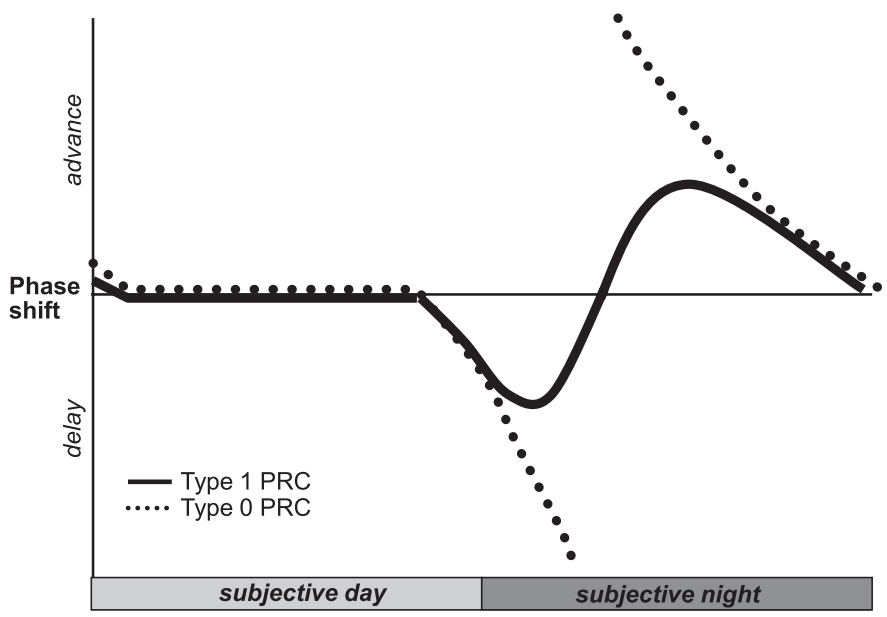

FIG. 4. Types of phase response curves. In type 1 (weak) PRCs (solid line), small-amplitude responses to light are elicited (usually phase shifts of $<6 \mathrm{~h}$ ), and there is a continuity between delay and advance responses. Stimuli of increasing strength might result in a (strong) type 0 PRC (dashed line), with larger phase shifts and a discontinuity between delays and advances.

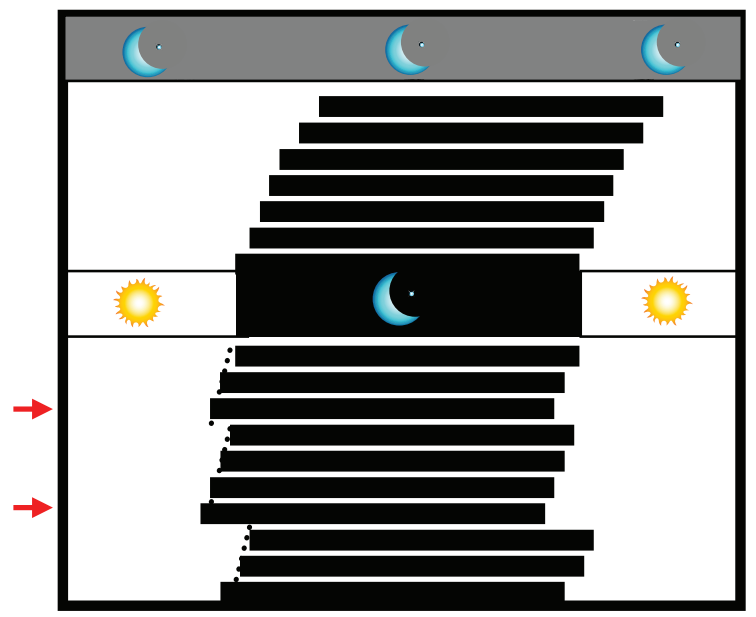

FIG. 5. Light sampling behavior in a nocturnal rodent. Under constant dark conditions, the circadian rhythm exhibits its endogenous period $(\tau)$. When transferred into light-dark conditions, the rhythm continuous to free-run until the system is briefly stimulated by light at a time in which the photic PRC indicates a phase shift is achieved (red arrows). This phase shift (in the example, a phase delay caused by a light pulse at the onset of the night) moves the activity phase back to the dark portion of the LD cycle, where it free-runs until reaching a new lightsensitive phase.

of entrainment seemed similar to the one elicited by social stimuli, and the results were incorporated into a family of stimuli which was thereafter known as "nonphotic" entrainment, which included novel running wheels and some types of handling or presentation of individuals of the opposite sex, among others (328, 352, 411). Indeed, these stimuli were able to determine nonphotic PRCs, which share the distinctive feature of phase-advances during the subjective day (Fig. 3). Although this PRC is not as precise as the one for light pulses, it might also have adaptive relevance for fine-tuning the ecological temporal niche for locomotor activity and other behaviors (407).

There is also evidence that physical exercise is able to change the phase of locomotor activity in humans (56, $57,327)$.

As stated, pharmacological agents can induce phase advances during the subjective day, depending on the degree of arousal they exert on the individual (43, 44, 159, $293,295,326,481)$. Indeed, behavior is able to change neurophysiological properties of SCN neurons $(101,426)$. There is extensive evidence suggesting that nonphotic stimuli signal into the SCN clock through two main pathways: 1) a geniculohypothalamic tract (GHT) which originates in the thalamic intergeniculate leaflet (IGL) and uses neuropeptide Y (NPY), GABA, and endorphins as neurotransmitters (194); and 2) a serotonergic median raphe nuclei projection to the SCN $(315,323)$. The GHT tract acts, among others, through a Y2 receptor/PKC activation pathway $(43,159,212)$, while serotonin effects are mediated through $5-\mathrm{HT}_{1 \mathrm{~A} / 7}$ receptors and protein kinase A (PKA) activation $(126,323,400,401)$. These stimuli 
act on the expression of clock genes such as per1 or per2, decreasing their diurnal peaks (143, 208, 299, 527).

Maybe more in the focus of this review is the fact that nonphotic stimuli can interact with photic entrainment, usually in opposite directions. Thus nonphotic stimuli are able to inhibit light-induced phase shifts, and vice versa (42, 302, 525). Moreover, inhibition of nonphotic pathways increases the circadian response to light (524), although this is not necessarily the case when long light pulses are applied (21), suggesting a potential adjuvant treatment for entrainment disruptions.

\section{A. "Unmasking" the Effects of Light}

Entrainment is not the only means of communication between the circadian oscillator and the environment, and it might not even be the principal one. Environmental signals are able to adjust the output of the clock acting directly upon overt rhythms. This mechanism was first described by Aschoff (25) as "certain experimental conditions that obscure the effect of the zeitgeber" and was thereafter named as "masking." Indeed, masking might help individuals respond to external stimuli quickly and directly, thus enabling a fast and adaptive response to potentially threatening stimuli.

Although masking was traditionally considered an impediment to study the expression of a temporal program $(137,269,320)$, its mechanism is certainly as important as entrainment to determine the correct phase relationship between the body and its environment, in particular when the visual system is affected (346). It is also interesting that masking is subject to temporal gating, i.e., the same masking stimulus will act or not upon a cyclic output depending on the time of stimulation (27).

A PRC for masking has also been derived from the effect of such stimuli (in this case, acute turning on of lights under constant dark conditions) on locomotor activity at different times of the day (410). In this case, masking might fine-tune entrainment; although the anatomical substrate of this mechanism is not currently known, it is interesting to hypothesize the thalamic IGL (well-known for its role in nonphotic entrainment) as an actor in this pathway (194).

The phototransduction pathway involved in masking is not completely understood and might be different from conventional vision or entrainment pathways. Indeed, locomotor activity of $r d / r d$ mice, with a drastic reduction in the number of retinal photoreceptors and in visual function, can be negatively masked by nocturnal 1-h light pulses (346), suggesting that these animals not only maintain certain entrainment capabilities but also the ability to respond to ecologically relevant stimulation, independently of image formation (348). Moreover, in animals with a slow degenerating mutation in rods ( $r d s / r d s)$, negative masking to light pulses increased with age, suggesting that masking is dependent on the degree of neurodegeneration $(355,465)$.

Indeed, multiple photoreceptor pathways are involved in circadian entrainment and, most probably, masking $(114,178)$. In particular, as we will discuss later, melanopsin-containing retinal ganglion cells, which do indeed play a role in photic synchronization, are likely to be related to masking as well. Recent evidence suggests that targeted destruction of a certain type of ganglion cells (photoreceptive ganglion cells, pRGCs) not only attenuated circadian responses to light but made animals unresponsive to negative masking to light pulses (170).

In addition, other neurotransmitter-receptor systems might be involved in nonimage visual photoreception, including entrainment and masking. The pituitary adenylate cyclase-activating polypeptide (PACAP) is a retinohypothalamic neurotransmitter acting upon PAC1 receptors in the SCN. Mice lacking this receptor exhibit a significant decrease in light-induced entrainment and, most notably, negative masking at different light intensities (72, 190, 241). Dexras 1-deficient mice (which lack a dexamethasone-binding protein that activates the mitogen-activated protein kinase pathway) have been reported to reduce their photic entrainment and increase nonphotic responses $(83,84)$; however, no differences were found regarding their masking responses to light (93), indicating that at least some non-image-forming photoreception pathways are independent of Dexras 1.

Perhaps more interesting is the involvement of dopamine and $\mathrm{D} 2$ receptor pathway in masking responses. Doi et al. (113) have shown that D2 receptor knockout mice, although exhibiting normal circadian rhythms in locomotor activity, lack masking responses to light, although maintain normal entrainment to light pulses (including locomotion and pineal activity). Although dopamine is important in neural adaptation to light, this role of D2 receptors remains to be established, in particular in terms of the neuroanatomical and molecular pathway involved, possibly acting directly through clock gene transcriptional steps (529).

Classical and elegant experiments have suggested that humoral signals from the SCN are probably responsible for part of the output pathways that control overt rhythmicity $(275,444,445)$. Moreover, tetrodotoxin (TTX)-sensitive action potentials are needed for the expression of rhythmicity, but not for the activity of the circadian oscillator, since TTX masks locomotor activity rhythms, which after treatment resume with the same phase as that before pharmacological stimulation, both in vivo (432) and in single SCN cells (508). More recently, some of the putative humoral signals from the SCN have been identified, including prokineticin $2(86,537)$, epidermal growth factor (EGF), and transforming growth factor-1 (TGF-1), although further analysis of screenings for secreted factors might yield new potential humoral output candidates for the nuclei $(256,257)$. These signals 
mediate masking effects, as suggested by experiments with EGFr mutant mice, with reduced EGF receptor activity. However, a closer examination under different illumination levels of the masking stimuli suggest that these mice do exhibit masking responses, albeit with a different sensitivity (351). Table 2 summarizes the proposed role of several genes in circadian masking, mostly based on the effects of specific mutations on negative masking of locomotor activity by light.

Together with photic and nonphotic entrainment, masking might be instrumental in the fine tuning of the temporal niche for different species and individuals (407). Light-dark and dark-light transitions are key signals for entrainment, and part of their effect is certainly elicited by acute masking due to the abrupt changes in light intensity (at least, under laboratory conditions, which definitely differ from the more subtle and gradual natural changes in the light-dark cycle). Some circadian mutants even experience a temporal switch from diurnality to nocturnality, or vice versa (349), which are influenced by retinal pathways involving melanopsin and chromophore recycling (115).

\section{ENTRAINMENT IN THE FIELD}

Laboratory conditions, although optimal for the modelization of physiological processes underlying entrainment, are not always accurate in terms of real-life synchronization in the field. Differences in photoperiodic exposure probably imply variations in the neurochemistry of the mechanisms for entrainment. Indeed, the behavioral response to simulated twilights differs from that for square-type photoperiods, increasing the range and quality of entrainment $(45,46,482)$. Natural synchronization is probably a combination of parametric and nonparametric effects of light. As mentioned before, an interesting, now classical, approach to the problem, at least for nocturnal animals, was an experimental paradigm devised by DeCoursey (102) which recorded the activity of a nocturnal flying squirrel allowed to construct a burrow and to explore different parts of a cage exposed to a complete photoperiod. Animals are usually in free-running conditions and wander out of the burrow at the adequate circadian times. After a few days, the animals were briefly exposed to light and reentrained to their nocturnal niche; "light sampling" is therefore responsible for masking of locomotor activity and, if stimuli fall onto the sensitive zone of the PRC, phase shifting will occur (Fig. 5). Diurnal animals probably perceive luminosity outside their burrows and only wander outside when light levels (and/or spectral composition, including ultraviolet frequencies) are above a certain threshold $(213,214)$.

However, if masking and light sampling are at least partially responsible for adequate temporal behavior for most animals, the circadian system could be considered a secondary feature, an evolutionary redundancy, a spandrel in the cathedral of physiology (169). Notwithstanding, circadian programs do offer adaptive advantages, from cyanobacteria $(233,377)$ to flies and vertebrates (390). An interesting proof comes from work by, again, Pat DeCoursey, who lesioned the SCN of squirrels and chipmunks in the laboratory and studied their behavior in the field to test their real-life value (103-105). Lesioned animals were subject to more significant predation and exhibited, over the seasons, a higher mortality rate.

\section{DIFFERENT SUPERCHIASMATIC NUCLEI OSCILLATORS RESPONDING TO LIGHT}

Classical experiments by Colin Pittendrigh and coworkers led to the hypothesis of two distinct oscillators with different phases and light responses, the so-called $\mathrm{E}$ (vening) and $\mathrm{M}$ (orning) oscillators (391, 393). A strong hint that these oscillators could be contained within the SCN came from studies that indicated that the length of the peak of SCN electrophysiological activity in coronal brain slices depended on previous photoperiodic history of the animal (356). An experimental preparation recently shed light into the nature of such oscillators, by recording electrophysiological neuronal patterns in horizontal SCN slices (223). With this kind of preparation, two peaks in

TABLE 2. Mammalian mutations affecting circadian masking

\begin{tabular}{|c|c|c|}
\hline Genotype & Effect & Reference Nos. \\
\hline $\mathrm{PAC}^{-/-}$mice & Impaired negative masking behavior at low light intensities & 190 \\
\hline$r d / r d$ mice & Negative masking to light pulses & 346 \\
\hline$r d s / r d s$ mice & Negative masking to light pulses, increasing with age & 355,465 \\
\hline D2R-null mice & Lack of masking responses to light & 113 \\
\hline Melanopsin ${ }^{-1-}$ mice & Impaired masking under bright light conditions & 291,350 \\
\hline Vitamin A-depleted $\mathrm{rbp}^{-/-} \mathrm{cry}^{-/-} \mathrm{cry}^{-/-}$mice & Masking abnormalities (some diurnal behavior) & 464 \\
\hline mPer $1 / m$ Per 2 double mutant mice & Entrainment in LD caused by masking effect of light & 535 \\
\hline
\end{tabular}

The precise neural and molecular pathway involved in circadian masking is not completely understood. However, mutations of specific SCN receptors and/or photoreceptor genes yield a circadian phenotype in which masking is comrpomised (see text for details). Cry, cryptochrome; D2, dopamine receptor type 2; PCA1, PACAP receptor type 1 (PAC1); rd, retinal degeneration; rds, retinal degeneration slow; rbp, retinol-binding protein. 
electrical activity were found (in contrast to the unimodal rhythm recorded from coronal slices) that were interpreted as corresponding to the $\mathrm{E}$ and $\mathrm{M}$ oscillators (Fig. 6). These two peaks are independently controlled by photoperiodic history of the organism and independently phase shifted by stimuli mimicking phase advances or delays of the light-dark (LD) cycle, as is predicted by the model and other experimental data $(218,416,417,507)$. However, this special feature uncovered by horizontal slice preparations seems to be species specific and was only found in hamsters, not in rats or mice (52). Moreover, in the mouse, two different oscillatory neuronal populations have been found to couple to E and M circadian patterns (218), and these oscillation patterns can be plastically modified by network reorganization in response to changing photoperiods $(49,359)$. There have been suggestions pointing to a differential role of clock genes in the $\mathrm{E}$ and $\mathrm{M}$ oscillators (90), although this hypothesis has yet to be tested rigorously. Moreover, SCN neuronal activity patterns and their intercellular coupling mechanisms can encode day length information and therefore serve as the basis for seasonal encoding and circannual rhythmicity (307). Indeed, SCN neurons exhibit profound changes in their coupling characteristics when animals are subjected to different photoperiods. Schaap et al. (425) reported that the average circadian wave- form of the SCN at the tissue level is directly related to its neuronal network properties and, moreover, the heterogeneity in firing patterns serves as the basis for photoperiodic encoding. Moreover, the phase distribution of these neurons, as determined by both multiple unit activity or at the single-cell level, and its intrinsic plasticity are fundamental for responses to light or short photoperiods (488), including photoperiod-dependent photic phase shifts (489). In other words, photoperiodic encoding, which includes a differential response to light pulses, is an SCN property, supporting the classical notion of a "clock for all seasons" encoded in the pacemaker structure and function (391).

Another model in which dual circadian oscillators are evident within the SCN is forced desynchronization in the rat, in which animals are exposed to extreme photoperiods, e.g., 22-h LD cycles, and express two stable circadian locomotor activity rhythms with different period lengths in individual animals (62) (Fig. 7). Again, clock gene expression was useful in tracing the cellular basis of this phenomenon (98) and reflected a subdivision between ventrolateral and dorsomedial SCN areas that were active during the different components of the desynchronized behavior (97). Moreover, core body temperature and sleep stages are also associated with the activity of these distinct oscillators revealed by the forced desyn-
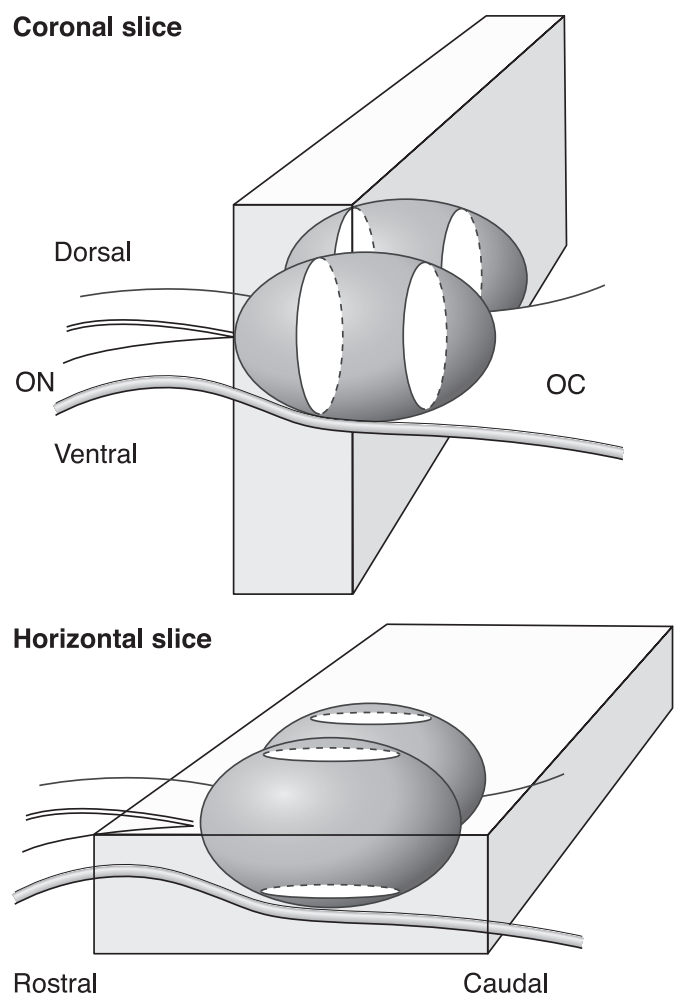

FIG. 6. Recording of electrophysiological rhythms in superchiasmatic nucleus (SCN) slices. Multiunit electrophysiological recordings show a clear circadian rhythm in firing rate, peaking during the subjective day. Left panels indicate the orientation of the slices. Top panel depicts a traditional configuration of coronal slices, with a single peak at around CT 10-12, while recordings in a horizontal slice exhibited two discrete peaks of multiunit activity, one early in the subjective day and the other one occuring in the subjective night, within a few hours after projected dusk. [From Jagota et al. (223), reprinted by permission from Macmillan Publishers Ltd.] 


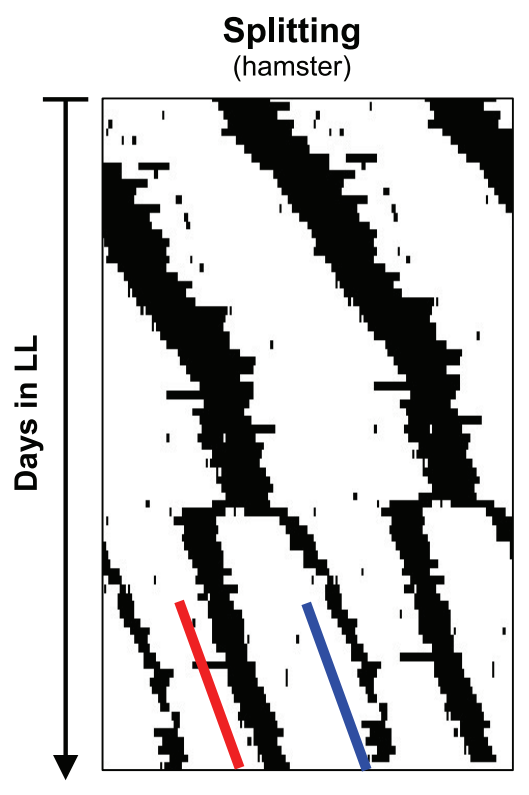

Forced desynchrony

(rat)
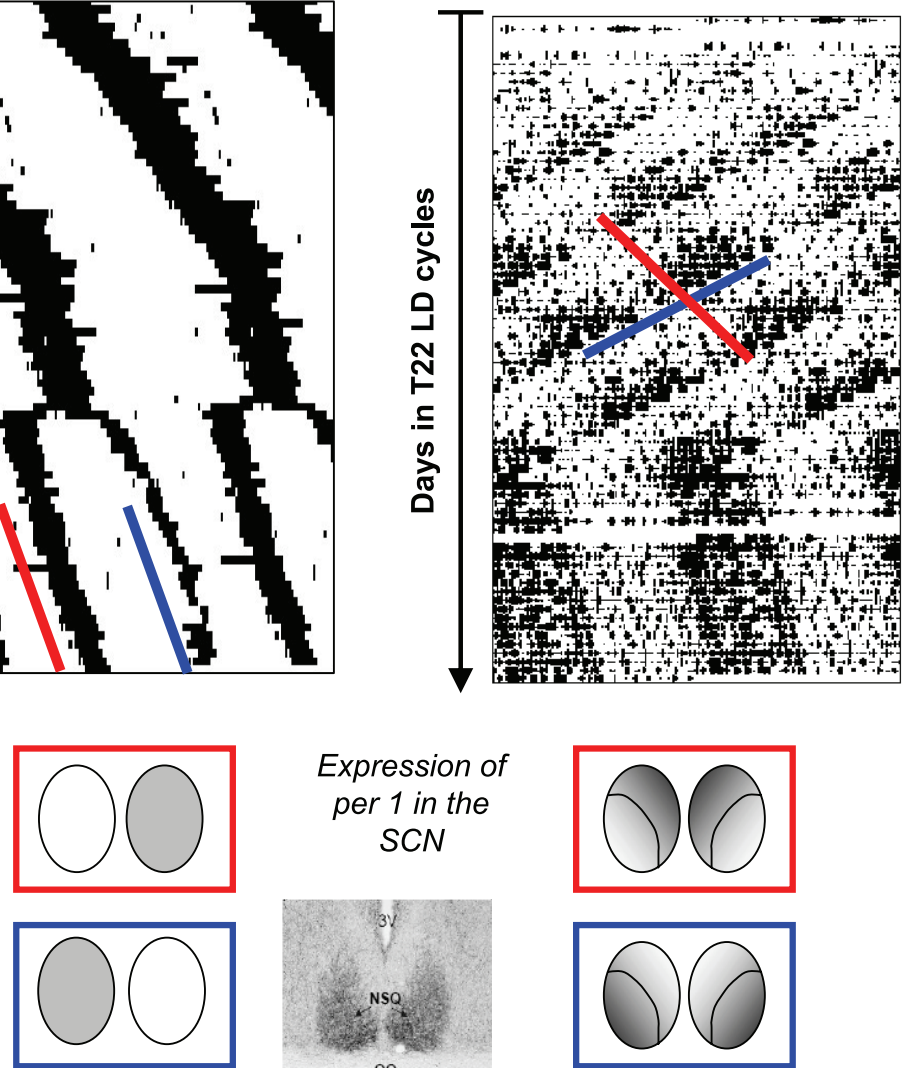

\section{Expression of per 1 in the SCN}

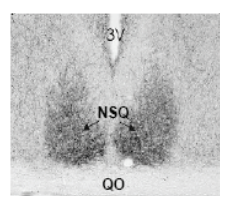

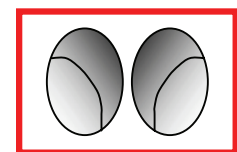

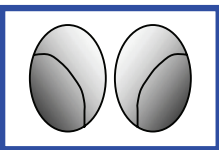

FIG. 7. Frequency demultiplication in experimental conditions. Schematic representations of $A$ ) splitting in hamsters, where spontaneous demultiplication of $\tau$ occurs after several days under constant light conditions, and $B$ ) locomotor behavior of rats under a T22 light-dark cycle, where two distinct frequency components can be appreciated, one responding to the environmental photoperiod $(\mathrm{T})$ and the other one to the endogenous circadian period $(\tau)$. $C$ : representation of per expression in the SCN of animals in the aforementioned conditions. Hamsters undergoing splitting show per expression in the left or right SCN in correlation with one of the two bouts of locomotor activity, while the two activity components in rats under T22 conditions correlate with ventral or dorsal per expression in both nuclei. [Redrawn from De la Iglesia and co-workers (97, 98).] chrony protocol (61), as well as humoral rhythms such as melatonin secretion (430).

Again, neuroplasticity within the circadian master clock allows for the reorganization of anatomically identifiable neuronal networks (traced by the expression of marker clock genes) that are forced to operate independently as a result of the desynchronization protocol. This desynchronization of neural networks allows for the identification of boundaries between suboscillators that are driving independent circadian physiological outputs. Although circadian desynchronization between endogenous rhythms, or between these and the environment, has been classically studied in humans, the relevance and relationship of these animal models of desynchronization to humans remain to be established.

\section{THE DOORS OF PERCEPTION: THE RETINA AS A CIRCADIAN PHOTIC TRANSDUCER}

The diurnal changes in environmental illumination are conveyed from the retina to the brain to entrain circadian rhythms throughout the body. In sighted people, light triggers several changes in retinal neurochemistry that are transmitted by means of the retinohypothalamic tract (RHT) to the SCN. Light is the major time cue (Zeitgeber) responsible for synchronizing the circadian timing system. Although early work suggested that nonphotic time cues such as meals, caffeine, exercise, and sleep-wake cycle were important synchronizers of the human circadian clock (26), at present, light is considered the primary time cue (75). In addition to studies in sighted subjects, strong evidence to support this view has come from detailed studies of totally blind people. The demonstration that, in spite of living with strong social cues (e.g., employment, families, alarm clocks, and guide dogs) totally blind people exhibit free-running circadian rhythms $(23,284,423,424)$ strongly supports the primary role of light in human entrainment. The contribution of nonphotic time cues to circadian entrainment in humans, however, cannot be ruled out entirely (327).

\section{A. Retinal Circadian Rhythms}

The retina is a remarkably rhythmic tissue. Many cellular, biochemical, and physiological processes change in a circadian fashion, including visual sensitivity, rod outer segment disc shedding and phagocytosis by the 
retinal pigment epithelium (RPE), expression of immediate early genes and visual pigment genes in photoreceptors, second messenger levels, and activities of enzymes in signal transduction pathways, expression of arylalkylamine $N$-acetyltransferase (AANAT), as well as the biosynthesis of melatonin and dopamine, among many others (for a review, see Ref. 475). Retinal circadian rhythms allow the organism to anticipate and adapt to the $>1,000,000$-fold change in light intensity during a $24-\mathrm{h}$ period, thereby optimizing visual function for each photic situation. Studies in the early 1980s demonstrated that a circadian clock was present in the eye of the frog Xenopus laevis (40). A few years later, circadian clocks in Xenopus and chick retinas were localized to the photoreceptor cells $(59,388,462)$. These clocks drive rhythms of melatonin production and expression of red cone opsin mRNA. Additional studies in mammals demonstrated that outer segment disc shedding of the rod photoreceptors and AANAT mRNA persist $(475,476)$ in animals with SCN lesions or transected optic nerves, indicating that this rhythm was driven by an extra-SCN circadian clock (459). At present, circadian clocks are known to be localized in the retinas of many vertebrates (see Table 3). More recent studies indicate that melatonin could be also synthesized in chick retinal ganglion cells, with higher levels during both the subjective day in constant darkness and the light phase under a light-dark cycle (150). Moreover, it was shown that cultures of embryonic retinal ganglion cells also showed self-sustained daily rhythms in AANAT mRNA expression during at least three cycles with a period near $24 \mathrm{~h}$, supporting that chick retinal ganglion cells may function as autonomous circadian oscillators synthesizing melatonin during the day (150).

Retinal clocks may influence the SCN, as enucleation disrupts rhythms of p44/p42 mitogen-activated protein kinase (MAPK) phosphorylation (271) and photoreceptor degeneration delays the nighttime increase of phosphorylation of the cAMP-response element binding protein (CREB) in the master clock (18); these effects may not simply reflect removal of light/dark cues, but may also reflect clock-driven functions in the retina. In addition, enucleation lengthens the free-running period of behavioral rhythms compared with those observed in intact animals kept in constant darkness (518). Thus the circadian clock in the vertebrate eye may contribute to systemlevel circadian organization through effects on the SCN. Table 3 summarizes some of the most researched circadian rhythms at the retinal level.

\section{B. Novel Photoreceptors and the Circadian Biology}

Although the first definition for "eye" in the Oxford English Dictionary is simply "the organ of sight" (in humans and animals), over the past decade, a second role for the eye has been described: even in the absence of form vision, the eye can serve as a sensor for ambient lighting, akin to the light meter in a camera. Several light-regulated functions, including entrainment of circadian clocks, suppression of activity by light, photic suppression of pineal melatonin synthesis, and pupil light response (PLR) are retained in animals that are blind as a result of mutations causing complete or near-complete degeneration of the classical photoreceptors, rods, and cones. Only recently have the photoreceptors involved in mammalian photoentrainment been identified. Although it is well known that the eyes are necessary for the lightmediated regulation of the circadian axis because bilateral removal of the eyes abolished photoentrainment (365), the rods and cones are not necessary for circadian photoregulation. Indeed, genetic ablation of these photoreceptors has no effect on the photic circadian phase-

TABLE 3. Some examples of retinal circadian rhythms

Retinal functions

Signal transduction mechanisms

Transcription mechanism

Structural process

Metabolic and neurochemical functions
Visual sensitivity and ERG responses (34)

Rod-cone dominance (292)

cAMP levels in photoreceptors and ganglion cells (150)

Ras, B-Raf, ERK, and pCREB signaling pathways in photoreceptors; affinity of cyclic nucleotide-gated channels for cGMP (253)

Transducin mRNA (48)

Iodopsin mRNA (387)

Melanopsin mRNA (79)

Nocturnin mRNA (172)

AANAT mRNA in photoreceptors (38) and in retinal ganglion cells (150)

Spinule formation at cone-horizontal cell synapses (498)

Cone photoreceptor retinomotor movements (509)

Rod outer segment disc shedding (459)

Extracellular $\mathrm{pH}$ and energy metabolism (110)

Phospholipid metabolism in photoreceptor and ganglion cells (177)

Melatonin biosynthesis in photoreceptors (476) and chicken retinal ganglion cells (150)

Dopaminergic and GABAergic activity $(225,226)$

Examples of diurnal and circadian rhythms in retinal functions are shown, from structural processes to physiological mechanisms. Reference numbers are given in parentheses. For a review of rhythms in the mammalian retina and additional references, see Reference 475. 
shifting response (139, 142, 290). These light-responsive functions are controlled by another retinal photoreceptor because animals lacking retinal ganglion cells lose circadian photoresponses and PLR. In recent years, the discovery of pRGCs has given nonvisual phototransduction an anatomical basis. Several lines of evidence support that a subset of retinal ganglion cells is directly photoresponsive and transduces information about ambient lighting conditions to brain centers involved in irradiance detection (such as the SCN) and are involved in tasks including entrainment of the circadian clock and PLR (39, 201, 405). Detailed analysis showed that there exists a heterogeneous coupled network of pRGCs in the ganglion cell layer (GCL) of the retina that detects environmental brightness. pRGCs appear to also contribute to photic regulation of pineal melatonin release. Light at night suppresses otherwise high nocturnal plasma melatonin levels through a pathway originating in the RHT (334). Such photic melatonin suppression persists in rodless and coneless mice and in some blind people $(193,506)$. Melanopsin and cryptochromes have been proposed as candidate photopigments for inner retinal phototransduction $(138,179,187)$. Recent analysis of mice lacking melanopsin or cryptochromes indicates that both outer and inner photoreceptors can contribute to nonvisual photoresponses and that both melanopsin and cryptochromes play important roles in this process. Cryptochromes are flavin and pterin binding proteins closely related to DNA photolyases which function as blue light-sensitive photopigments in Drosophila. However, it is still controversial whether the mammalian homologs retain a photoreceptive capacity (171). The presence of cryptochromes in the rodent inner retina could suggest that cryptochromes may be involved in the circadian axis photoentraining (330, 466). A clear biochemical response to light, however, has not been convincingly demonstrated for mammalian cryptochromes (171), calling into question whether they are indeed photoreceptive. Physiological analysis of circadian entrainment and pupil light responsiveness in mice lacking these proteins leads to three conclusions (485): 1) outer and inner retinal photoreceptors provide partially redundant information to the inner retina, 2) melanopsin is required for inner retinal phototransduction in the absence of rod and cone signaling, and 3) cryptochromes contribute to the amplitude of inner retinal phototransduction but are not strictly required. However, it was demonstrated that the loss of cryptochromes in retinal-degenerate mice substantially decreases photic signaling to the SCN, and markedly decreases PLR (463). These findings suggest a model where either classical photopigments or inner retinal photopigments are sufficient for nonvisual irradiance detection (506).

Action spectrum studies for light-induced circadian phase shifting were performed in the golden hamster (Mesocricetus auratus), indicating a spectral sensitivity peaking around $500 \mathrm{~nm}$ (blue-green wavelength) (452), which coincided with the spectral maximum for rods, implicating these photoreceptors in photoentrainment. However, a later study in retinally degenerated mice indicated a sensitivity peaking in $480 \mathrm{~nm}$ (528), which did not correspond to any of the known visual photoreceptors. Action spectra studies for other end points such as the PLR (289) and the acute photosuppression of serum melatonin levels $(47,461)$ suggested mediation at least in part by nonvisual photoreceptors. The large number of central projections arising from pRGCs could indicate numerous functions. To study their function, several groups created melanopsin-null mice, with the interesting paradox that after years of searching for an elusive circadian photopigment, the race was on to get rid of the cells that produce it $(179,200-202,350,379,380,419)$. In addition, ectopic expression of melanopsin restores visual function in retinally degenerate mice (280). These studies show that melanopsin-containing pRGCs play a role in circadian photoentrainment, adjustment of circadian phase in response to light pulses, regulation of circadian period in response to constant light, PLR, acute photoinhibition of nocturnal activity, and the photic regulation of pineal melatonin biosynthesis. Many of the deficits in these responses were subtle or not apparent in melanopsin-null mice $(291,350,380,419)$. Only after these mice were crossed with mice lacking functional rods and cones were extreme phenotypes observed (202, 379). Transgenic mice lacking functional photoreceptors (32, 142) or mice homozygous for a naturally occurring retinal degeneration allele $(r d)(139)$ are able to regulate circadian locomotor activity by light in a similar manner to sighted controls. In melanopsin-null mice, this capability to shift the phase of circadian rhythms in response to light pulses is attenuated $(380,419)$, but a residual capacity for light-induced phase shifting remains, whereas mice lacking functional rods and cones and null for melanopsin are completely incapable of light-induced phase shifts (202, 379). Similarly, although $r d / r d$ mice show a 1.5 log unit loss in the sensitivity of the consensual PLR, the maximal response can be achieved at very high irradiances $\left(\geq 10^{14}\right.$ photons $\cdot \mathrm{s}^{-1} \cdot \mathrm{cm}^{-2}$ ), while melanopsin-null mice show no decreased sensitivity although they exhibit about a 10\% decrease in the response amplitude at the highest irradiances analyzed (379). These data suggest that the visual photoreceptors complement the role of melanopsin in the regulation of nonvisual responses.

Whether melanopsin plays a role in vision is still an open question. Dendrites of pRGCs receive input from amacrine and bipolar cells, thereby providing an anatomical underpinning by which pRGCs may regulate visual pathways (37). Moreover, melanopsin has been involved in the regulation of the human cone visual pathway in response to long-term light exposure (186). It was shown that melanopsin-containing RGCs (likely paralogs of 
pRGCs in rodents), combine with rod and cone mechanisms to encode irradiance over the entire primate visual system range (92). These findings indicate that future models of vision may have to account for the contributions of the melanopsin-based photoreceptive system. In addition to their direct projection to the SCN, these cells also project to the intergeniculate leaflet and olivary pretectal nucleus, brain regions involved in modulation of circadian rhythms and the PLR (201). More recently, several groups have shown that melanopsin-containing pRGCs also project to the ventral subparaventricular zone, the ventrolateral preoptic nucleus, regions of the brain involved in sleep, and circadian locomotion (168, 342).

\section{Light is the Message}

It is remarkable that ubiquitous light serves as specific stimuli for two senses that are mediated via one sense organ, the eye. The nexus of light and time in the human's intricate neuronal network is clearly intriguing. When Granit referred to "our noblest sense organ" (424), such qualification was certainly justified in view of how the complex interpretation of the world of light, form, and color is organized. But this wording has even more weight today considering the implications of the eye being a dual sense organ that not only links light and vision but also light and time. The material presented herein indicates why the eye can be considered as a "sense organ for time." A sense organ is usually able to receive only a certain kind of stimulus, and thus only certain kinds of communication from the environment. In the case of the human eye, a very limited band of the known electromagnetic spectrum is actually detected. In fact, visible light from the sun or man-made sources, in particular the blue-green spectrum, provides specific electromagnetic stimuli for photoreceptors in the retinas and thus mediates temporal information about external day and night and season to a master clock in the SCN. This information is then used by the SCN to adjust otherwise less efficient internal biological rhythms to the environmental light-dark cycle. Therefore, in addition to photoreceptors which primarily serve vision, i.e., rods and cones, humans and other species have photoreceptors which, apart from a series of further non-image-forming responses to light, convey crucial information about environmental time. Clearly, the novel ocular receptors are sensitive to light but, in addition, receptors have been referred to appropriately with regard to their effect rather than the type of stimulus.

\section{RETINOHYPOTHALAMIC INTERACTIONS AND SUPRACHIASMATIC NUCLEI NEUROPHYSIOLOGY}

As we have already stated, the main input pathway to the SCN comes from the retina through a monosynaptic
RHT. The demonstration of the importance of the RHT in circadian entrainment came from classical lesion experiments (235); moreover, electrical stimulation of this tract generates a PRC in SCN neuronal firing, with phase delays and phase advances (437). This tract was fundamental for the discovery of the SCN as a circadian clock (336), defining what has been known as a "circadian visual system" $(339,341)$, as opposed to the cognitive visual system. Even in blind animals (such as the blind mole rat), the RHT is responsible for circadian entrainment $(73,95$, 364).

Upon photic stimulation, up to $40 \%$ of SCN neurons change their excitability, with rather long latencies (3, $117,247,427)$. The diurnal rhythm in membrane conductance of SCN neurons (228) is changed by light, inhibiting neuronal activity in most cases $(229,308)$. In this sense, many SCN neurons are light detectors quite sensitive for low intensities such as the ones found at dawn and dusk, between 0.1 and 1 lux $(306,309)$.

The main photic input to the SCN comes from the RHT, which uses glutamate $(124,188)$ as well as aspartate, PACAP, and substance $\mathrm{P}$ as neurotransmitters (80, 124, 131, 161, 189), although the evidence is still not conclusive for substance P (see Refs. 192, 245). A multisynaptic pathway, also originating from the retina, innervates the clock from the ventral lateral geniculate nucleus and the thalamic intergeniculate leaflet, using NPY and GABA as transmitters (194) (Fig. 8).

Several lines of evidence suggest that glutamate is the main photic signal for the circadian clock: 1) glutamate is released upon electrical stimulation of the RHT, and its application induces photic-like PRCs, while blocking glutamate receptors in the SCN inhibits the effects of light pulses; 2) different glutamatergic receptors have been found in the SCN, including NMDA, AMPA, and metabotropic types; and 3) some NMDA receptor subunits exhibit circadian changes in the SCN, suggesting that the temporal gating of photic effects on rhythms might include the very first step of entrainment: the reception of the RHT photic message (58, 78, 100, 124, 166, $305,310,319,383,385)$. In addition, PACAP has multiple roles in the nervous system (131), although its role in the RHT has been proposed to be a diurnal or nocturnal modulator of circadian rhythms $(191,195)$. More recently, the availability of mutant animals with null- or overexpression of PACAP or its receptors has revealed a fundamental role of this neuropeptide in entrainment $(72,190$, 198, 435).

In addition, the photic response is modulated by several different signaling processes, including histamine (222), and GABA $(164,408)$, which is also rhythmic in the SCN $(9,363)$, as well as acetylcholine $(50,69,531)$.

Other afferent pathways interact functionally with RHT projections. Such is the case, for example, with interactions between geniculate-hypothalamic and RHT 

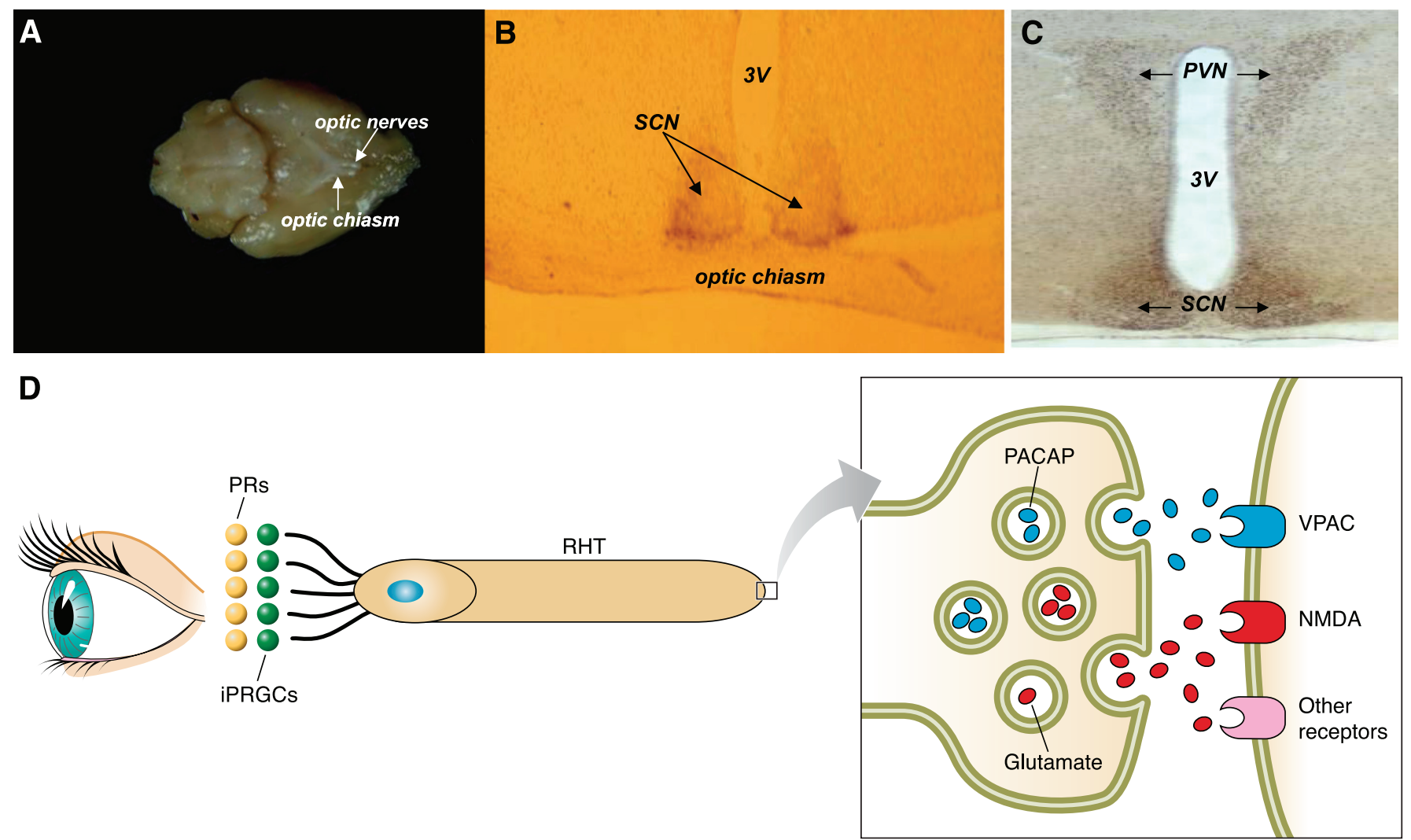

FIG. 8. A: ventral view of the mouse brain, showing the optic nerve and optic chiasm. $B$ : cholera toxin B subunit (CTB) labeling of the SCN. CTB was injected bilaterally in the eye of a $\mathrm{C} 57 \mathrm{Bl} / 6$ mouse. Two days later, the animal was killed, and the brain was excised, cut in $40-\mu \mathrm{m}$ sections, and stained for CTB to test for the integrity of the retinohypothalamic tract. $C$ : light-induced c-Fos expression in the ventromedial hypothalamus. A mouse was killed 90 min after 15-min light pulse delivered at circadian time (CT) 15, and immunohistochemistry was performed with a c-Fos antibody (Santa Cruz Biotechnology), depicting strong expression in the SCN and the paraventricular nuclei (PVN). D: schematic representation of the retinohypothalamic tract, originating in the retinal ganglion cells (including photoreceptive GCs) and innervating (through glutamate and PACAP neurotransmission) the ventral part of the SCN.

tracts, evidencing visual convergence that is decoded within the SCN. Lesions of the geniculate-hypothalamic tract result in a decrease in reentrainment rate after changes in the daily photoperiod $(196,197,234,386)$, while electrical stimulation of this structure induces phase shifts in locomotor activity (421). Although these effects, mainly mediated by NPY $(13,43)$, are of the nonphotic type, there is a clear interaction with the light synchronization pathway, probably through the activity of NMDA receptors in the SCN (reviewed in Refs. 524, 525). The same applies to the serotonergic pathway from the raphe nuclei; although it has been reported mainly as a key player in nonphotic signaling, it is clear that it also interacts with light-dependent mechanisms. Raphe lesions accelerate reentrainment to $\mathrm{LD}$ cycles (277) while serotonin (or agonists) administration affects behavioral entrainment and Fos expression in the SCN $(126,277)$. In addition, photic entrainment is altered in $5-\mathrm{HT}_{1}(446,447)$ or $5-\mathrm{HT}_{7}(151)$ receptor knockouts.

Glutamatergic SCN fibers make synaptic contacts with different types of SCN neurons (249). Indeed, the
SCN are heterogeneous nuclei in terms of their neurochemical characteristics, as well as their afferent and efferent pathways $(260,337,484)$ (Fig. 9A). The two main subdivisions of the SCN are the core or ventrolateral area and the shell or dorsomedial region, based on RHT innervation and the neurochemical nature of cells in each area (337). The topographical organization of specific neuronal clusters suggests a differential functional division of SCN areas (20, 340, 519). The ventrolateral (VL)-SCN is located above the optic chiasm and is characterized by neurons that synthesize vasoactive intestinal polypeptide (VIP) and gastrin-releasing peptide (GRP), surrounded by the dorsomedial region which contains arginine vasopressin (AVP) and calretinin neurons. The VL-SCN receives most of the afferents from the retina and brain regions that receive photic input, as well as innervation from the median raphe. The dorsomedial (DM)-SCN, on the other hand, receives most of the input from the hypothalamus and limbic areas, as well as from the VL-SCN. Although the DM-SCN acts as a stronger autonomous oscillator, its robust and synchronized neuronal oscillation depends 

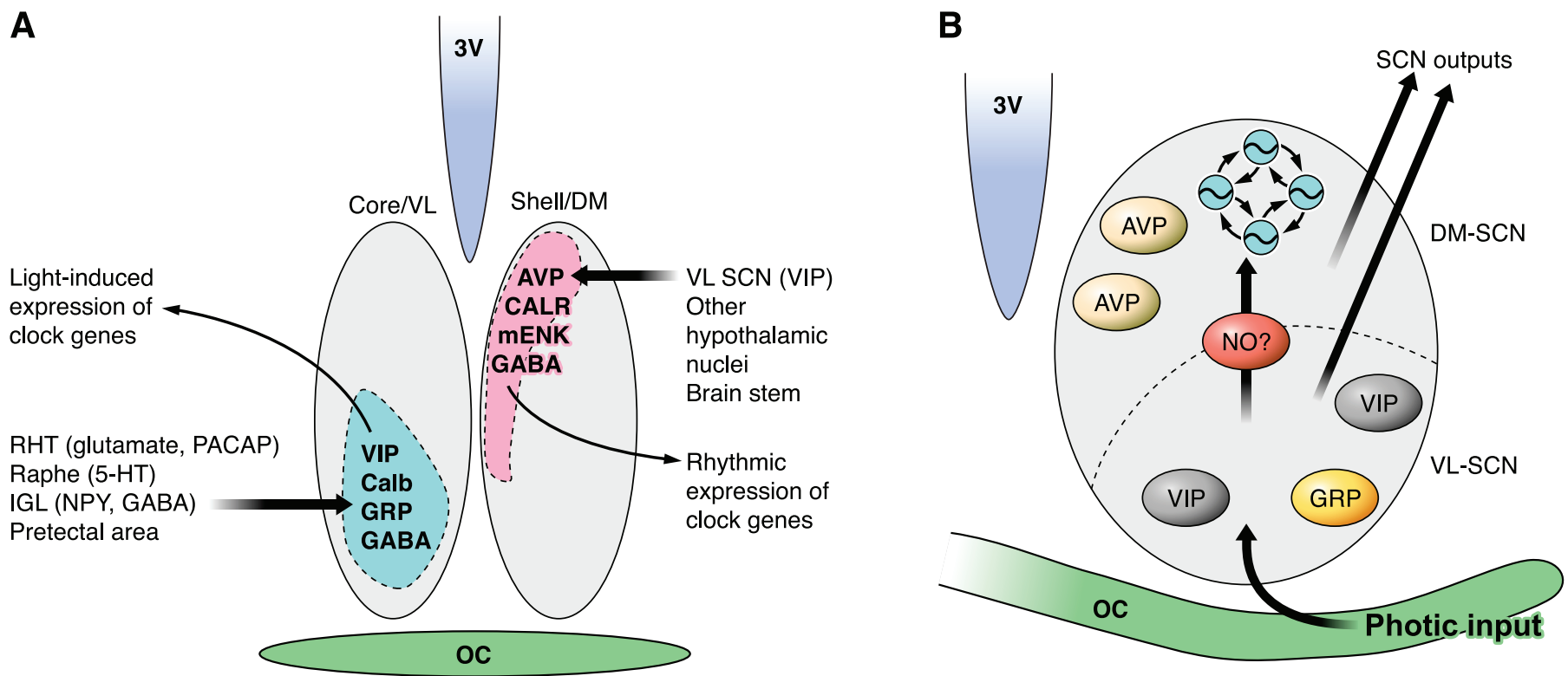

FIG. 9. A: SCN functional and neurochemical subdivisions. The left SCN represents the neurochemical identity of the ventrolateral portion of the nuclei, in neurons that express clock genes in response to light and are directly innervated by the RHT, the raphe nuclei, and the IGL. The right SCN shows the neurotransmitters found in the dorsomedial portion of the nuclei, an area where clock genes are expressed rhythmically, and receives innervation from the ventrolateral SCN and other hypothalamic areas. RHT, retinohypothalamic tract; 3V, third ventricle; OC, optic chiasm; IGL, intergeniculate leaflet; VL, ventrolateral; DM, dorsomedial; VIP, vasoactive intestinal polypeptide; Calb, calbindin; GRP, gastrin-releasing peptide; AVP, arginine vasopressin; CALR, calretinin; mENK, Met-enkephalin. $B$ : coupling between ventrolateral and dorsomedial regions of the SCN. Ventrolateral neurons are light-responsive and convey the photic message to the dorsal portion of the nuclei. A candidate for this coupling message is nitric oxide (NO), a transcellular messenger. After scavenging extracellular NO, there is no light-induced phase shift nor c-Fos expression in the dorsal SCN (see text for details).

to a great extent on neuropeptidergic release from the VL-SCN (20, 309, 332).

The SCN shell concentrates AVP neurons, while the core exhibits VIP-expressing neurons, as well as a cluster of calbindin-expressing cells in the hamster (see Ref. 20 for a review). Cells in the ventrolateral core are innervated by the RHT and express several genes, such as immediate-early gene fos and clock genes per 1 and per2 in response to photic stimulation (183, 418, 520-523). VL-SCN cells respond to a photic stimulus during the subjective night with an increase in the expression of clock genes of the Period (Per) family and immediate early genes of the Fos family, whereas the DM-SCN shows a circadian oscillation of their expression. There are species-specific differences in the neurochemical nature of core cells, e.g., mice lack calbindin-expressing cells but exhibit a cluster of light-inducible GRP-expressing neurons (237). It has been proposed that these calbindin cells in the SCN core, although not endogenously rhythmic, might be responsible for cell-to-cell synchronization in the whole nuclei (517). An elegant way of following the regionalization of the $\mathrm{SCN}$ is to look along the path of clock gene expression after a light pulse (e.g., Refs. 329, $520,523)$. Per1 and Per2 are regulated differentially throughout the core and shell regions (521). Per expression occurs first in the SCN core, which "travels" to the shell; moreover, there are differences between Per expression related to light-induced phase delays, apparently mediated by Per2 shell expression, and phase advances, correlated with Per1 expression in the same region (see Ref. 20 for a review). This is further supported by studies in animals with targeted or pharmacological inhibition of per expression $(15,65,448)$.

The shell portion is not retinorecipient, but many of its AVP-expressing neurons are intrinsically rhythmic $(183,520)$. Therefore, one of the key questions in entrainment deals with the intercellular and interregional communication within the SCN. Indeed, while individual clock cells in culture express rhythms with different periods (508), in vivo or in organotypic cultures, their oscillation is synchronized sustaining a coherent phase and period $(206,283,441)$. These oscillator network properties of the SCN are essential for the nucleus to act as a tissue pacemaker with coherent circadian outputs. Neuropeptide signaling, including VIP (through VPAC receptors) and GRP-mediated communication, has been reported to be necessary for this synchronizing role (300, 303). Indeed, the role for VIP in light-induced entrainment is supported by several studies in mice lacking VIP receptors, where not only is the locomotion pattern altered, but photic responses are not as strong as in wild-type animals (e.g., Ref. 211). In addition, a recent study on intercellular synchronization in VIP receptor knockout mice, looking at the expression of Per-GFP constructs in individual cells, suggests that this receptor is important for cellular coupling in the SCN (210). Other intra-SCN synchronizing 
mechanisms proposed include NO and GABA neurotransmission $(16,29,282,283,318,471,497)$ as signals that couple SCN cells and might relay photic phase-adjustment information from the retinorecipient SCN to the dorsal region.

Trophic factors might also participate in photic signaling in the SCN. Indeed, brain-derived neurotrophic factor (BDNF) has been suggested to play a role in entrainment, as reported in in vivo studies with heterozygous BDNF mutant mice that exhibit impaired responses to light (279), as well as in vitro experiments that show that this neurotrophin can increase NMDA-induced phase shifts in suprachiasmatic neurons $(246,317)$. Mice targeted for neurotrophin-receptor genes, such as TrkB or p75, also exhibit decreased phase shifts in response to light pulses $(19,162)$, supporting the notion that trophic factors play a role in photic entrainment. Indeed, as we shall discuss later, neurotrophins, including nerve growth factor (NGF), might share common steps in the intracellular photic entrainment pathway.

As for intra-SCN signaling, we have recently proposed that $\mathrm{NO}$ is an appealing candidate for modulating coupling among cellular networks, due to its rapid and transcellular effects (397). It is therefore plausible that NO acts as a transcellular messenger in the SCN in vivo, contributing to interregional communication between suprachiasmatic areas with different primary functions. NO is synthesized in SCN neurons from L-arginine by neuronal NO synthase (nNOS) (501); increases in NO mimic lightinduced phase shifts (108), and nNOS inhibition impede photic phase-shifts of the activity rhythm in the hamster (311). Also, photic stimulation increases nNOS activity in the $\operatorname{SCN}(4,134)$. Moreover, there is compelling evidence that NO-mediated signal transduction (in particular, through guanylyl cyclase activation) is specifically necessary for light-induced phase advances of the clock (see below; see Ref. 158 for a review).

In addition to its role as an intracellular messenger, NO could also convey photic information by diffusing within the SCN tissue as an extracellular messenger. Due to its nonpolar nature, it can cross cellular membranes, easily diffuse across the extracellular matrix, and regulate neural activity outside of its synthesis site. In this way, it could also act as a fast and specific extracellular signal for the coupling of individual neuronal oscillators within the SCN. To study the role of NO in intercellular communication, we have used a selective scavenger of extracellular NO, PTIO, which cannot pass the cellular membrane. PTIO blocked both light-induced phase advances and cFos expression in the SCN, suggesting that extracellular NO signaling is necessary for circadian photic entrainment (397 and unpublished data) (Fig. 9B).

It is also interesting to consider the retina and the RHT not only as passive transducers of environmental photic information but also as active characters in the theater of circadian oscillations in the SCN. Indeed, local retinal oscillators (476) might influence not only their local environment but also the activity of their efferent targets. Although relatively subtle, there are specific effects of orbital enucleation on suprachiasmatic cycles and responses to diverse stimuli. It is not only photoreceptor degeneration that is responsible for these effects, since enucleation induces different changes in the SCN and circadian rhythms that those induced by degeneration models (e.g., Refs. 474, 518).

While some SCN rhythms are abolished by enucleation, such as the cycle of extracellular signal-regulated kinase (ERK) in a subset of SCN cells (271), most evidence suggests that the removal of the eyes induces plastic changes in the architecture of pacemaker neurons. Indeed, trophic factors (331) and adhesion molecules (516) change their SCN expression and distribution after enucleation, as well as astroglial distribution in the nuclei (267). Removal of the eyes also induces an increase in Fos expression in the SCN $(35,294)$. The eyes also seem to participate in the response of the SCN to other brain structures. As already stated, thalamic stimulation affects SCN-driven circadian rhythms, and part of this effect is dependent on retinohypothalamic projections to the nuclei, suggesting that antidromic innervation of retinal ganglion cells is essential for the correct communication of different relay stations of the system (240). Even if small, these changes do have an impact on circadian parameters, in particular on the period variability (518). Moreover, the development of the RHT tract certainly influences the establishment of neural connections in the SCN and, correspondingly, the pattern of the sleep-wake cycle (in terms of the nocturnal niche) in the developing rat (145).

\section{SIGNAL TRANSDUCTION IN THE MAMMALIAN SUPRACHIASMATIC NUCLEI}

As already mentioned, glutamate is the main signal for photic entrainment. In addition, the metabolism of this neurotransmitter in the SCN, although having received relatively little attention, plays an important role in the cellular characteristics of SCN communication. There is evidence that glutamate can also play a role in SCN output to other hypothalamic structures, suggesting this neurotransmitter might be a signaling molecule of suprachiasmatic cells (532). Glutamate can also be synthesized in SCN glia or neurons and is recycled through the glutamate/glutamine cycle in glial cells $(203,341)$. Moreover, although glutamate uptake is not regulated in glia in a circadian fashion, it is modulated by clock gene expression (36). Figure 10 summarizes the glutamate/glutamine cycle in the SCN. In addition, glial cells are also rhythmic, at least in terms of their neurochemical arrangements 


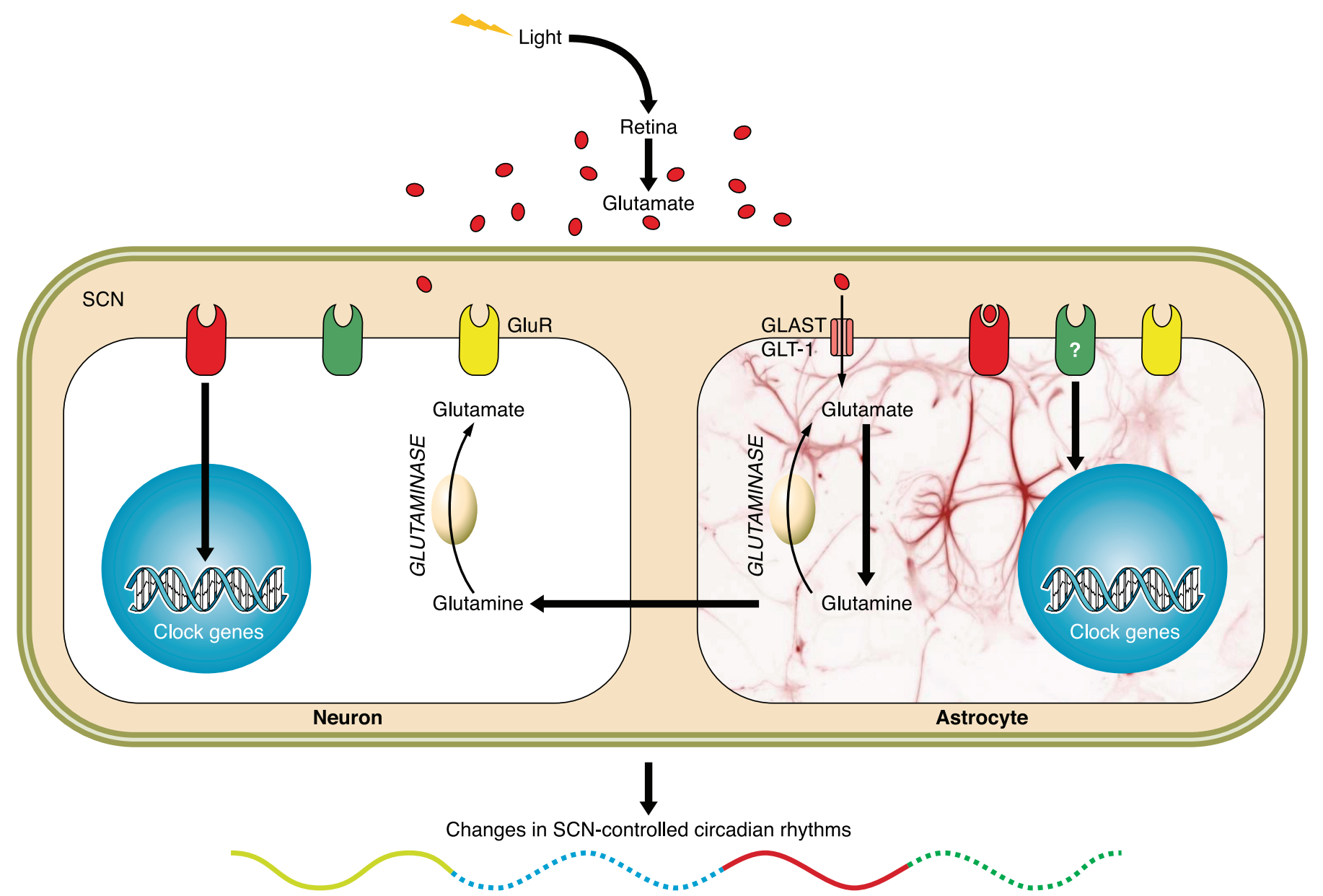

FIG. 10. A model of the glutamine-glutamate cycle in the SCN. Glutamate is the central neurotransmitter released by retinal cells in response to light. Neurons and astrocytes express different types of glutamate receptors (GluR). Most of glutamate uptake after its release to extracellular space is mediated by glial transporters (GLAST, GLT-1). In astrocytes, glutamate may be converted in glutamine by glutamine synthetase (GS). In turn, glutamine may be released; neurons are able to uptake it and convert it to glutamate through glutaminase (an enzyme present in both cell types). We have found diurnal and circadian variations in GS activity in the SCN and a diurnal variation in glutamate uptake in SCN synaptosomes (Leone et al., unpublished data).

(i.e., glial fibrillary acidic protein distribution) $(60,153$, $268,274,281,344)$, and this cyclic environment could also contribute to the temporal gating of photic input to the $\mathrm{SCN}$, a possibility that has yet to be tested rigorously, especially taking into account that glial cultures are able to exhibit endogenous, although weak, circadian rhythmicity (399). Glial architecture seems to be related to retinohypothalamic innervation, in particular during development $(267,268,357,518)$.

Back to glutamate, the application of NMDA or nonNMDA antagonists blocks light-induced phase shifts, suggesting that these receptors are part of the entrainment process $(70,148,149,343,492)$. These antagonists also inhibit light-induced c-Fos $(124,176,319,343,383)$ and Per1/Per2 expression $(343,383)$ in the SCN. On the other hand, glutamate or NMDA administration mimics the effects of light in terms of its PRC $(310,322,324)$. In another study (108), glutamate microdrop application to SCN slices resulted in phase advances and delays that very closely resembled a photic PRC.

Downstream of glutamate receptor activation, voltage-dependent calcium channels have been implicated in glutamate- or light-induced phase shifts (244), and it has been suggested that calcium dynamics might be part or interact closely with the molecular feedback loops of the biological clock $(216,217)$. NMDA-induced calcium transients in the SCN exhibit circadian changes in their magnitude and duration (67). These transients probably play a role in the temporal regulation of photic input to the clock and are also modulated by other neurotransmitters such as PACAP, 5-HT, NPY, or GABA (with GABA effects being reported as excitatory or inhibitory, depending on developmental stage and other variables) $(81,87,254,371,483)$. It is interesting that circadian gating of photic responses might be at least partially exerted at the glutamate receptor-calcium in- 
flux process, since the effect of agonist application is time dependent (68) (Fig. 11).

There are differences in basal $\left[\mathrm{Ca}^{2+}\right]_{\mathrm{i}}$ in rats killed during the light or the dark phase of their cycle (68), which persist under constant darkness and might play a role in the regulation of photic information reaching the SCN. Since those variations were abolished by presynaptic inhibition, it is likely that an extracellular control of basal $\left[\mathrm{Ca}^{2+}\right]_{\mathrm{i}}$ exists.

Although extensively modulated by several neurotransmitters, the main signal involved in $\mathrm{Ca}^{2+}$ influx into SCN neurons is glutamatergic, and the $\mathrm{Na}^{+} / \mathrm{Ca}^{2+}$-permeable receptor NMDA is necessarily involved in its function (2). The $\mathrm{Ca}^{2+}$ influx associated with NMDA receptor activation is thought to produce brief, high concentration $(>100 \mu \mathrm{M})$ localized gradients of $\mathrm{Ca}^{2+}$ near open channels. In addition, other $\mathrm{Ca}^{2+}$ membrane channels (such as voltage-gated ones) or $\mathrm{Ca}^{2+}$ organelle stores could play an important role in signal transduction, because metabotropic glutamate receptors and intracellular release also modulate $\left[\mathrm{Ca}^{2+}\right]_{\mathrm{i}}(180,181)$. Moreover, these receptors have also been reported to be part of the output pathway of the circadian clock (382). Recent evidence suggests that voltage-dependent $\mathrm{Ca}^{2+}$ channels are responsible for changes in postsynaptic calcium influx in the SCN; blockade by nimodipine indicates the involvement of L-type $\mathrm{Ca}^{2+}$ channels (219). Voltage-dependent $\mathrm{Ca}^{2+}$ channels are rhythmically expressed in the rat $\mathrm{SCN}$ and in an

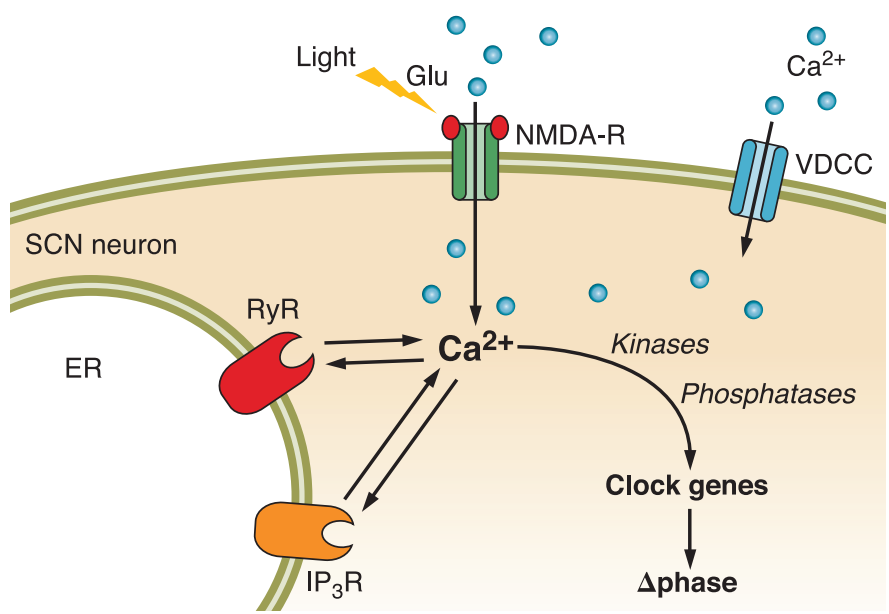

FIG. 11. Glutamate-induced calcium influx into SCN neurons represents the first step in the signal transduction pathway leading to entrainment. Retinohypothalamic glutamate interacts with NMDA (and other) receptors in the ventral SCN and induces calcium influx, which is also modulated by other neurotransmitters. Voltage-dependent calcium channels (VDCC) are also expressed in SCN neurons and are partially responsible for the increase in $\left[\mathrm{Ca}^{2+}\right]_{\mathrm{i}}$. The increase in intracellular calcium levels can interact with intracellular stores by activation of $\mathrm{IP}_{3}$ and ryanodine receptors. Moreover, calcium can act directly on posttranscriptional mechanisms leading to changes in clock gene expression and/or activity. [Modified from Golombek et al. (158).] immortalized SCN cell line (358). As for downstream mechanisms related to $\left[\mathrm{Ca}^{2+}\right]_{\mathrm{i}}$, it has recently been shown that extracellular calcium influx is necessary for depolarization-induced mouse Period1 (mPer1, one of the most studied clock genes, see below) expression in cerebellar cells (12). This effect was blocked by nifedipine and $\mathrm{Ca}^{2+} /$ calmodulin-dependent protein kinase inhibitors. Moreover, calcium channel inhibition by cadmium prevented Per and Bmal oscillations in SCN cells (358).

According to pharmacological and electrophysiological evidences, intracellular calcium is also important in terms of SCN regulation. Ryanodine receptors present a circadian variation in its ligand binding properties (8, 106), which influences intracellular calcium dynamics. Ding et al. (107) demonstrated that these receptors are involved in light synchronization at the beginning of the subjective night, when light induces phase delays of circadian rhythms. Ryanodine inhibition or calcium reservoir depletion block glutamate-induced phase delays at this day time.

Inositol trisphosphate $\left(\mathrm{IP}_{3}\right)$ receptors are also likely candidates for regulating $\mathrm{Ca}^{2+}$ mobilization in the SCN (184). Types I and III $\mathrm{IP}_{3}$ receptors are expressed in a circadian fashion, peaking during the early and late subjective night, respectively (185).

Following the pathway, many intracellular $\mathrm{Ca}^{2+}$ effects are mediated by the activation of a family of $\mathrm{Ca}^{2+}$ / calmodulin-dependent protein kinases (CaMKs), which itself might be regulated by light and a circadian clock (4). Among other isoforms, CaMKII is present in the SCN and, together with calmodulin, has been implied in the photic synchronization process $(144,163,165,436)$. On the other hand, CaMKII inhibition also blocked Per1/2 expression in the SCN (526), while the activation of the enzyme induced Per1 expression in vitro $(366,367)$ (see Fig. 12).

\section{A. Entrainment "Alla CREB"}

A CaMKII (and other kinases) substrate also implied in entrainment is CREB. CaMKII inhibition blocks lightinduced CREB phosphorylation (163). Indeed, the phosphorylation and the subsequent increase in Per expression is one of the likeliest general mechanisms involved in photic phase shifting $(109,152,155,369,429,496)$. Moreover, CREB might be a common element where multiple entrainment pathways converge (496) (Fig. 12).

Although regulated by several pathways, CREB traditionally points to a cAMP-responsive transduction signal. Binding to cAMP-responsive elements (CREs) regulates gene transcription, and several posttranslational mechanisms converge into this regulation, including not only CREB phosphorylation but also the induction of ICER (inducible cAMP early repressor), which enables a transient control of gene expression (264). ICER is en- 


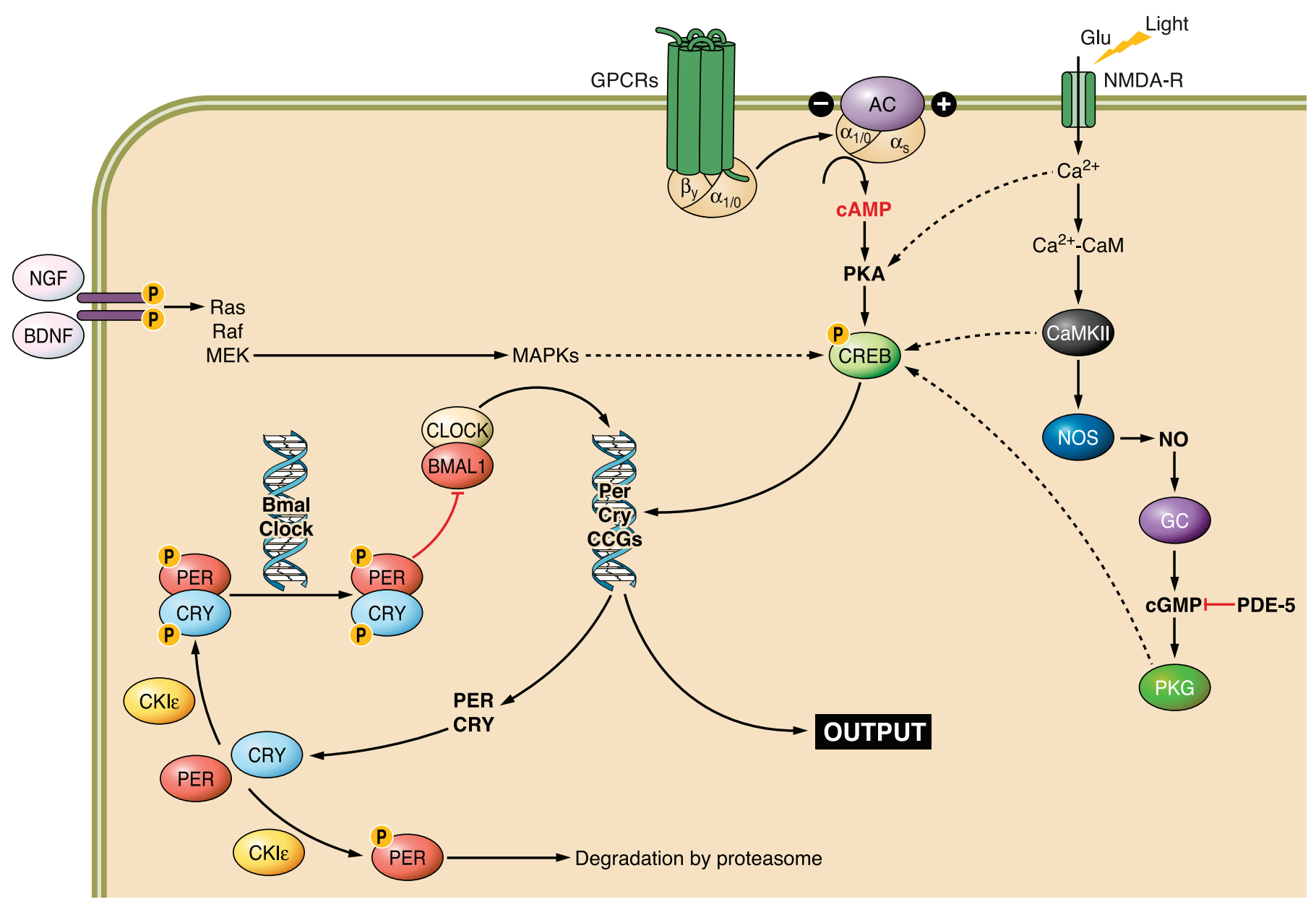

FIG. 12. A general scheme of signal transduction mechanisms involved in circadian entrainment. Glutamate activates NMDA-induced calcium influx which, together with other second messengers, triggers the activation of diverse signal transduction cascades, including calmodulin kinase II (CaMKII) and neuronal nitric oxide synthase (nNOS) activity, cAMP- and cGMP-dependent protein kinases, and mitogen-activated protein kinase (MAPK). Although the cross-talk between these diverse cascades is not currently well-known, it is plausible that a common mechanism involved in the pathway is phosphorylation of cAMP response element binding protein (CREB). In turn, pCREB activates per1 and per2 transcription by binding to a CRE element in their promoter regions (these genes are also activated by Clock/Bmal binding to E boxes). Solid lines represent mechanisms that have been described experimentally, and dashed lines indicate possible additional links of the pathway. The molecular clock mechanism is described in more detail in Figure 15.

coded by the CREM gene, which has been found to be fundamental in the control of pineal melatonin secretion, both under daily and photoperiodic conditions $(140,141)$. ICER is also induced by light pulses in the SCN during the subjective night (449). More recently, ICER-CREM was found to be light-responsive in the VL-SCN after light administration, following several temporal events that included CREB phosphorylation (5 min after light pulse), per mRNA expression $(\sim 1 \mathrm{~h}$ after light exposure) and, finally, ICER-CREM expression (431), maybe expressing a photoperiodic code in the SCN (314).

Indeed, the temporal regulation and the speed in the expression of posttranscriptional events following entraining light pulses helps to understand the pathway leading from light to the hands of the circadian clock. Classical two-pulse studies had suggested that, although there is a delay in the phase change of overt rhythms, the circadian oscillator is instantaneously shifted after light pulses (389). This two-pulse paradigm assumes that the second light pulse will find the oscillator in a different state, provided the first pulse had an immediate impact on the clock. Indeed, light pulses separated by just $1 \mathrm{~h}$ demonstrated a very rapid change in terms of CREB phosphorylation (41).

More recently, cAMP signaling was proposed to be not only part of the entrainment pathway but rather to the molecular mechanism of the circadian clock (as we shall briefly cover in a following section) itself. O'Neill et al. (368) have reported that cAMP is needed to sustain the molecular feedback loops in the SCN. According to their model, constructed with a diversity of pharmacological approaches that include different cAMP inhibitors, cAMP might be an output of the clock that feedbacks as an input, thus providing robustness and fine-tuning of period, 
phase, and amplitude. Again, the ouroboros concept: it is difficult to distinguish the exact location of components of the circadian system; indeed, multiple layers of feedback provide insurance against perturbations in a variety of physical and biological systems.

Another effector of cAMP signaling is PKA, a cAMPdependent protein kinase, which is able, among many other effects, to catalyze CREB phosphorylation in several models. cAMP content and PKA activity fluctuate in the SCN both in vitro (402) and ex vivo (135); cAMP application in vitro induces daytime phase shifts (403), suggesting that this signaling pathway is primarily involved in nonphotic phase shifting. However, the fact that the cAMP/PKA pathway is responsive to glutamate (467) or VIP (316) stimulation, the fact that its inhibition phase shifts the clock (272), and, moreover, its role in CREB regulation suggest a complex role for cAMP signaling in the SCN, which might be decoded with the help of functional genomics studies (530). Indeed, the exact relationship between cAMP/PKA signaling with clock gene pathways remains to be established, other than its need for per oscillation robustness (368) or PKA-mediated CREB phosphorylation implicated in in vitro Per activation in a model of peripheral oscillators (345).

\section{B. A MAPK of Circadian Entrainment}

Another classical effector of the cAMP signaling pathway is the family of MAPKs (Fig. 13). Indeed, nocturnal light pulses activate ERK2 in the rat SCN, while in vivo inhibition of the pathway blocks the circadian response to light $(53,55,122,370)$. We have extended those results to other members of the MAPK family in the hamster, including ERK1/2, p38, and JNK (395). The three of them exhibit diurnal and circadian changes in their SCN activity, as measured by the increase in their phosphorylated form during the day. Moreover, ERK1/2 and JNK (but not p38) respond to nocturnal light pulses. These changes might be triggered by a differential effect of light on MAPK kinases and/or MAPK phosphatases, an issue currently under investigation. Again, CREB stands out as a putative interface for photic entrainment, since some MAPKs are capable of phosphorylating this factor in the SCN (73). Moreover, there are also reports indicating that MAPKs might be regulated by CaMKII $(53,366)$, indicating a complex network of signal transduction pathways in the SCN (Fig. 13). MAPK activation cycles can be sustained by two different regulatory mechanisms: phosphorylation by MEKs or dephosphorylation by MAPK phosphatases (MKPs). Recent evidences suggest that the latter is controlled by light and the circadian clock (54, 55, 111, 394), providing a potential target for pharmacological manipulations of the entrainment pathway. Downstream from MAPK, however, the pathway looks more obscure, since

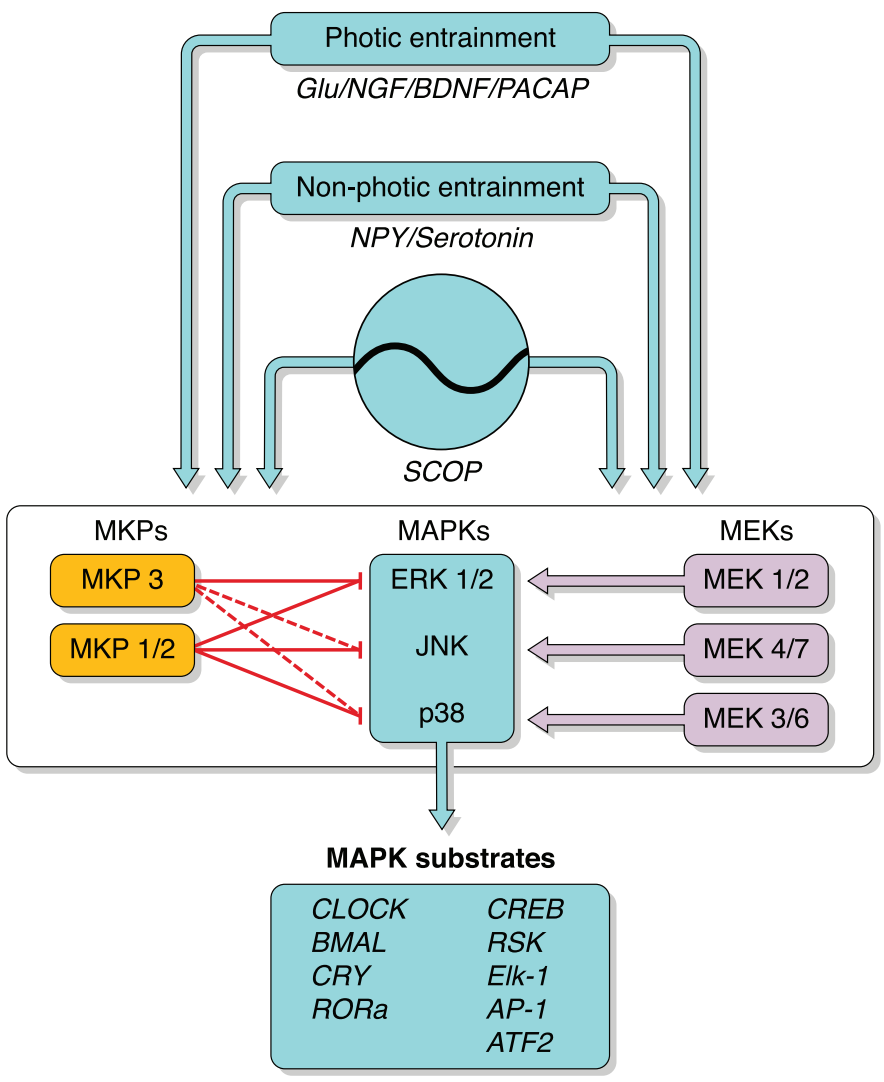

FIG. 13. Mitogen-activated protein kinases (MAPKs) in SCN neurons can be activated by light-induced neurotransmission and/or extracellular signals such as trophic factors. The three main members of the MAPK family are expressed and activated rhythmically in the SCN and also respond to light pulses at the times during which light induces phase shifts of circadian rhythms. This activation (phosphorylation) might be related to changes in MAPK kinases (MEKs) or MAPK phosphatases (MKPs), several of which were found to be expressed and active in the SCN. Diverse putative MAPK substrates have been proposed in the SCN, including clock genes and transcription factors.

there are few indications of which substrates mediate MAPK action and its cross-talk with clock genes, although CREB (as already stated) and MSK-1 (54) phosphorylation are the most likely candidates.

The input pathways for MAPK activation in the SCN are not completely known, and we have provided evidences for NGF regulation of these kinases (396). Indeed, NGF induces a photic-like PRC in hamsters and activates ERK by phosphorylation. Additional evidence of MAPK involvement in entrainment comes from our experiments in which activation of ERK was achieved by in vivo transfection of a constitutive form of MAP kinase kinase (MEKee), thus inhibiting the normal cyclic progression of the pathway. Under these conditions, light was unable to induce phase shifts, indicating that it is not only the presence, but the rhythm of MAPK activation, that is needed for entrainment (182). Recent work has also provided evidence supporting the role of MAPK-CREB modulation of microRNAs that ultimately affect photic entrainment (85). 
Interestingly, MAPK oscillations have been implicated in other CNS pathways, including the establishment and persistence of long-term hippocampal-dependent memory, suggesting a multitemporal system not only cyclic, but also defining a past and a future of events (125).

\section{Lights Means NO: the NO-cGMP System in Circadian Entrainment}

Another downstream candidate for the pathway is NOS phosphorylation by CaMKII. As already mentioned, NOS activity is necessary for entrainment, at least according to pharmacological experiments $(108,311,502,504)$. In addition, $\mathrm{NO}$ donors increase the circadian response to light (311). However, mice with a null mutation for the neuronal or endothelial isoforms of $\mathrm{NOS}\left(\mathrm{nNOS}^{-/-}\right.$and $\mathrm{eNOS}^{-1-}$ ) did not show any difference from controls in terms of their photic responses, suggesting that other isoforms might also be involved in such mechanism (258, 259 ). We have reported that nNOS is phosphorylated by CaMKII in the SCN and that this enzymatic interaction is also needed for normal phase shifts in response to light (4).

Up to this stage, the entrainment pathway so far described can only explain the first of the gating mechanisms that regulate light-induced phase shifting of circadian rhythms, i.e., the differential response to light during the day and the night. However, CaMKII and nNOS do not necessarily differentiate between the opposite effects of light within the subjective night: delaying the clock in the early night and advancing it towards the end of the night. The Argentine writer, Jorge Luis Borges, would have been delighted with this successive bifurcation of light temporal signaling: "Time forks perpetually towards endless futures" (44a).

Downstream from CamKII/NOS, the photic pathway experiments a second gating process that is not completely understood, but whose understanding is fundamental to grasp the differences between phase delays and advances, and to devise specific treatments for circadian disorders. A specific intracellular event that only correlates with light-induced phase delays is $\mathrm{Ca}^{2+}$-induced $\mathrm{Ca}^{2+}$ release activated by ryanodine receptors (107).

On the other hand, during the late night (when phase advances occur in response to light), NO is able to activate the soluble form of guanylyl cyclase (sGC), leading to an increase in cGMP levels and the eventual activation of cGMP-dependent kinase (PKG) (Fig. 14). During the late night, therefore, the activation of the sGC-cGMP-PKG pathway is known to be involved in phase advances (136, $158,298,468,470,505)$, suggesting that the accessibility of this specific signaling pathway is fundamental for regulation of circadian timing. The SCN clock is sensitive to cGMP analogs only during the subjective night of the

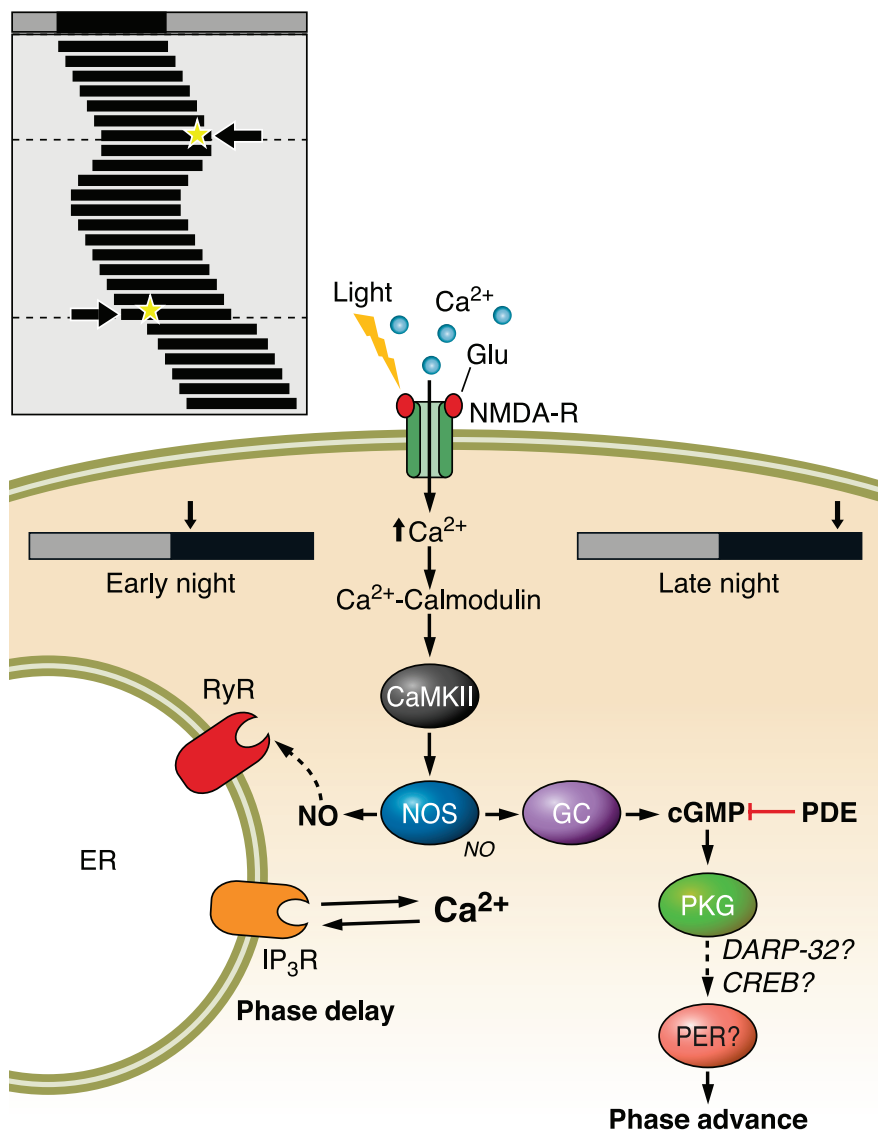

FIG. 14. Divergent transduction pathways for circadian phase delays and phase advances. Both pathways have in common their sensitivity to glutamate stimulation (from the retinohypothalamic tract) and their final interaction with clock genes via specific transcription factors (such as pCREB). It is possible that phase delays and advances represent converging steps into the same molecular feedback loop but differ in the phase at which they reach this loop, thus affecting the cycle at different levels of clock genes. However, there is evidence suggesting specific pathways for accelerating or delaying the clock. In the early night, light pulses activate ryanodine $(\mathrm{RyR}) / \mathrm{IP}_{3}$-related intracellular calcium mobilization. On the other hand, during the night night, nitric oxide (NO) activates cGMP synthesis, leading to cGMP-dependent protein kinase (PKG) activation. Pharmacological manipulation of cGMP levels (e.g., by inhibiting cGMP-phosphodiesterase, PDE, and thus increasing cGMP levels) enhance light-induced phase advances of circadian rhythms. Mechanisms downstream of PKG, leading to clock gene activation and behavioral phase shifts, are currently not well understood.

circadian cycle, a temporal window when light stimuli in vivo advance behavioral rhythms (404), in antiphase with the effect described for cAMP (which induces phase shifts when applied during the subjective day).

In the SCN, the type II isoform of PKG is expressed (136, 376, 468), and cGMP levels and PKG activity peak during the day or subjective day $(136,158)$. The latter variables are significantly increased by late (but not early) night light pulses, in accordance with light-induced phase advance timing. In addition, pharmacological inhibition of the cGMP-related pathway in the SCN significantly reduces light-induced phase advances $(136,298,505)$. 
One of the aims of studying signal transduction of photic entrainment is to imagine and eventually design pharmacological treatments to aid in certain conditions where synchronization is compromised. The question is, then, how to use the information about the cGMP-related pathway in practical terms. cGMP variations can be caused by either synthesis (by guanylyl cyclase) or degradation [by phosphodiesterase (PDE)] (157). The cGMP variation in the SCN appears to be related to temporal changes in PDE activity, peaking at night (136). While we have found at least five PDE isoforms in the SCN (Agostino et al., unpublished data), it is important to state that the PDE5 isoform is included in the group, an enzyme well known in terms of its pharmacological susceptibility. Indeed, several drugs inhibit PDE5 and could be used to increase cGMP levels in the SCN, under the hypothesis that this manipulation would render the system more sensitive to light stimulation. As we have recently reported, the selective PDE5 inhibitor sildenafil (along with other inhibitors of different pharmacokinetics profile) not only increased light-induced phase advances of locomotor activity circadian rhythms (and not phase delays) but also accelerated reentrainment to a 6 -h phase advance in the light-dark cycle in an animal model of jetlag (7).

\section{FROM LIGHT TO GENES: MOVING THE HANDS OF THE CIRCADIAN CLOCK}

Although not the main feature of this review, and having received considerable attention in recent years (94, 248, 252, 287, 288, 428, 443, 451), the molecular circadian clock is at the core of contemporary chronobiological research.

Within the SCN, rhythms are generated in circadian pacemaker cells by a complex of molecular feedback loops that positively and negatively regulate the transcription of core genes (e.g., period, cryptochrome, bmal1) of the circadian clock $(375,412,433)$. It is interesting that the transcription-translation loop that generates molecular oscillations of clock genes is remarkably conserved among species and even distant groups, suggesting a possibly monophyletic origin of such a mechanism $(119,121)$. The system is described and summarized in Figure 15.

Forward genetic approaches have unraveled several genetic components isolated from distinct circadian phenotypes, advancing our knowledge of the molecular circadian clock $(442,451,454)$. In addition, genome-wide identification of clock-controlled genes, as well as their protein products and their interactions, provide important information for the understanding of the systemic behav-

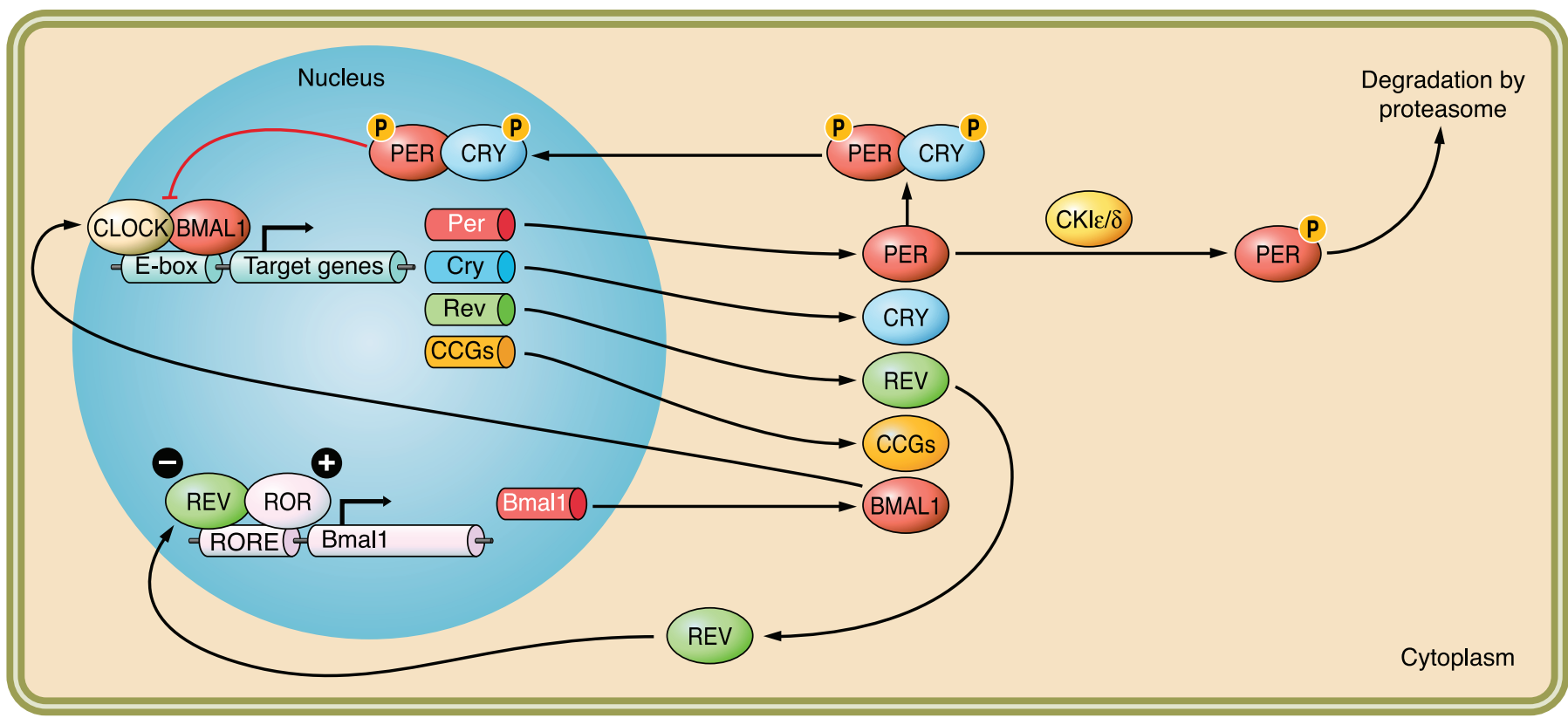

FIG. 15. A simplified view of the molecular circadian clock. The mammalian clock is composed of a negative-feedback loop involving clock genes clock, bmal1, per1, per2, cry1, and cry2. Transcription factors Clock and Bmal1 interact and activate per and cry expression by binding to an $\mathrm{E}$ box in their promoter regions. In turn, Per and Cry heterodimerize, translocate to the nucleus, and inhibit Clock/Bmal-induced gene expression. After the Per/Cry complex is degraded, the cycle starts again. Posttranlational modification (mainly by phosphorylation) is fundamental for regulating translocation, dimerization, and/or degradation of clock proteins. For example, Per1 and Per2 are phosproylated by casein kinases $\varepsilon$ and $\delta$, controlling their nuclear translocation and also degradation by the proteasome. A second feedback loop involves the expression of Rev-Erba (also regulated by Clock/Bmal1 binding to its E-box region), which in turn represses Bmal1 transcription through an RAR-related orphan receptor (ROR) element, adding robustness to the cycle. Other clock-controlled genes (CCGs) include E boxes in their promoters and are therefore regulated by the molecular circadian clock. 
ior of circadian cogs and wheels within and between cells (e.g., Ref. 96).

Early evidences point to the dependency of photic entrainment on protein synthesis (534); however, posttranslational modifications of clock proteins are deeply related to circadian features such as period and phase. Among these, protein phosphorylation is a key event regulating circadian period $(147,491,493)$, and also provides putative targets for the pharmacological adjustment of the system $(5,6,31,493)$.

Protein kinases casein kinase 1 epsilon $(\mathrm{CK} 1 \varepsilon)$ and delta (CK1 $\delta$ ) are among the first that have been implied in posttranscriptional regulation of activity in the components of the core molecular clock. Casein kinases regulate PER1/2 and CRY1/2 proteins accumulation and degradation metabolism, as well as the activity of BMAL1; in addition, phosphorylation chaperones dimeric combinations of these proteins into the nucleus to regulate mper and mcry transcription $(119,375,412,433)$. Mutations in both $c k 1 \varepsilon$ and $c k 1 \delta$ induce profound changes in circadian period by altering both the accumulation of protein in the cytoplasm as well as nuclear translocation of the dimers $(10,127,129,270)$. The $c k 1 \varepsilon^{\text {tau }}$ mutation represented the first complete description of a circadian mutant in mammals $(285,286,409)$, and in addition, it fosters changes in entrainment, including a larger response to light pulses $(439,440)$. We have recently demonstrated that $c k 1 \varepsilon$ is not only important for period determination but also participates in the photic input pathway to the clock $(5,6)$. Indeed, changes in circadian period require alterations in photic entrainment to adjust the endogenous oscillation to the environmental photoperiod $(286,287,313,448$,
500). Our and other recent data indicate that the photic sensitivity of the system is also dependent on the activity of $c k 1 \varepsilon$, since enzyme activity prior to a light pulse is necessary for normal phase shifting and entrainment (5, 6 , 220 ). Although the tau mutation was originally believed to induce a loss of function of the coded enzyme (286), recent data suggest that specifically for Per as a substrate, $\mathrm{CK} 1 \varepsilon^{\mathrm{tau}}$ proteins might actually represent a gain-of-function mutation (146); moreover, other clock genes might also be CK1 $\varepsilon$ targets (128). In any case, the activity of this enzyme offers a new target and perspectives for pharmacological changes in circadian entrainment.

The study of animals carrying specific mutations in different components of the molecular circadian clock opens a window to study their role in entrainment mechanism, as is summarized in Table 4, which includes the effect of mutations in clock genes and in genes that encode modulatory proteins of the molecular clock mechanism.

The molecular framework of circadian rhythmicity offers several windows on which light might be able to change the speed of the oscillation and induce the phase shifts necessary for daily entrainment. A classical effect of light stimulation induces the expression of several genes in the SCN; historically, the first photically responsive genes to be described were the immediate-early genes fos and jun, which led to the formation of the transcriptional activator complex AP-1. The synthesis of AP-1 exhibits a circadian rhythm mediated by its different components (456) and is clearly light dependent, correlating with the PRC to light in terms of behavioral responses (see Refs. 161, 166, 309 for reviews). c-Fos (and

TABLE 4. Mammalian mutations affecting circadian entrainment

\begin{tabular}{|c|c|c|}
\hline BDNF heterozygous mutant mice & Decreased amplitude of light-induced phase shifts & 279 \\
\hline Bmal1 ${ }^{-1-}$ mice & Altered activity in LD; arrythmic in DD & 51 \\
\hline Clock \pm mice & High-amplitude PRC; enhanced responses to 6 -h light pulses & 494 \\
\hline Dec1 ${ }^{-1-}$ mice & Faster reentrainment rate after a 6 -h phase advance of the $L D$ cycle & 361 \\
\hline Dexras $1^{-\prime-}$ mice & Decrease in photic entrainment and increase in nonphotic responses & 83,84 \\
\hline mCry $1^{-\prime-}$ and $\mathrm{mCry}^{-/-}$mice & Increased response to phase-delaying light pulses & 448 \\
\hline mPer1 $1^{-1-}$ mice $\left(\mathrm{mPer}^{\mathrm{Brdm} 1}\right)$ & Lack of photic phase advances under Aschoff type 2 protocol & 15 \\
\hline mPer2 ${ }^{-/-}$mice $\left(\mathrm{mPer} 2^{\text {Brdm1 }}\right)$ & $\begin{array}{l}\text { Lack of photic phase delays and large photic phase advances under } \\
\text { Aschoff type } 2 \text { protocol }\end{array}$ & 15 \\
\hline $\mathrm{NPAS} 2^{-/-}$mice & Enhanced adaptability to a phase advance in the LD cycle & 118 \\
\hline $\mathrm{PAC1}^{-1-}$ mice & Decrease in light-induced circadian phase shifts & $72,190,241$ \\
\hline $\operatorname{Rev-erb} \alpha^{-\prime-}$ mice & Large photic phase advances & 398 \\
\hline
\end{tabular}

Mutations in key elements of the molecular circadian clock, as well as mutants in the circadian photoreceptor pathway, exhibit changes in photic entrainment. CK1 1 , casein kinase 1 epsilon; NPAS2, neuronal PAS domain protein 2; PCA1, PACAP receptor type 1 (PAC1); rbp, retinol-binding protein; Vip, vasoactive intestinal polypeptide; Vipr2, gene encoding the VIP receptor VPAC2; RorB, retinoid-related orphan receptor $\beta$. 
most likely other immediate-early genes), however, is probably better interpreted as a marker of unspecific neuronal activity and is also redundant in terms of function, since c-fos null mutants still respond to light (207). Anyway, the first evidences for a temporal gating in lightinduced gene expression came from studies investigating the regulation of the immediate-early gene c-Fos in the SCN. Although revolutionary in their times, since these studies provided some of the first molecular tools related to a gene expression change in response to light in the SCN, this pathway did not really lead to a precise understanding of the circadian entrainment pathway. In addition, about one-third of the genome (at least in humans) shares AP-1 sites, so the response in terms of transcription is certainly not highly specific (536).

The rapid pCREB induction $(109,155,496)$ and the subsequent CRE activation (369) led to the discovery of CRE-regulated genes that were rhythmically expressed in the SCN, including clock genes such as per $(469,477)$. We will focus on some of the mutations that affect photic entrainment, specifically on the effect of clock genes on synchronization. Period genes (per1 and per2) are induced by light in the SCN, at the same time in which light elicits phase shifts $(14,343,434,438,457,538)$. In mice, their mRNA levels start to increase $\sim 10-15$ min after light exposure and peak between 60 and $120 \mathrm{~min}$ after the light pulse (with per2 peaking later than per1) and return to basal values $\sim 3 \mathrm{~h}$ later; protein levels also increase after light treatment (522). Photic phase shifts in locomotor activity are attenuated by antisense oligonucleotides to mPer1 and mPer2 in mice (11), the coadministration of both oligonucleotides completely inhibits photic phase shifts, suggesting an additive role in entrainment (499). There appears to be some divergence between clock gene expression and behavioral entrainment; for example, light-induced expression of Per2 occurs in the late subjective day $(14,457,538)$, a time when there is no photicrelated change in the phase of locomotor activity rhythms.

Cry genes also play an important role not only in the generation of circadian rhythms, although their participation in circadian entrainment is not completely clear. The expression of cry is regulated by light, and although animals bearing a null mutation in mCry $1 /$ mCry2 become arrhythmic under constant dark conditions, in doublemutant animals there is still light-induced expression of per genes in the SCN (374) and, moreover, mCry2-/and, even more, mCry1-/- mutants exhibited an increased response in light-induced phase delays in the early subjective night (448).

The control of per, and presumably cry, expression, both for its endogenous cycling and its light-induced activity, is driven by CRE elements in its promoter region, as well as by E-box elements that respond to BMAL-CLOCK transcriptional activation $(252,413)$. Bmal1 mRNA is also modulated by light in the SCN, with a stronger induction in the early subjective day (1), while the BMAL1 protein expression is reduced after nocturnal light stimulation (458). Moreover, Bmall mutant mice exhibit significant deficits in entrainment to a LD cycle (51), which could reflect intrinsic changes in Bmal1 activity or a disregulation of other clock genes expression.

As for Bmal's transcriptional partner CLOCK, the analysis of heterozygous null mutants has shown enhanced photic behavioral phase shifts, although the expression of per genes in response to light was not significantly affected. Indeed, since endogenous rhythms in per expression are reduced in CLOCK mutants, a stronger response to resetting stimuli such as light pulses might be expected (494).

Posttranscriptional modifications of core clock genes also play a role in circadian entrainment, as exemplified by the analysis of tau mutant hamsters bearing a $c k 1 \varepsilon^{\text {tau }}$ mutation, which exhibit period shortening, phase-advanced entrainment (409), and high-amplitude light-induced phase shifts with respect to controls $(286,440)$. Changes in phosphorylation state of PER and CRY in tau mutants might alter period by acting directly on the rhythm generation mechanism at the molecular level (287) and, as we have recently shown, the mutation results in a heightened sensitivity to light, suggesting that CK1 $\varepsilon$ also regulates the photic entrainment pathway (5). On the other hand, the circadian entrainment role of other kinases that interact and set the level and phase of clock genes, such as GSK-3 $\beta$ (215), remains to be established.

The molecular state of the circadian system has become more complex since the description of epigenetic mechanisms that are controlled by the clock and also regulate the transcription of clock genes. Alteration of chromatin structure is a fundamental step that gates transcription, and the molecular clock is not an exception, being regulated by several biochemical modifications such as histone acetylation among others $(17,112,174$, $175,204,360$ ). Is it possible that light-induced expression of clock (and other) genes is also dependent on these epigenetic mechanisms, since phospho-CREB binding to CRE promoter sites also depends on histone acetylation (362).

\section{EVOLUTIONARY AND CLINICAL PERSPECTIVES ON CIRCADIAN ENTRAINMENT}

Both the clock mechanism and the entrainment pathway represent extremely robust processes that have been fairly conserved in evolutionary terms. Photic input to the clock seems to have been spared from the need of cognitive vision, since there are several indications of entrainment in the absence of conscious visual cues. The 
dynamics of the SCN appear to be well adapted to both the daily photoperiod and its seasonal variation. A welladapted temporal niche is certainly relevant for survival, and photic and nonphotic cues contribute to a correct temporal allocation of resources and physiological economies $(77,120)$.

However, we could consider human circadian rhythms in the post-Edison era as an aberration in terms of adaptation to their natural environment. It has been said that we are prepared for a world that does not exist anymore, with reliable external markers for timing that are not masked by artificial cues (333). Life in this "Enlightment" era comes accompanied by specific circadian disruptions that could be considered a sign of our times. Among these, adaptation to rotating or abruptly changed time schedules (such as shift work or jetlag) is limited by the inertia of the circadian system that, although plastic, exhibits difficulties in adjusting to changing environments. Indeed, chronic circadian disruptions (which are considered a particular sleep disorder, Ref. 422) lead not only to an impairment in the sleep-wake cycle, but also to reduced performance and productivity, a higher accident rate, and even serious health risks. Treatment for circadian sleep disruptions include chronotherapy (i.e., behavioral phase shifting of rhythms until the right phase is achieved), phototherapy (light treatment), and the pharmacological use of chronobiotics, i.e., compounds that move the hands of the circadian clock. Indeed, two of the most studied agents for changing the speed and phase of circadian oscillations are light and the pineal hormone melatonin $(63,381)$. Although important phase shifting capabilities have been found for melatonin and a variety of compounds in human circadian rhythms, it is clear that the main entrainment agent in most terrestrial animals is light. When appropriately administered and timed, photic stimulation is able to phase shift human circadian rhythms, including the sleep-wake cycle, and accommodate the circadian phase to the desired time point (76).
Light is cheap (and even free, when considering a nice diurnal walk in the park as a potential therapeutic agent), very effective and, when properly used, without any side effects, so combining any circadian treatment with some kind of photic therapy is certainly bound for success. Circadian and sleep clinical trials are sometimes heroic efforts, with relatively low levels of compliance; however, the figures available for people suffering some form of circadian-related transient insomnia (including an estimated $20 \%$ of the work force undergoing some kind of shift work schedule and an unknown prevalence of jetlagrelated disorders) deserve the best of our efforts.

Health and quality of life are affected in several ways directly linked to the circadian system, which could be grouped into three main families: 1 ) intrinsic failure of the clock or disarrangements of the internal synchrony among rhythms and oscillators, 2) pathological alterations in the input pathway, and 3) disadjustments between internal and external temporal cues.

The clock is altered in normal aging, resulting in a decreased amplitude of overt rhythms and, in turn, difficulties in adjusting to temporal changes (154). In addition, some polymorphisms in human clock genes have been implied in abnormal phase changes in the sleep-wake cycle, leading to severe forms of insomnia. For example, a mutation in $c k 1 \delta$ and a loss of a phosphorylation target of $\mathrm{CK} 1 \varepsilon, \delta$ in the mper2 gene (S662G) shorten circadian period and result in a form of advanced sleep phase syndrome $(472,473,515)$; other mutations have recently been traced to sleep disease (406) (Table 5). Since mutations in clock genes have also been related to differential responses to psychoactive drugs, the circadian system is an important target for psychiatric research (33). Although some forms of depression have traditionally been labeled as "circadian," such as seasonal affective disorder (510), since many rhythms are disrupted in depressed patients and clock genes appear to be related to the

TABLE 5. Human circadian mutations affecting entrainment

\begin{tabular}{|c|c|c|c|c|}
\hline per1 & SNP T2434C & Diurnal preference & English & 64 \\
\hline per2 & Amino acid substitution S662G & FASPS & American & 473 \\
\hline & & & English & 22 \\
\hline & & & Argentine & $64 \mathrm{a}$ \\
\hline & Amino acid substitution G647V & DSPS & Japanese & 123 \\
\hline & & Diurnal preference & American & 239 \\
\hline & & & Japanese & 325 \\
\hline casein kinase $I-\delta$ & SNP T44A & FASPS & American & 515 \\
\hline casein kinase $I-\varepsilon$ & Amino acid substitution S408N & DSPS y N-24 & Japanese & 455 \\
\hline
\end{tabular}

Human mutations that affect circadian rhythms and entrainment are given, including chronotypes (diurnal/nocturnal preference) and circadianrelated sleep disorders. For a review and additional references, see References 265 and 266. 
genesis of the disease, the circadian rhythm might also be implied in general depression characteristics $(304,478)$.

More relevant to the focus of this review, the circadian input pathway is sensitive to pathological alterations that will result in entrainment abnormalities. Although it is well established that in cases where blindness ensues the affected individual experiences poorly entrained circadian rhythms, along with sleep disturbances and depressed moods (273, 424, 450), so far, no conclusive evidence supports a cause-and-effect relationship between ophthalmic diseases and circadian-rhythm functions. Much of the studies in human chronobiology have focused on healthy aging volunteers, but little has been done to study effects of age-related anatomic and physiological changes on the photic system. Several ophthalmic factors are associated with age-related reduction in light transmission, such as senile miosis, characterized by a reduction in the pupil diameter, reducing retinal light transmission (513). Age-related reduction in light responsivity has also been demonstrated in animal research. It was shown that circadian phase responsivity to light may be 20 times greater in young than in old hamsters (533). Furthermore, older rats seem to need brighter light to achieve a desired amplitude of the activity rhythm (480, 514). Although it is not entirely known how age-related ocular changes compromise the effectiveness of ambient illumination in maintaining circadian entrainment in humans, it has been demonstrated that older adults exhibit advanced circadian phases of sleep, cortisol, and 6-sulfatoxymelatonin (aMT6s) onset (262). More research is needed to ascertain whether older individuals develop light resistance because of ocular/optic diseases. It's also important to determine the best light stimulus for optimal circadian entrainment among adults with ophthalmic diseases. A study investigating adolescents and young adults ages between 12 and 20 years from the Missouri School for the Blind indicated that patients with optic diseases showed significantly greater circadian dysfunction (e.g., more daytime napping and variable timing of awakening), relative to those without such diseases (506). Another study investigating circadian rhythms of melatonin levels and body temperature of 15 patients with no light perception found that 9 of those patients maintained circadian synchronization, although the phase angle of entrainment was atypical (251). It is noteworthy that a study of experimental bright light treatments showed improvement of circadian rhythm functions only among patients with intact vision, but not among visually impaired patients (487).

Ophthalmic diseases that might affect photic input to the circadian system include cataract, diabetic retinopathy, macular degeneration, retinitis pigmentosa, optic nerve atrophy, and glaucoma (for a review, see Ref. 227). Cataract, an opacity of the crystalline lens, does not diminish light input significantly unless the disease is far advanced, as in densely Brunescent or Morgagnian cataracts (236). Diabetic retinopathy can cause severe vision loss or even blindness (250). Diabetic retinopathy considerably varies in severity; hence, light input to the circadian system might be affected differently based on the disease process. Certainly, an end-stage scarred retina from diabetic proliferative disease would be transmitting less light input centrally. Furthermore, a pan-retinal lasered eye in the setting of diabetic disease has lost function in many discrete areas, which would also reduce light stimuli reaching the circadian system. Age-related macular degeneration is a disease process affecting various layers in the deep retina with possible scarring and loss of transmission of light stimuli (490). Retinitis pigmentosa is recognized by a progressive degeneration of the rods, leading to night blindness and loss of peripheral visual field (486). Clinical manifestations of this disease include pigment deposition in the retina and attenuation of retinal blood vessels. The finding that loss of retinal ganglion cells occurs in glaucoma (224) may yet be the most important observation concerning circadian human physiology. Glaucoma is a leading cause of blindness worldwide, characterized by specific visual field defects due to the loss of retinal ganglion cells and damage to the optic nerve head. Since the presence of melanopsin (193) and chryptochromes (463) in human ganglion cells, as well as a decrease of PLR in glaucomatous patients had been demonstrated (66), one might conjecture that individuals with severe retinal ganglion cell loss (i.e., glaucoma) would exhibit circadian rhythm desynchronization, since ganglion cell damage in glaucoma might result in melanopsin cell death (227). In this sense, a disturbance of the circadian rhythm of the autonomic nervous system was shown in patients with glaucoma (238). Although an animal study suggests that melanopsin-expressing retinal ganglion cells might be less susceptible to death after induction of chronic ocular hypertension (278), in another model of experimental glaucoma in rats induced by chronic administration of hyaluronic acid, we found a significant decrease in retinal melatopsin levels (N. De Zavalía, D. C. Fernandez, and R. E. Rosenstein, unpublished results). Moreover, a significant reduction of RGC axon terminals in the SCN, as well as a decrease in retinal melanopsin mRNA levels in an experimental model of glaucoma in rats, was recently shown (116). In addition, it was reported that glaucomatous rats require more time to readjust to a shifted LD cycle compared with normal rats (116).

It is of great interest to determine how ophthalmic diseases affect the circadian timing system. Evidently, since several ocular diseases lead to visual impairment and worse yet blindness, they indirectly provoke physical inactivity, which may cascade into sleep problems and daytime sleepiness. Likewise, afflicted individuals would have less opportunity for exposure to bright light expo- 
sure, which may cause circadian rhythm dysfunctions $(261,263)$. In contrast to other ocular diseases, the effects of glaucoma on the circadian timing system might be twofold: 1) a direct impact through degeneration of retinal ganglion cells and/or ocular ischemia and reperfusion damage and 2) an indirect impact through social isolation due to blindness, as is the case for other ophthalmic diseases.

In summary, the study of entrainment not only leads to a better understanding of the adaptive value of the circadian clock, but also to putative alternatives for treatment of disease (including but not limited to circadianrelated disease). Chronotherapy, i.e., the time-specific treatment of pathological symptoms, appears to be very relevant for therapeutics, not only in terms of chronopharmacology but also for ensuring the correct entrainment of rhythms to their environment and a synchronized internal temporal order (276). After more than two decades of circadian research (199), including peering into mechanisms of entrainment and of distributed clock systems (74), it is possible that a chronobiological understanding of health and disease is slowly, but timely, coming of age so that we can finally grasp the concept that exists "between night and day/ an undecided territory/nor shadow nor light/ time" (383a).

\section{ACKNOWLEDGMENTS}

The assistance of Drs. Patricia Agostino and María Juliana Leone, as well as the advice of Dr. Horacio de la Iglesia, is gratefully acknowledged.

Address for reprint requests and other correspondence: D. Golombek, Laboratory of Chronobiology, Dept. of Science and Technology, National University of Quilmes, R.S. Peña 352, 1876 Bernal, Buenos Aires, Argentina (e-mail: dgolombek@unq.edu.ar).

\section{GRANTS}

Studies in the authors' laboratories were funded by grants from the National Science Agency (ANPCyT), the National Research Council (CONICET), the University of Buenos Aires, and the National University of Quilmes as well as a Fogarty International Research Collaboration Award (FIRCA, NIH).

\section{REFERENCES}

1. Abe H, Honma S, Namihira M, Tanahashi Y, Ikeda M, Honma K. Circadian rhythm and light responsiveness of BMAL1 expression, a partner of mammalian clock gene Clock, in the suprachiasmatic nucleus of rats. Neurosci Lett 258: 93-96, 1998.

2. Abe H, Rusak B, Robertson HA. NMDA and non-NMDA receptor antagonists inhibit photic induction of Fos protein in the hamster suprachiasmatic nucleus. Brain Res Bull 28: 831-835, 1992.

3. Aggelopoulos NC, Meissl H. Responses of neurones of the rat suprachiasmatic nucleus to retinal illumination under photopic and scotopic conditions. J Physiol 523: 211-222, 2000.

4. Agostino PV, Ferreyra GA, Murad AD, Watanabe Y, Golombek DA. Diurnal, circadian and photic regulation of calcium/calmodulin-dependent kinase II and neuronal nitric oxide synthase in the hamster suprachiasmatic nuclei. Neurochem Int 44: 617-625, 2004.

5. Agostino PV, Harrington ME, Ralph MR, Golombek DA. Casein kinase I-epsilon and circadian photic entrainment in hamsters. Chronobiol Int 26: 1-8, 2009.
6. Agostino PV, Plano SA, Golombek DA. Circadian and pharmacological regulation of casein kinase I in the hamster SCN. J Genet 87: 467-471, 2008.

7. Agostino PV, Plano SA, Golombek DA. Sildenafil accelerates reentrainment of circadian rhythms after advancing light schedules. Proc Natl Acad Sci USA 104: 9834-9839, 2007.

8. Aguilar-Roblero R, Mercado C, Alamilla J, Laville A, DiazMunoz M. Ryanodine receptor $\mathrm{Ca}^{2+}$-release channels are an output pathway for the circadian clock in the rat suprachiasmatic nuclei. Eur J Neurosci 26: 575-582, 2007.

9. Aguilar-Roblero R, Verduzco-Carbajal L, Rodriguez C, Mendez-Franco J, Moran J, de la Mora MP. Circadian rhythmicity in the GABAergic system in the suprachiasmatic nuclei of the rat. Neurosci Lett 157: 199-202, 1993.

10. Akashi M, Tsuchiya Y, Yoshino T, Nishida E. Control of intracellular dynamics of mammalian period proteins by casein kinase I epsilon (CKIepsilon) and CKIdelta in cultured cells. Mol Cell Biol 22: 1693-1703, 2002.

11. Akiyama M, Kouzu Y, Takahashi S, Wakamatsu H, Moriya T, Maetani M, Watanabe S, Tei H, Sakaki Y, Shibata S. Inhibition of light- or glutamate-induced mPer1 expression represses the phase shifts into the mouse circadian locomotor and suprachiasmatic firing rhythms. J Neurosci 19: 1115-1121, 1999.

12. Akiyama M, Minami Y, Nakajima T, Moriya T, Shibata S. Calcium and pituitary adenylate cyclase-activating polypeptide induced expression of circadian clock gene mPerl in the mouse cerebellar granule cell culture. J Neurochem 78: 499-508, 2001.

13. Albers HE, Ferris CF. Neuropeptide Y: role in light-dark cycle entrainment of hamster circadian rhythms. Neurosci Lett 50: 163$168,1984$.

14. Albrecht U, Sun ZS, Eichele G, Lee CC. A differential response of two putative mammalian circadian regulators, mper1 and mper2, to light. Cell 91: 1055-1064, 1997.

15. Albrecht U, Zheng B, Larkin D, Sun ZS, Lee CC. MPer1 and mper2 are essential for normal resetting of the circadian clock. $J$ Biol Rhythms 16: 100-104, 2001.

16. Albus H, Vansteensel MJ, Michel S, Block GD, Meijer JH. A GABAergic mechanism is necessary for coupling dissociable ventral and dorsal regional oscillators within the circadian clock. Curr Biol 15: 886-893, 2005.

17. Alenghat T, Meyers K, Mullican SE, Leitner K, Adeniji-Adele A, Avila J, Bucan M, Ahima RS, Kaestner KH, Lazar MA. Nuclear receptor corepressor and histone deacetylase 3 govern circadian metabolic physiology. Nature 456: 997-1000, 2008.

18. Alvarez-Lopez C, Cernuda-Cernuda R, Alcorta E, AlvarezViejo M, Garcia-Fernandez JM. Altered endogenous activation of CREB in the suprachiasmatic nucleus of mice with retinal degeneration. Brain Res 1024: 137-145, 2004.

19. Allen GC, Qu X, Earnest DJ. TrkB-deficient mice show diminished phase shifts of the circadian activity rhythm in response to light. Neurosci Lett 378: 150-155, 2005.

20. Antle MC, Silver R. Orchestrating time: arrangements of the brain circadian clock. Trends Neurosci 28: 145-151, 2005.

21. Antle MC, Sterniczuk R, Smith VM, Hagel K. Non-photic modulation of phase shifts to long light pulses. J Biol Rhythms 22: 524-533, 2007.

22. Archer SN, Robilliard DL, Skene DJ, Smits M, Williams A, Arendt J, von Schantz M. A length polymorphism in the circadian clock gene Per3 is linked to delayed sleep phase syndrome and extreme diurnal preference. Sleep 26: 413-415, 2003.

23. Arendt J, Aldhous M, Wright J. Synchronisation of a disturbed sleep-wake cycle in a blind man by melatonin treatment. Lancet 1 : 772-773, 1988 .

24. Aschoff J. Circadian rhythms in man. Science 148: 1427-1432, 1965.

25. Aschoff J. Exogenous and endogenous components in circadian rhythms. Cold Spring Harb Symp Quant Biol 25: 11-28, 1960.

26. Aschoff J, Fatranska M, Giedke H, Doerr P, Stamm D, Wisser H. Human circadian rhythms in continuous darkness: entrainment by social cues. Science 171: 213-215, 1971.

27. Aschoff J, von Goetz C. Masking of circadian activity rhythms in hamsters by darkness. J Comp Physiol A Sens Neural Behav Physiol 162: 559-562, 1988. 
28. Aschoff J, Wever R. Human circadian rhythms: a multioscillatory system. Federation Proc 35: 236-232, 1976.

29. Aton SJ, Colwell CS, Harmar AJ, Waschek J, Herzog ED. Vasoactive intestinal polypeptide mediates circadian rhythmicity and synchrony in mammalian clock neurons. Nat Neurosci 8: 476483, 2005.

30. Bachleitner W, Kempinger L, Wulbeck C, Rieger D, HelfrichForster C. Moonlight shifts the endogenous clock of Drosophila melanogaster. Proc Natl Acad Sci USA 104: 3538-3543, 2007.

31. Badura L, Swanson T, Adamowicz W, Adams J, Cianfrogna J, Fisher K, Holland J, Kleiman R, Nelson F, Reynolds L, St Germain K, Schaeffer E, Tate B, Sprouse J. An inhibitor of casein kinase I epsilon induces phase delays in circadian rhythms under free-running and entrained conditions. J Pharmacol Exp Ther 322: 730-738, 2007.

32. Barnard AR, Appleford JM, Sekaran S, Chinthapalli K, Jenkins A, Seeliger M, Biel M, Humphries P, Douglas RH, Wenzel A, Foster RG, Hankins MW, Lucas RJ. Residual photosensitivity in mice lacking both rod opsin and cone photoreceptor cyclic nucleotide gated channel 3 alpha subunit. Vis Neurosci 21: 675683, 2004.

33. Barnard AR, Nolan PM. When clocks go bad: neurobehavioural consequences of disrupted circadian timing. PLoS Genet 4: e1000040, 2008.

34. Bassi CJ, Powers MK. Circadian rhythm in goldfish visual sensitivity. Invest Ophthalmol Vis Sci 28: 1811-1815, 1987.

35. Beaule C, Amir S. The eyes suppress a circadian rhythm of FOS expression in the suprachiasmatic nucleus in the absence of light. Neuroscience 121: 253-257, 2003.

36. Beaule C, Swanstrom A, Leone MJ, Herzog ED. Circadian modulation of gene expression, but not glutamate uptake, in mouse and rat cortical astrocytes. PLoS One 4: e7476, 2009.

37. Belenky MA, Smeraski CA, Provencio I, Sollars PJ, Pickard GE. Melanopsin retinal ganglion cells receive bipolar and amacrine cell synapses. J Comp Neurol 460: 380-393, 2003.

38. Bernard M, Guerlotte J, Greve P, Grechez-Cassiau A, Iuvone MP, Zatz M, Chong NW, Klein DC, Voisin P. Melatonin synthesis pathway: circadian regulation of the genes encoding the key enzymes in the chicken pineal gland and retina. Reprod Nutr Dev 39: 325-334, 1999.

39. Berson DM, Dunn FA, Takao M. Phototransduction by retinal ganglion cells that set the circadian clock. Science 295: 1070-1073, 2002.

40. Besharse JC, Iuvone PM. Circadian clock in Xenopus eye controlling retinal serotonin $N$-acetyltransferase. Nature 305: 133-135, 1983.

41. Best JD, Maywood ES, Smith KL, Hastings MH. Rapid resetting of the mammalian circadian clock. J Neurosci 19: 828-835, 1999.

42. Biello SM, Golombek DA, Harrington ME. Neuropeptide Y and glutamate block each other's phase shifts in the suprachiasmatic nucleus in vitro. Neuroscience 77: 1049-1057, 1997.

43. Biello SM, Golombek DA, Schak KM, Harrington ME. Circadian phase shifts to neuropeptide $\mathrm{Y}$ in vitro: cellular communication and signal transduction. J Neurosci 17: 8468-8475, 1997.

44. Biello SM, Janik D, Mrosovsky N. Neuropeptide Y and behaviorally induced phase shifts. Neuroscience 62: 273-279, 1994.

44a.Borges JL. The garden of forking paths. In: Labyrinths: Selected Stories and Other Writings, edited by Yates DA and Irby JE. New York: New Directions, 1962.

45. Boulos Z, Macchi M, Terman M. Effects of twilights on circadian entrainment patterns and reentrainment rates in squirrel monkeys. J Comp Physiol A Sens Neural Behav Physiol 179: 687-694, 1996.

46. Boulos Z, Macchi MM, Terman M. Twilights widen the range of photic entrainment in hamsters. J Biol Rhythms 17: 353-363, 2002.

47. Brainard GC, Hanifin JP, Greeson JM, Byrne B, Glickman G, Gerner E, Rollag MD. Action spectrum for melatonin regulation in humans: evidence for a novel circadian photoreceptor. $J \mathrm{Neu}$ rosci 21: 6405-6412, 2001.

48. Brann MR, Cohen LV. Diurnal expression of transducin mRNA and translocation of transducin in rods of rat retina. Science 235: 585-587, 1987.
49. Brown TM, Piggins HD. Spatiotemporal heterogeneity in the electrical activity of suprachiasmatic nuclei neurons and their response to photoperiod. J Biol Rhythms 24: 44-54, 2009.

50. Buchanan GF, Gillette MU. New light on an old paradox: sitedependent effects of carbachol on circadian rhythms. Exp Neurol 193: 489-496, 2005.

51. Bunger MK, Wilsbacher LD, Moran SM, Clendenin C, Radcliffe LA, Hogenesch JB, Simon MC, Takahashi JS, Bradfield CA. Mop3 is an essential component of the master circadian pacemaker in mammals. Cell 103: 1009-1017, 2000.

52. Burgoon PW, Lindberg PT, Gillette MU. Different patterns of circadian oscillation in the suprachiasmatic nucleus of hamster, mouse, and rat. J Comp Physiol A Sens Neural Behav Physiol 190: 167-171, 2004.

53. Butcher GQ, Doner J, Dziema H, Collamore M, Burgoon PW, Obrietan $\mathbf{K}$. The p42/44 mitogen-activated protein kinase pathway couples photic input to circadian clock entrainment. $J$ Biol Chem 277: 29519-29525, 2002.

54. Butcher GQ, Lee B, Cheng HY, Obrietan K. Light stimulates MSK1 activation in the suprachiasmatic nucleus via a PACAP-ERK/ MAP kinase-dependent mechanism. J Neurosci 25: 5305-5313, 2005.

55. Butcher GQ, Lee B, Obrietan K. Temporal regulation of lightinduced extracellular signal-regulated kinase activation in the suprachiasmatic nucleus. J Neurophysiol 90: 3854-3863, 2003.

56. Buxton OM, Frank SA, L'Hermite-Baleriaux M, Leproult $\mathbf{R}$, Turek FW, Van Cauter E. Roles of intensity and duration of nocturnal exercise in causing phase delays of human circadian rhythms. Am J Physiol Endocrinol Metab 273: E536-E542, 1997.

57. Buxton OM, L'Hermite-Baleriaux M, Hirschfeld U, Cauter E. Acute and delayed effects of exercise on human melatonin secretion. J Biol Rhythms 12: 568-574, 1997.

58. Cagampang FR, Rattray M, Powell JF, Chong NW, Campbell IC, Coen CW. Circadian variation of EAAC1 glutamate transporter messenger RNA in the rat suprachiasmatic nuclei. Brain Res 35: 190-196, 1996.

59. Cahill GM, Besharse JC. Circadian clock functions localized in Xenopus retinal photoreceptors. Neuron 10: 573-577, 1993.

60. Cambras T, Lopez L, Arias JL, Diez-Noguera A. Quantitative changes in neuronal and glial cells in the suprachiasmatic nucleus as a function of the lighting conditions during weaning. Brain Res 157: 27-33, 2005.

61. Cambras T, Weller JR, Angles-Pujoras M, Lee ML, Christopher A, Diez-Noguera A, Krueger JM, de la Iglesia HO. Circadian desynchronization of core body temperature and sleep stages in the rat. Proc Natl Acad Sci USA 104: 7634-7639, 2007.

62. Campuzano A, Vilaplana J, Cambras T, Diez-Noguera A. Dissociation of the rat motor activity rhythm under $\mathrm{T}$ cycles shorter than 24 hours. Physiol Behav 63: 171-176, 1998.

63. Cardinali DP, Golombek DA. Let there be sleep-on time. Lancet 373: 439-441, 2009.

64. Carpen JD, von Schantz M, Smits M, Skene DJ, Archer SN. A silent polymorphism in the PER1 gene associates with extreme diurnal preference in humans. J Hum Genet 51: 1122-1125, 2006.

64a.Casiraghi LP, Martino D, Marengo E, Igoa A, Ais E, Strejilevich S, Golombek DA. Human period-3 gene is involved in diurnal preference in an Argentinean population of bipolar disorders patients. J Sleep Sci. In press.

65. Cermakian N, Monaco L, Pando MP, Dierich A, Sassone-Corsi P. Altered behavioral rhythms and clock gene expression in mice with a targeted mutation in the Period1 gene. EMBO J 20: 39673974, 2001.

66. Clark CV, Mapstone R. Pupil cycle time in primary closed-angle glaucoma. Can J Ophthalmol 21: 88-91, 1986.

67. Colwell CS. Circadian modulation of calcium levels in cells in the suprachiasmatic nucleus. Eur J Neurosci 12: 571-576, 2000.

68. Colwell CS. NMDA-evoked calcium transients and currents in the suprachiasmatic nucleus: gating by the circadian system. Eur $J$ Neurosci 13: 1420-1428, 2001.

69. Colwell CS, Kaufman CM, Menaker M. Phase-shifting mechanisms in the mammalian circadian system: new light on the carbachol paradox. J Neurosci 13: 1454-1459, 1993. 
70. Colwell CS, Menaker M. NMDA as well as non-NMDA receptor antagonists can prevent the phase-shifting effects of light on the circadian system of the golden hamster. J Biol Rhythms 7: 125-136, 1992.

71. Colwell CS, Michel S, Itri J, Rodriguez W, Tam J, Lelievre V, Hu Z, Liu X, Waschek JA. Disrupted circadian rhythms in VIPand PHI-deficient mice. Am J Physiol Regul Integr Comp Physiol 285: R939-R949, 2003.

72. Colwell CS, Michel S, Itri J, Rodriguez W, Tam J, Lelievre V, Hu Z, Waschek JA. Selective deficits in the circadian light response in mice lacking PACAP. Am J Physiol Regul Integr Comp Physiol 287: R1194-R1201, 2004.

73. Cooper HM, Herbin M, Nevo E. Ocular regression conceals adaptive progression of the visual system in a blind subterranean mammal. Nature 361: 156-159, 1993.

74. Cuninkova L, Brown SA. Peripheral circadian oscillators: interesting mechanisms and powerful tools. Ann NY Acad Sci 1129: 358-370, 2008.

75. Czeisler CA. The effect of light on the human circadian pacemaker. Ciba Found Symp 183: 254-302, 1995.

76. Czeisler CA, Gooley JJ. Sleep and circadian rhythms in humans. Cold Spring Harb Symp Quant Biol 72: 579-597, 2007.

77. Challet E. Minireview: entrainment of the suprachiasmatic clockwork in diurnal and nocturnal mammals. Endocrinology 148: 5648$5655,2007$.

78. Chambille I. Circadian rhythm of AMPA receptor GluR2/3 subunitimmunoreactivity in the suprachiasmatic nuclei of Syrian hamster and effect of a light-dark cycle. Brain Res 833: 27-38, 1999.

79. Chaurasia SS, Rollag MD, Jiang G, Hayes WP, Haque R, Natesan A, Zatz M, Tosini G, Liu C, Korf HW, Iuvone PM, Provencio I. Molecular cloning, localization and circadian expression of chicken melanopsin (Opn4): differential regulation of expression in pineal and retinal cell types. J Neurochem 92: 158-170, 2005.

80. Chen D, Buchanan GF, Ding JM, Hannibal J, Gillette MU. Pituitary adenylyl cyclase-activating peptide: a pivotal modulator of glutamatergic regulation of the suprachiasmatic circadian clock. Proc Natl Acad Sci USA 96: 13468-13473, 1999.

81. Chen G, van den Pol AN. Presynaptic $\mathrm{GABA}_{\mathrm{B}}$ autoreceptor modulation of $\mathrm{P} / \mathrm{Q}$-type calcium channels and GABA release in rat suprachiasmatic nucleus neurons. J Neurosci 18: 1913-1922, 1998.

82. Chen R, Seo DO, Bell E, von Gall C, Lee C. Strong resetting of the mammalian clock by constant light followed by constant darkness. J Neurosci 28: 11839-11847, 2008.

83. Cheng HY, Obrietan K. Dexras1: shaping the responsiveness of the circadian clock. Semin Cell Dev Biol 17: 345-351, 2006

84. Cheng HY, Obrietan K, Cain SW, Lee BY, Agostino PV, Joza NA, Harrington ME, Ralph MR, Penninger JM. Dexras1 potentiates photic and suppresses nonphotic responses of the circadian clock. Neuron 43: 715-728, 2004.

85. Cheng HY, Papp JW, Varlamova O, Dziema H, Russell B, Curfman JP, Nakazawa T, Shimizu K, Okamura H, Impey S, Obrietan $\mathrm{K}$. microRNA modulation of circadian-clock period and entrainment. Neuron 54: 813-829, 2007.

86. Cheng MY, Bullock CM, Li C, Lee AG, Bermak JC, Belluzzi J, Weaver DR, Leslie FM, Zhou QY. Prokineticin 2 transmits the behavioural circadian rhythm of the suprachiasmatic nucleus. $\mathrm{Na}$ ture 417: 405-410, 2002.

87. Choi HJ, Lee CJ, Schroeder A, Kim YS, Jung SH, Kim JS, Kim do Y, Son EJ, Han HC, Hong SK, Colwell CS, Kim YI. Excitatory actions of GABA in the suprachiasmatic nucleus. $J$ Neurosci 28: 5450-5459, 2008

87a.Cortazar J. The Winners. New York: Pantheon, 1965.

88. Daan S. The Colin S. Pittendrigh Lecture. Colin Pittendrigh, Jurgen Aschoff, and the natural entrainment of circadian systems. $J$ Biol Rhythms 15: 195-207, 2000.

89. Daan S. Tonic and phasic effects of light in the entrainment of circadian rhythms. Ann NY Acad Sci 290: 51-59, 1977.

90. Daan S, Albrecht U, van der Horst GT, Illnerova H, Roenneberg T, Wehr TA, Schwartz WJ. Assembling a clock for all seasons: are there $\mathrm{M}$ and $\mathrm{E}$ oscillators in the genes? J Biol Rhythms 16: 105-116, 2001.
91. Daan S, Pittendrigh C. A functional analysis of circadian pacemakers in nocturnal rodents. II. The variability of phase response curves. J Comp Physiol 106: 253-266, 1976.

92. Dacey DM, Liao HW, Peterson BB, Robinson FR, Smith VC, Pokorny J, Yau KW, Gamlin PD. Melanopsin-expressing ganglion cells in primate retina signal colour and irradiance and project to the LGN. Nature 433: 749-754, 2005.

93. Dallmann R, Mrosovsky N. Non-photic phase resetting of Dexras1 deficient mice: a more complicated story. Behav Brain Res 180: 197-202, 2007.

94. Dardente H, Cermakian N. Molecular circadian rhythms in central and peripheral clocks in mammals. Chronobiol Int 24: 195-213, 2007.

95. David-Gray ZK, Janssen JW, DeGrip WJ, Nevo E, Foster RG. Light detection in a "blind" mammal. Nat Neurosci 1: 655-656, 1998.

96. De Haro L, Panda S. Systems biology of circadian rhythms: an outlook. J Biol Rhythms 21: 507-518, 2006.

97. De la Iglesia HO, Cambras T, Schwartz WJ, Diez-Noguera A. Forced desynchronization of dual circadian oscillators within the rat suprachiasmatic nucleus. Curr Biol 14: 796-800, 2004.

98. De la Iglesia HO, Meyer J, Schwartz WJ. Using Per gene expression to search for photoperiodic oscillators in the hamster suprachiasmatic nucleus. Brain Res 127: 121-127, 2004.

99. De Mairan JJD. Observation Botanique. Hist Acad Royale Sci Paris 35: 1729.

100. De Vries MJ, Nunes Cardozo B, van der Want J, de Wolf A, Meijer JH. Glutamate immunoreactivity in terminals of the retinohypothalamic tract of the brown Norwegian rat. Brain Res 612: 231-237, 1993.

101. Deboer T, Vansteensel MJ, Detari L, Meijer JH. Sleep states alter activity of suprachiasmatic nucleus neurons. Nat Neurosci 6 : 1086-1090, 2003.

102. DeCoursey PJ. Light-sampling behavior in photoentrainment of a rodent circadian rhythm. J Comp Physiol A Sens Neural Behav Physiol 159: 161-169, 1986.

103. DeCoursey PJ, Krulas JR. Behavior of SCN-lesioned chipmunks in natural habitat: a pilot study. J Biol Rhythms 13: 229-244, 1998.

104. DeCoursey PJ, Krulas JR, Mele G, Holley DC. Circadian performance of suprachiasmatic nuclei (SCN)-lesioned antelope ground squirrels in a desert enclosure. Physiol Behav 62: 1099$1108,1997$.

105. DeCoursey PJ, Walker JK, Smith SA. A circadian pacemaker in free-living chipmunks: essential for survival? J Comp Physiol A Sens Neural Behav Physiol 186: 169-180, 2000.

106. Diaz-Munoz M, Dent MA, Granados-Fuentes D, Hall AC, Hernandez-Cruz A, Harrington ME, Aguilar-Roblero R. Circadian modulation of the ryanodine receptor type 2 in the SCN of rodents. Neuroreport 10: 481-486, 1999.

107. Ding JM, Buchanan GF, Tischkau SA, Chen D, Kuriashkina L, Faiman LE, Alster JM, McPherson PS, Campbell KP, Gillette MU. A neuronal ryanodine receptor mediates light-induced phase delays of the circadian clock. Nature 394: 381-384, 1998.

108. Ding JM, Chen D, Weber ET, Faiman LE, Rea MA, Gillette MU. Resetting the biological clock: mediation of nocturnal circadian shifts by glutamate and NO. Science 266: 1713-1717, 1994.

109. Ding JM, Faiman LE, Hurst WJ, Kuriashkina LR, Gillette MU. Resetting the biological clock: mediation of nocturnal CREB phosphorylation via light, glutamate, and nitric oxide. J Neurosci 17: 667-675, 1997.

110. Dmitriev AV, Mangel SC. Circadian clock regulation of $\mathrm{pH}$ in the rabbit retina. J Neurosci 21: 2897-2902, 2001.

111. Doi M, Cho S, Yujnovsky I, Hirayama J, Cermakian N, Cato AC, Sassone-Corsi P. Light-inducible and clock-controlled expression of MAP kinase phosphatase 1 in mouse central pacemaker neurons. J Biol Rhythms 22: 127-139, 2007.

112. Doi M, Hirayama J, Sassone-Corsi P. Circadian regulator CLOCK is a histone acetyltransferase. Cell 125: 497-508, 2006.

113. Doi M, Yujnovsky I, Hirayama J, Malerba M, Tirotta E, Sassone-Corsi P, Borrelli E. Impaired light masking in dopamine D2 receptor-null mice. Nat Neurosci 9: 732-734, 2006.

114. Doyle S, Menaker M. Circadian photoreception in vertebrates. Cold Spring Harb Symp Quant Biol 72: 499-508, 2007. 
115. Doyle SE, Yoshikawa T, Hillson H, Menaker M. Retinal pathways influence temporal niche. Proc Natl Acad Sci USA 105: 1313313138, 2008.

116. Drouyer E, Dkhissi-Benyahya O, Chiquet C, WoldeMussie E, Ruiz G, Wheeler LA, Denis P, Cooper HM. Glaucoma alters the circadian timing system. PLoS ONE 3: e3931, 2008.

117. Dudek FE, Kim YI, Bouskila Y. Electrophysiology of the suprachiasmatic nucleus: synaptic transmission, membrane properties, and neuronal synchronization. J Biol Rhythms 8 Suppl: S33-37, 1993.

118. Dudley CA, Erbel-Sieler C, Estill SJ, Reick M, Franken P, Pitts S, McKnight SL. Altered patterns of sleep and behavioral adaptability in NPAS2-deficient mice. Science 301: 379-383, 2003.

119. Dunlap JC. Molecular bases for circadian clocks. Cell 96: 271-290, 1999.

120. Dunlap JC, Loros JJ, DeCoursey PJ. Chronobiology: Biological Timekeeping. Sunderland, MA: Sinauer, 2004

121. Dunlap JC, Loros JJ, Liu Y, Crosthwaite SK. Eukaryotic circadian systems: cycles in common. Genes Cells 4: 1-10, 1999.

122. Dziema H, Oatis B, Butcher GQ, Yates R, Hoyt KR, Obrietan K. The ERK/MAP kinase pathway couples light to immediate-early gene expression in the suprachiasmatic nucleus. Eur J Neurosci 17: 1617-1627, 2003.

123. Ebisawa T, Uchiyama M, Kajimura N, Mishima K, Kamei Y, Katoh M, Watanabe T, Sekimoto M, Shibui K, Kim K, Kudo Y, Ozeki Y, Sugishita M, Toyoshima R, Inoue Y, Yamada N, Nagase T, Ozaki N, Ohara O, Ishida N, Okawa M, Takahashi $\mathrm{K}$, Yamauchi T. Association of structural polymorphisms in the human period3 gene with delayed sleep phase syndrome. EMBO Rep 2: 342-346, 2001.

124. Ebling FJ. The role of glutamate in the photic regulation of the suprachiasmatic nucleus. Prog Neurobiol 50: 109-132, 1996.

125. Eckel-Mahan KL, Phan T, Han S, Wang H, Chan GC, Scheiner ZS, Storm DR. Circadian oscillation of hippocampal MAPK activity and cAMP: implications for memory persistence. Nat Neurosci 11: 1074-1082, 2008.

126. Edgar DM, Miller JD, Prosser RA, Dean RR, Dement WC. Serotonin and the mammalian circadian system. II. Phase-shifting rat behavioral rhythms with serotonergic agonists. J Biol Rhythms 8: 17-31, 1993

127. Eide EJ, Kang H, Crapo S, Gallego M, Virshup DM. Casein kinase I in the mammalian circadian clock. Methods Enzymol 393: 408-418, 2005.

128. Eide EJ, Vielhaber EL, Hinz WA, Virshup DM. The circadian regulatory proteins BMAL1 and cryptochromes are substrates of casein kinase Iepsilon. J Biol Chem 277: 17248-17254, 2002.

129. Eide EJ, Virshup DM. Casein kinase I: another cog in the circadian clockworks. Chronobiol Int 18: 389-398, 2001.

130. Fahey CD, Zee PC. Circadian rhythm sleep disorders and phototherapy. Psychiatr Clin North Am 29: 989-1007, 2006.

131. Fahrenkrug J. PACAP-a multifacetted neuropeptide. Chronobiol Int 23: 53-61, 2006.

132. Feillet CA, Albrecht U, Challet E. "Feeding time" for the brain: a matter of clocks. J Physiol 100: 252-260, 2006.

133. Fernandez-Duque E, Erkert HG. Cathemerality and lunar periodicity of activity rhythms in owl monkeys of the Argentinian Chaco. Folia Primatol 77: 123-138, 2006.

134. Ferreyra GA, Cammarota MP, Golombek DA. Photic control of nitric oxide synthase activity in the hamster suprachiasmatic nuclei. Brain Res 797: 190-196, 1998

135. Ferreyra GA, Golombek DA. Cyclic AMP and protein kinase A rhythmicity in the mammalian suprachiasmatic nuclei. Brain Res 858: 33-39, 2000.

136. Ferreyra GA, Golombek DA. Rhythmicity of the cGMP-related signal transduction pathway in the mammalian circadian system. Am J Physiol Regul Integr Comp Physiol 280: R1348-R1355, 2001.

137. Folkard S. The pragmatic approach to masking. Chronobiol Int 6 : 55-64, 1989.

138. Foster RG, Hankins MW. Circadian vision. Curr Biol 17: R746751, 2007.

139. Foster RG, Provencio I, Hudson D, Fiske S, De Grip W, Menaker M. Circadian photoreception in the retinally degenerate mouse (rd/rd). J Comp Physiol A Sens Neural Behav Physiol 169: $39-50,1991$

140. Foulkes NS, Borjigin J, Snyder SH, Sassone-Corsi P. Rhythmic transcription: the molecular basis of circadian melatonin synthesis. Trends Neurosci 20: 487-492, 1997.

141. Foulkes NS, Duval G, Sassone-Corsi P. Adaptive inducibility of CREM as transcriptional memory of circadian rhythms. Nature 381: 83-85, 1996.

142. Freedman MS, Lucas RJ, Soni B, von Schantz M, Munoz M, David-Gray Z, Foster R. Regulation of mammalian circadian behavior by non-rod, non-cone, ocular photoreceptors. Science 284: 502-504, 1999

143. Fukuhara C, Brewer JM, Dirden JC, Bittman EL, Tosini G, Harrington ME. Neuropeptide Y rapidly reduces Period 1 and Period 2 mRNA levels in the hamster suprachiasmatic nucleus. Neurosci Lett 314: 119-122, 2001

144. Fukushima T, Shimazoe T, Shibata S, Watanabe A, Ono M, Hamada T, Watanabe S. The involvement of calmodulin and $\mathrm{Ca}^{2+} /$ calmodulin-dependent protein kinase II in the circadian rhythms controlled by the suprachiasmatic nucleus. Neurosci Lett 227: 45-48, 1997.

145. Gall AJ, Todd WD, Ray B, Coleman CM, Blumberg MS. The development of day-night differences in sleep and wakefulness in norway rats and the effect of bilateral enucleation. J Biol Rhythms 23: 232-241, 2008

146. Gallego M, Eide EJ, Woolf MF, Virshup DM, Forger DB. An opposite role for tau in circadian rhythms revealed by mathematical modeling. Proc Natl Acad Sci USA 103: 10618-10623, 2006.

147. Gallego M, Virshup DM. Post-translational modifications regulate the ticking of the circadian clock. Nat Rev Mol Cell Biol 8: 139-148, 2007.

148. Gannon RL, Rea MA. Glutamate receptor immunoreactivity in the rat suprachiasmatic nucleus. Brain Res 622: 337-342, 1993.

149. Gannon RL, Rea MA. In situ hybridization of antisense mRNA oligonucleotides for AMPA, NMDA and metabotropic glutamate receptor subtypes in the rat suprachiasmatic nucleus at different phases of the circadian cycle. Brain Res 23: 338-344, 1994.

150. Garbarino-Pico E, Carpentieri AR, Contin MA, Sarmiento MI, Brocco MA, Panzetta P, Rosenstein RE, Caputto BL, Guido ME. Retinal ganglion cells are autonomous circadian oscillators synthesizing $N$-acetylserotonin during the day. J Biol Chem 279: 51172-51181, 2004.

151. Gardani M, Biello SM. The effects of photic and nonphotic stimuli in the $5-\mathrm{HT}_{7}$ receptor knockout mouse. Neuroscience 152: 245$253,2008$.

152. Gau D, Lemberger T, von Gall C, Kretz O, Le Minh N, Gass P, Schmid W, Schibler U, Korf HW, Schutz G. Phosphorylation of CREB Ser142 regulates light-induced phase shifts of the circadian clock. Neuron 34: 245-253, 2002

153. Gerics B, Szalay F, Hajos F. Glial fibrillary acidic protein immunoreactivity in the rat suprachiasmatic nucleus: circadian changes and their seasonal dependence. J Anat 209: 231-237, 2006.

154. Gibson EM, Williams WP 3rd, Kriegsfeld LJ. Aging in the circadian system: considerations for health, disease prevention and longevity. Exp Gerontol 44: 51-56, 2009.

155. Ginty DD, Kornhauser JM, Thompson MA, Bading H, Mayo KE, Takahashi JS, Greenberg ME. Regulation of CREB phosphorylation in the suprachiasmatic nucleus by light and a circadian clock. Science 260: 238-241, 1993.

156. Glass L, Winfree AT. Discontinuities in phase-resetting experiments. Am J Physiol Regul Integr Comp Physiol 246: R251-R258, 1984 .

157. Golombek DA, Agostino PV. Cyclic nucleotides in the central nervous system. In: The Handbook of Cell Signaling, edited by Bradshaw R, Denis E. Amsterdam: Elsevier, 2009.

158. Golombek DA, Agostino PV, Plano SA, Ferreyra GA. Signaling in the mammalian circadian clock: the NO/cGMP pathway. Neurochem Int 45: 929-936, 2004.

159. Golombek DA, Biello SM, Rendon RA, Harrington ME. Neuropeptide $\mathrm{Y}$ phase shifts the circadian clock in vitro via a Y2 receptor. Neuroreport 7: 1315-1319, 1996.

160. Golombek DA, Calcagno J, Luquet C. Circadian activity rhythm of the chinstrap penguin Pygoscelis antarctica of Isla Media Luna, 
South Shetland Islands, Antartida Argentina. J Field Ornithol 62: 293-298, 1991.

161. Golombek DA, Ferreyra GA, Agostino PV, Murad AD, Rubio MF, Pizzio GA, Katz ME, Marpegan L, Bekinschtein TA. From light to genes: moving the hands of the circadian clock. Front Biosci 8: s285-293, 2003 .

162. Golombek DA, Hurd MW, Lee K, Ralph MR. Effects of a p75 NGF receptor mutation on the circadian system. Biol Rhythm Res 27: 409-418, 1996.

163. Golombek DA, Ralph MR. Circadian responses to light: the calmodulin connection. Neurosci Lett 192: 101-104, 1995.

164. Golombek DA, Ralph MR. Inhibition of GABA transaminase enhances light-induced circadian phase delays but not advances. $J$ Biol Rhythms 9: 251-261, 1994

165. Golombek DA, Ralph MR. KN-62, an inhibitor of $\mathrm{Ca}^{2+} /$ calmodulin kinase II, attenuates circadian responses to light. Neuroreport 5: 1638-1640, 1994.

166. Golombek DA, Ralph MR. Let there be light: signal transduction in a mammalian circadian system. Braz J Med Biol Res 29: 131-140, 1996.

167. Gooley JJ. Treatment of circadian rhythm sleep disorders with light. Ann Acad Med Singapore 37: 669-676, 2008.

168. Gooley JJ, Lu J, Fischer D, Saper CB. A broad role for melanopsin in nonvisual photoreception. J Neurosci 23: 7093-7106, 2003.

169. Gould SJ, Lewontin RC. The spandrels of San Marco and the Panglossian paradigm: a critique of the adaptationist programme. Proc R Soc Lond B Biol Sci 205: 581-598, 1979.

170. Goz D, Studholme K, Lappi DA, Rollag MD, Provencio I, Morin LP. Targeted destruction of photosensitive retinal ganglion cells with a saporin conjugate alters the effects of light on mouse circadian rhythms. PLOS ONE 3: e3153, 2008.

171. Green CB. Cryptochromes: tail-ored for distinct functions. Curr Biol 14: R847-849, 2004.

172. Green CB, Besharse JC. Identification of a novel vertebrate circadian clock-regulated gene encoding the protein nocturnin. Proc Natl Acad Sci USA 93: 14884-14888, 1996.

173. Green CB, Takahashi JS, Bass J. The meter of metabolism. Cell 134: 728-742, 2008.

174. Grimaldi B, Nakahata Y, Kaluzova M, Masubuchi S, SassoneCorsi P. Chromatin remodeling, metabolism and circadian clocks: the interplay of CLOCK and SIRT1. Int J Biochem Cell Biol 41: 81-86, 2009.

175. Grimaldi B, Nakahata Y, Sahar S, Kaluzova M, Gauthier D, Pham K, Patel N, Hirayama J, Sassone-Corsi P. Chromatin remodeling and circadian control: master regulator CLOCK is an enzyme. Cold Spring Harb Symp Quant Biol 72: 105-112, 2007.

176. Guido ME, de Guido L, Goguen D, Robertson HA, Rusak B. Differential effects of glutamatergic blockade on circadian and photic regulation of gene expression in the hamster suprachiasmatic nucleus. Brain Res 67: 247-257, 1999.

177. Guido ME, Garbarino Pico E, Caputto BL. Circadian regulation of phospholipid metabolism in retinal photoreceptors and ganglion cells. J Neurochem 76: 835-845, 2001.

178. Guler AD, Altimus CM, Ecker JL, Hattar S. Multiple photoreceptors contribute to nonimage-forming visual functions predominantly through melanopsin-containing retinal ganglion cells. Cold Spring Harb Symp Quant Biol 72: 509-515, 2007.

179. Guler AD, Ecker JL, Lall GS, Haq S, Altimus CM, Liao HW, Barnard AR, Cahill H, Badea TC, Zhao H, Hankins MW, Berson DM, Lucas RJ, Yau KW, Hattar S. Melanopsin cells are the principal conduits for rod-cone input to non-image-forming vision. Nature 453: 102-105, 2008.

180. Haak LL. Metabotropic glutamate receptor modulation of glutamate responses in the suprachiasmatic nucleus. J Neurophysiol 81: 1308-1317, 1999.

181. Haak LL, Albers HE, Mintz EM. Modulation of photic response by the metabotropic glutamate receptor agonist t-ACPD. Brain Res Bull 71: 97-100, 2006.

182. Hainich EC, Pizzio GA, Golombek DA. Constitutive activation of the ERK-MAPK pathway in the suprachiasmatic nuclei inhibits circadian resetting. FEBS Lett 580: 6665-6668, 2006.
183. Hamada T, Antle MC, Silver R. Temporal and spatial expression patterns of canonical clock genes and clock-controlled genes in the suprachiasmatic nucleus. Eur J Neurosci 19: 1741-1748, 2004.

184. Hamada T, Liou SY, Fukushima T, Maruyama T, Watanabe S, Mikoshiba K, Ishida N. The role of inositol trisphosphate-induced $\mathrm{Ca}^{2+}$ release from $\mathrm{IP}_{3}$-receptor in the rat suprachiasmatic nucleus on circadian entrainment mechanism. Neurosci Lett 263: 125-128, 1999.

185. Hamada T, Niki T, Ziging P, Sugiyama T, Watanabe S, Mikoshiba K, Ishida N. Differential expression patterns of inositol trisphosphate receptor types 1 and 3 in the rat suprachiasmatic nucleus. Brain Res 838: 131-135, 1999.

186. Hankins MW, Lucas RJ. The primary visual pathway in humans is regulated according to long-term light exposure through the action of a nonclassical photopigment. Curr Biol 12: 191-198, 2002.

187. Hankins MW, Peirson SN, Foster RG. Melanopsin: an exciting photopigment. Trends Neurosci 31: 27-36, 2008.

188. Hannibal J. Neurotransmitters of the retino-hypothalamic tract. Cell Tissue Res 309: 73-88, 2002.

189. Hannibal J. Roles of PACAP-containing retinal ganglion cells in circadian timing. Int Rev Cytol 251: 1-39, 2006.

190. Hannibal J, Brabet P, Fahrenkrug J. Mice lacking the PACAP type I receptor have impaired photic entrainment and negative masking. Am J Physiol Regul Integr Comp Physiol 295: R2050R2058, 2008

191. Hannibal J, Ding JM, Chen D, Fahrenkrug J, Larsen PJ, Gillette MU, Mikkelsen JD. Pituitary adenylate cyclase activating peptide (PACAP) in the retinohypothalamic tract: a daytime regulator of the biological clock. Ann NY Acad Sci 865: 197-206, 1998.

192. Hannibal J, Fahrenkrug J. Immunoreactive substance P is not part of the retinohypothalamic tract in the rat. Cell Tissue Res 309: 293-299, 2002.

193. Hannibal J, Hindersson P, Ostergaard J, Georg B, Heegaard S, Larsen PJ, Fahrenkrug J. Melanopsin is expressed in PACAPcontaining retinal ganglion cells of the human retinohypothalamic tract. Invest Ophthalmol Vis Sci 45: 4202-4209, 2004.

194. Harrington ME. The ventral lateral geniculate nucleus and the intergeniculate leaflet: interrelated structures in the visual and circadian systems. Neurosci Biobehav Rev 21: 705-727, 1997.

195. Harrington ME, Hoque S, Hall A, Golombek D, Biello S. Pituitary adenylate cyclase activating peptide phase shifts circadian rhythms in a manner similar to light. J Neurosci 19: 6637-6642, 1999.

196. Harrington ME, Rusak B. Ablation of the geniculo-hypothalamic tract alters circadian activity rhythms of hamsters housed under constant light. Physiol Behav 42: 183-189, 1988.

197. Harrington ME, Rusak B. Lesions of the thalamic intergeniculate leaflet alter hamster circadian rhythms. J Biol Rhythms 1: 309-325, 1986.

198. Hashimoto H, Shintani N, Baba A. New insights into the central PACAPergic system from the phenotypes in PACAP- and PACAP receptor-knockout mice. Ann NY Acad Sci 1070: 75-89, 2006.

199. Hastings MH, Maywood ES, Reddy AB. Two decades of circadian time. J Neuroendocrinol 20: 812-819, 2008.

200. Hatori M, Le H, Vollmers C, Keding SR, Tanaka N, Schmedt C, Jegla T, Panda S. Inducible ablation of melanopsin-expressing retinal ganglion cells reveals their central role in non-image forming visual responses. PLoS ONE 3: e2451, 2008.

201. Hattar S, Liao HW, Takao M, Berson DM, Yau KW. Melanopsincontaining retinal ganglion cells: architecture, projections, and intrinsic photosensitivity. Science 295: 1065-1070, 2002.

202. Hattar S, Lucas RJ, Mrosovsky N, Thompson S, Douglas RH, Hankins MW, Lem J, Biel M, Hofmann F, Foster RG, Yau KW. Melanopsin and rod-cone photoreceptive systems account for all major accessory visual functions in mice. Nature 424: 76-81, 2003.

203. Hertz L, Zielke HR. Astrocytic control of glutamatergic activity: astrocytes as stars of the show. Trends Neurosci 27: 735-743, 2004.

204. Hirayama J, Sahar S, Grimaldi B, Tamaru T, Takamatsu K, Nakahata Y, Sassone-Corsi P. CLOCK-mediated acetylation of BMAL1 controls circadian function. Nature 450: 1086-1090, 2007.

205. Hogenesch JB, Panda S, Kay S, Takahashi JS. Circadian transcriptional output in the SCN and liver of the mouse. Novartis Found Symp 253: 171-180, 2003. 
206. Honma S, Shirakawa T, Katsuno Y, Namihira M, Honma K. Circadian periods of single suprachiasmatic neurons in rats. $\mathrm{Neu}$ rosci Lett 250: 157-160, 1998.

207. Honrado GI, Johnson RS, Golombek DA, Spiegelman BM, Papaioannou VE, Ralph MR. The circadian system of c-fos deficient mice. J Comp Physiol A Sens Neural Behav Physiol 178: $563-570,1996$.

208. Horikawa K, Yokota S, Fuji K, Akiyama M, Moriya T, Okamura $\mathbf{H}$, Shibata $\mathbf{S}$. Nonphotic entrainment by $5-\mathrm{HT}_{1 \mathrm{~A} / 7}$ receptor agonists accompanied by reduced Per1 and Per2 mRNA levels in the suprachiasmatic nuclei. J Neurosci 20: 5867-5873, 2000.

209. Hughes AT, Fahey B, Cutler DJ, Coogan AN, Piggins HD. Aberrant gating of photic input to the suprachiasmatic circadian pacemaker of mice lacking the VPAC2 receptor. $J$ Neurosci 24: 3522-3526, 2004.

210. Hughes AT, Guilding C, Lennox L, Samuels RE, McMahon DG, Piggins HD. Live imaging of altered period1 expression in the suprachiasmatic nuclei of Vipr2-/- mice. J Neurochem 106: 1646 1657,2008

211. Hughes AT, Piggins HD. Behavioral responses of Vipr2-/- mice to light. J Biol Rhythms 23: 211-219, 2008.

212. Huhman KL, Gillespie CF, Marvel CL, Albers HE. Neuropeptide $\mathrm{Y}$ phase shifts circadian rhythms in vivo via a $\mathrm{Y} 2$ receptor. Neuroreport 7: 1249-1252, 1996.

213. Hut RA, Scheper A, Daan S. Can the circadian system of a diurnal and a nocturnal rodent entrain to ultraviolet light? J Comp Physiol A Sens Neural Behav Physiol 186: 707-715, 2000.

214. Hut RA, van Oort BE, Daan S. Natural entrainment without dawn and dusk: the case of the European ground squirrel (Spermophilus citellus). J Biol Rhythms 14: 290-299, 1999.

215. Iitaka C, Miyazaki K, Akaike T, Ishida N. A role for glycogen synthase kinase-3beta in the mammalian circadian clock. $J$ Biol Chem 280: 29397-29402, 2005.

216. Ikeda M. Calcium dynamics and circadian rhythms in suprachiasmatic nucleus neurons. Neuroscientist 10: 315-324, 2004.

217. Ikeda M, Sugiyama T, Wallace CS, Gompf HS, Yoshioka T, Miyawaki A, Allen CN. Circadian dynamics of cytosolic and nuclear $\mathrm{Ca}^{2+}$ in single suprachiasmatic nucleus neurons. Neuron 38: 253-263, 2003.

218. Inagaki N, Honma S, Ono D, Tanahashi Y, Honma K. Separate oscillating cell groups in mouse suprachiasmatic nucleus couple photoperiodically to the onset and end of daily activity. Proc Natl Acad Sci USA 104: 7664-7669, 2007.

219. Irwin RP, Allen CN. Calcium response to retinohypothalamic tract synaptic transmission in suprachiasmatic nucleus neurons. $J$ Neurosci 27: 11748-11757, 2007.

220. Ishida Y, Yagita K, Fukuyama T, Nishimura M, Nagano M, Shigeyoshi Y, Yamaguchi S, Komori T, Okamura H. Constitutive expression and delayed light response of casein kinase Iepsilon and Idelta mRNAs in the mouse suprachiasmatic nucleus. $J$ Neurosci Res 64: 612-616, 2001.

221. Iwase T, Kajimura N, Uchiyama M, Ebisawa T, Yoshimura K, Kamei Y, Shibui K, Kim K, Kudo Y, Katoh M, Watanabe T, Nakajima T, Ozeki Y, Sugishita M, Hori T, Ikeda M, Toyoshima R, Inoue Y, Yamada N, Mishima K, Nomura M, Ozaki N, Okawa M, Takahashi K, Yamauchi T. Mutation screening of the human Clock gene in circadian rhythm sleep disorders. Psychiatry Res 109: 121-128, 2002.

222. Jacobs EH, Yamatodani A, Timmerman H. Is histamine the final neurotransmitter in the entrainment of circadian rhythms in mammals? Trends Pharmacol Sci 21: 293-298, 2000.

223. Jagota A, de la Iglesia HO, Schwartz WJ. Morning and evening circadian oscillations in the suprachiasmatic nucleus in vitro. Nat Neurosci 3: 372-376, 2000

224. Jakobs TC, Libby RT, Ben Y, John SW, Masland RH. Retinal ganglion cell degeneration is topological but not cell type specific in DBA/2J mice. J Cell Biol 171: 313-325, 2005.

225. Jaliffa CO, Lacoste FF, Llomovatte DW, Sarmiento MI, Rosenstein RE. Dopamine decreases melatonin content in golden hamster retina. J Pharmacol Exp Ther 293: 91-95, 2000.

226. Jaliffa CO, Saenz D, Resnik E, Keller Sarmiento MI, Rosenstein RE. Circadian activity of the GABAergic system in the golden hamster retina. Brain Res 912: 195-202, 2001.
227. Jean-Louis G, Zizi F, Lazzaro DR, Wolintz AH. Circadian rhythm dysfunction in glaucoma: a hypothesis. J Circadian Rhythms 6: 1, 2008

228. Jiang ZG, Yang Y, Liu ZP, Allen CN. Membrane properties and synaptic inputs of suprachiasmatic nucleus neurons in rat brain slices. J Physiol 499: 141-159, 1997.

229. Jiao YY, Lee TM, Rusak B. Photic responses of suprachiasmatic area neurons in diurnal degus (Octodon degus) and nocturnal rats (Rattus norvegicus). Brain Res 817: 93-103, 1999.

230. Johansson C, Willeit M, Smedh C, Ekholm J, Paunio T, Kieseppa T, Lichtermann D, Praschak-Rieder N, Neumeister A, Nilsson LG, Kasper S, Peltonen L, Adolfsson R, Schalling M, Partonen T. Circadian clock-related polymorphisms in seasonal affective disorder and their relevance to diurnal preference. Neuropsychopharmacology 28: 734-739, 2003.

231. Johnson CH. Forty years of PRCs-what have we learned? Chronobiol Int 16: 711-743, 1999.

232. Johnson CH, Elliott JA, Foster R. Entrainment of circadian programs. Chronobiol Int 20: 741-774, 2003.

233. Johnson CH, Golden SS, Kondo T. Adaptive significance of circadian programs in cyanobacteria. Trends Microbiol 6: 407-410, 1998.

234. Johnson RF, Moore RY, Morin LP. Lateral geniculate lesions alter circadian activity rhythms in the hamster. Brain Res Bull 22: 411-422, 1989

235. Johnson RF, Moore RY, Morin LP. Loss of entrainment and anatomical plasticity after lesions of the hamster retinohypothalamic tract. Brain Res 460: 297-313, 1988.

236. Jongebloed WL, Kalicharan D, Los LI, Worst JG. The Morgagnian and Brunescens cataract morphology studied with with SEM and TEM. Eur J Morphol 31: 97-102, 1993.

237. Karatsoreos IN, Romeo RD, McEwen BS, Silver R. Diurnal regulation of the gastrin-releasing peptide receptor in the mouse circadian clock. Eur J Neurosci 23: 1047-1053, 2006.

238. Kashiwagi K, Tsumura T, Ishii H, Ijiri H, Tamura K, Tsukahara S. Circadian rhythm of autonomic nervous function in patients with normal-tension glaucoma compared with normal subjects using ambulatory electrocardiography. J Glaucoma 9: 239 246, 2000.

239. Katzenberg D, Young T, Finn L, Lin L, King DP, Takahashi JS, Mignot E. A CLOCK polymorphism associated with human diurnal preference. Sleep 21: 569-576, 1998.

240. Kaur S, Rusak B. Optic enucleation eliminates circadian rhythm shifts induced by stimulating the intergeniculate leaflet in Syrian hamsters. Neurosci Lett 427: 107-111, 2007.

241. Kawaguchi C, Tanaka K, Isojima Y, Shintani N, Hashimoto H, Baba A, Nagai K. Changes in light-induced phase shift of circadian rhythm in mice lacking PACAP. Biochem Biophys Res Commun 310: 169-175, 2003.

242. Kennaway DJ. Resetting the suprachiasmatic nucleus clock. Front Biosci 9: 56-62, 2004.

243. Khalsa SB, Jewett ME, Cajochen C, Czeisler CA. A phase response curve to single bright light pulses in human subjects. $J$ Physiol 549: 945-952, 2003.

244. Kim DY, Choi HJ, Kim JS, Kim YS, Jeong DU, Shin HC, Kim MJ, Han HC, Hong SK, Kim YI. Voltage-gated calcium channels play crucial roles in the glutamate-induced phase shifts of the rat suprachiasmatic circadian clock. Eur J Neurosci 21: 1215-1222, 2005.

245. Kim DY, Kang HC, Shin HC, Lee KJ, Yoon YW, Han HC, Na HS, Hong SK, Kim YI. Substance P plays a critical role in photic resetting of the circadian pacemaker in the rat hypothalamus. $J$ Neurosci 21: 4026-4031, 2001.

246. Kim YI, Choi HJ, Colwell CS. Brain-derived neurotrophic factor regulation of $N$-methyl-D-aspartate receptor-mediated synaptic currents in suprachiasmatic nucleus neurons. J Neurosci Res 84: 15121520,2006

247. Kim YI, Dudek FE. Membrane properties of rat suprachiasmatic nucleus neurons receiving optic nerve input. J Physiol 464: 229 243, 1993.

248. King DP, Takahashi JS. Molecular genetics of circadian rhythms in mammals. Annu Rev Neurosci 23: 713-742, 2000. 
249. Kiss J, Csaki A, Csaba Z, Halasz B. Synaptic contacts of vesicular glutamate transporter 2 fibres on chemically identified neurons of the hypothalamic suprachiasmatic nucleus of the rat. Eur $J$ Neurosci 28: 1760-1774, 2008.

250. Klein R, Moss SE, Klein BE. New management concepts for timely diagnosis of diabetic retinopathy treatable by photocoagulation. Diabetes Care 10: 633-638, 1987.

251. Klerman EB, Rimmer DW, Dijk DJ, Kronauer RE, Rizzo JF, 3rd, Czeisler CA. Nonphotic entrainment of the human circadian pacemaker. Am J Physiol Regul Integr Comp Physiol 274: R991R996, 1998.

252. Ko CH, Takahashi JS. Molecular components of the mammalian circadian clock. Hum Mol Genet 15: R271-277, 2006.

253. Ko GY, Ko ML, Dryer SE. Circadian regulation of cGMP-gated channels of vertebrate cone photoreceptors: role of cAMP and Ras. J Neurosci 24: 1296-1304, 2004.

254. Kopp MD, Meissl H, Dehghani F, Korf HW. The pituitary adenylate cyclase-activating polypeptide modulates glutamatergic calcium signalling: investigations on rat suprachiasmatic nucleus neurons. J Neurochem 79: 161-171, 2001.

255. Kowalska E, Brown SA. Peripheral clocks: keeping up with the master clock. Cold Spring Harb Symp Quant Biol 72: 301-305, 2007.

256. Kramer A, Yang FC, Kraves S, Weitz CJ. A screen for secreted factors of the suprachiasmatic nucleus. Methods Enzymol 393: 645-663, 2005.

257. Kramer A, Yang FC, Snodgrass P, Li X, Scammell TE, Davis FC, Weitz CJ. Regulation of daily locomotor activity and sleep by hypothalamic EGF receptor signalling. Novartis Found Symp 253: 250-262, 2003.

258. Kriegsfeld LJ, Demas GE, Lee SE Jr, Dawson TM, Dawson VL, Nelson RJ. Circadian locomotor analysis of male mice lacking the gene for neuronal nitric oxide synthase (nNOS-/-). J Biol Rhythms 14: 20-27, 1999.

259. Kriegsfeld LJ, Drazen DL, Nelson RJ. Circadian organization in male mice lacking the gene for endothelial nitric oxide synthase (eNOS-/-). J Biol Rhythms 16: 142-148, 2001.

260. Kriegsfeld LJ, LeSauter J, Silver R. Targeted microlesions reveal novel organization of the hamster suprachiasmatic nucleus. $J$ Neurosci 24: 2449-2457, 2004.

261. Kripke DF. Light treatment for nonseasonal depression: speed, efficacy, and combined treatment. J Affect Disord 49: 109-117, 1998.

262. Kripke DF, Elliott JA, Youngstedt SD, Rex KM. Circadian phase response curves to light in older and young women and men. J Circadian Rhythms 5: 4, 2007.

263. Kripke DF, Jean-Louis G, Elliott JA, Klauber MR, Rex KM, Tuunainen A, Langer RD. Ethnicity, sleep, mood, and illumination in postmenopausal women. BMC Psychiatry 4: 8, 2004.

264. Lamas M, Monaco L, Zazopoulos E, Lalli E, Tamai K, Penna L, Mazzucchelli C, Nantel F, Foulkes NS, Sassone-Corsi P. CREM: a master-switch in the transcriptional response to cAMP. Philos Trans R Soc Lond B Biol Sci 351: 561-567, 1996.

265. Lamont EW, James FO, Boivin DB, Cermakian N. From circadian clock gene expression to pathologies. Sleep Med 8: 547-556, 2007.

266. Lamont EW, Legault-Coutu D, Cermakian N, Boivin DB. The role of circadian clock genes in mental disorders. Dialogues Clin Neurosci 9: 333-342, 2007.

267. Lavialle M, Begue A, Papillon C, Vilaplana J. Modifications of retinal afferent activity induce changes in astroglial plasticity in the hamster circadian clock. Glia 34: 88-100, 2001.

268. Lavialle M, Serviere J. Developmental study in the circadian clock of the golden hamster: a putative role of astrocytes. Brain Res 86: 275-282, 1995.

269. Lavie P. Ultradian rhythms in arousal-the problem of masking. Chronobiol Int 6: 21-28, 1989.

270. Lee C, Etchegaray JP, Cagampang FR, Loudon AS, Reppert SM. Posttranslational mechanisms regulate the mammalian circadian clock. Cell 107: 855-867, 2001.

271. Lee HS, Nelms JL, Nguyen M, Silver R, Lehman MN. The eye is necessary for a circadian rhythm in the suprachiasmatic nucleus. Nat Neurosci 6: 111-112, 2003.
272. Lee JM, Schak KM, Harrington ME. Inhibition of protein kinase A phase delays the mammalian circadian clock. Brain Res 835: 350-353, 1999 .

273. Leger D, Guilleminault C, Defrance R, Domont A, Paillard M. Prevalence of sleep/wake disorders in persons with blindness. Clin Sci 97: 193-199, 1999.

274. Leone MJ, Marpegan L, Bekinschtein TA, Costas MA, Golombek DA. Suprachiasmatic astrocytes as an interface for immune-circadian signalling. J Neurosci Res 84: 1521-1527, 2006.

275. LeSauter J, Silver R. Output signals of the SCN. Chronobiol Int 15: 535-550, 1998

276. Levi F, Schibler U. Circadian rhythms: mechanisms and therapeutic implications. Annu Rev Pharmacol Toxicol 47: 593-628, 2007.

277. Levine JD, Rosenwasser AM, Yanovski JA, Adler NT. Circadian activity rhythms in rats with midbrain raphe lesions. Brain Res 384: 240-249, 1986.

278. Li RS, Chen BY, Tay DK, Chan HH, Pu ML, So KF. Melanopsinexpressing retinal ganglion cells are more injury-resistant in a chronic ocular hypertension model. Invest Ophthalmol Vis Sci 47: 2951-2958, 2006.

279. Liang FQ, Allen G, Earnest D. Role of brain-derived neurotrophic factor in the circadian regulation of the suprachiasmatic pacemaker by light. J Neurosci 20: 2978-2987, 2000.

280. Lin B, Koizumi A, Tanaka N, Panda S, Masland RH. Restoration of visual function in retinal degeneration mice by ectopic expression of melanopsin. Proc Natl Acad Sci USA 105: 16009-16014, 2008.

281. Lindley J, Deurveilher S, Rusak B, Semba K. Transforming growth factor-alpha and glial fibrillary acidic protein in the hamster circadian system: daily profile and cellular localization. Brain Res 1197: 94-105, 2008.

282. Liu C, Reppert SM. GABA synchronizes clock cells within the suprachiasmatic circadian clock. Neuron 25: 123-128, 2000.

283. Liu C, Weaver DR, Strogatz SH, Reppert SM. Cellular construction of a circadian clock: period determination in the suprachiasmatic nuclei. Cell 91: 855-860, 1997.

284. Lockley SW, Skene DJ, Arendt J, Tabandeh H, Bird AC, Defrance R. Relationship between melatonin rhythms and visual loss in the blind. J Clin Endocrinol Metab 82: 3763-3770, 1997.

285. Loudon AS, Meng QJ, Maywood ES, Bechtold DA, Boot-Handford RP, Hastings MH. The biology of the circadian Cklepsilon tau mutation in mice and Syrian hamsters: a tale of two species. Cold Spring Harb Symp Quant Biol 72: 261-271, 2007.

286. Lowrey PL, Shimomura K, Antoch MP, Yamazaki S, Zemenides PD, Ralph MR, Menaker M, Takahashi JS. Positional syntenic cloning and functional characterization of the mammalian circadian mutation tau. Science 288: 483-492, 2000.

287. Lowrey PL, Takahashi JS. Genetics of the mammalian circadian system: photic entrainment, circadian pacemaker mechanisms, and posttranslational regulation. Annu Rev Genet 34: 533-562, 2000.

288. Lowrey PL, Takahashi JS. Mammalian circadian biology: elucidating genome-wide levels of temporal organization. Annu Rev Genomics Hum Genet 5: 407-441, 2004.

289. Lucas RJ, Douglas RH, Foster RG. Characterization of an ocular photopigment capable of driving pupillary constriction in mice. Nat Neurosci 4: 621-626, 2001.

290. Lucas RJ, Freedman MS, Munoz M, Garcia-Fernandez JM, Foster RG. Regulation of the mammalian pineal by non-rod, noncone, ocular photoreceptors. Science 284: 505-507, 1999.

291. Lucas RJ, Hattar S, Takao M, Berson DM, Foster RG, Yau KW. Diminished pupillary light reflex at high irradiances in melanopsinknockout mice. Science 299: 245-247, 2003.

292. Manglapus MK, Iuvone PM, Underwood H, Pierce ME, Barlow RB. Dopamine mediates circadian rhythms of rod-cone dominance in the Japanese quail retina. J Neurosci 19: 4132-4141, 1999.

293. Marchant EG, Mistlberger RE. Morphine phase-shifts circadian rhythms in mice: role of behavioural activation. Neuroreport 7: 209-212, 1995 .

294. Marchant EG, Morin LP. Light augments FOS protein induction in brain of short-term enucleated hamsters. Brain Res 902: 51-65, 2001.

295. Marchant EG, Watson NV, Mistlberger RE. Both neuropeptide $\mathrm{Y}$ and serotonin are necessary for entrainment of circadian rhythms 
in mice by daily treadmill running schedules. J Neurosci 17: 79747987, 1997.

296. Marques MD, Waterhouse JM. Masking and the evolution of circadian rhythmicity. Chronobiol Int 11: 146-155, 1994.

297. Masana MI, Sumaya IC, Becker-Andre M, Dubocovich ML. Behavioral characterization and modulation of circadian rhythms by light and melatonin in $\mathrm{C} 3 \mathrm{H} / \mathrm{HeN}$ mice homozygous for the RORbeta knockout. Am J Physiol Regul Integr Comp Physiol 292: R2357-R2367, 2007.

298. Mathur A, Golombek DA, Ralph MR. cGMP-dependent protein kinase inhibitors block light-induced phase advances of circadian rhythms in vivo. Am J Physiol Regul Integr Comp Physiol 270: R1031-R1036, 1996.

299. Maywood ES, Mrosovsky N, Field MD, Hastings MH. Rapid down-regulation of mammalian period genes during behavioral resetting of the circadian clock. Proc Natl Acad Sci USA 96: 1521115216, 1999.

300. Maywood ES, O'Neill JS, Chesham JE, Hastings MH. Minireview: the circadian clockwork of the suprachiasmatic nuclei-analysis of a cellular oscillator that drives endocrine rhythms. Endocrinology 148: 5624-5634, 2007.

301. Maywood ES, O'Neill JS, Reddy AB, Chesham JE, Prosser HM, Kyriacou CP, Godinho SI, Nolan PM, Hastings MH. Genetic and molecular analysis of the central and peripheral circadian clockwork of mice. Cold Spring Harb Symp Quant Biol 72: 85-94, 2007.

302. Maywood ES, Okamura H, Hastings MH. Opposing actions of neuropeptide $\mathrm{Y}$ and light on the expression of circadian clock genes in the mouse suprachiasmatic nuclei. Eur $J$ Neurosci 15 : 216-220, 2002.

303. Maywood ES, Reddy AB, Wong GK, O'Neill JS, O'Brien JA, McMahon DG, Harmar AJ, Okamura H, Hastings MH. Synchronization and maintenance of timekeeping in suprachiasmatic circadian clock cells by neuropeptidergic signaling. Curr Biol 16: 599-605, 2006.

304. McClung CA. Circadian genes, rhythms and the biology of mood disorders. Pharmacol Ther 114: 222-232, 2007.

305. Meijer JH, Albus H, Weidema F, Ravesloot JH. The effects of glutamate on membrane potential and discharge rate of suprachiasmatic neurons. Brain Res 603: 284-288, 1993.

306. Meijer JH, Groos GA, Rusak B. Luminance coding in a circadian pacemaker: the suprachiasmatic nucleus of the rat and the hamster. Brain Res 382: 109-118, 1986.

307. Meijer JH, Michel S, Vansteensel MJ. Processing of daily and seasonal light information in the mammalian circadian clock. Gen Comp Endocrinol 152: 159-164, 2007.

308. Meijer JH, Rietveld WJ. Neurophysiology of the suprachiasmatic circadian pacemaker in rodents. Physiol Rev 69: 671-707, 1989.

309. Meijer JH, Schwartz WJ. In search of the pathways for lightinduced pacemaker resetting in the suprachiasmatic nucleus. $J$ Biol Rhythms 18: 235-249, 2003.

310. Meijer JH, van der Zee EA, Dietz M. Glutamate phase shifts circadian activity rhythms in hamsters. Neurosci Lett 86: 177-183, 1988.

311. Melo L, Golombek DA, Ralph MR. Regulation of circadian photic responses by nitric oxide. J Biol Rhythms 12: 319-326, 1997.

312. Mendoza J. Circadian clocks: setting time by food. J Neuroendocrinol 19: 127-137, 2007.

313. Meng QJ, Logunova L, Maywood ES, Gallego M, Lebiecki J, Brown TM, Sladek M, Semikhodskii AS, Glossop NR, Piggins HD, Chesham JE, Bechtold DA, Yoo SH, Takahashi JS, Virshup DM, Boot-Handford RP, Hastings MH, Loudon AS. Setting clock speed in mammals: the CK1 epsilon tau mutation in mice accelerates circadian pacemakers by selectively destabilizing PERIOD proteins. Neuron 58: 78-88, 2008.

314. Messager S, Hazlerigg DG, Mercer JG, Morgan PJ. Photoperiod differentially regulates the expression of Per1 and ICER in the pars tuberalis and the suprachiasmatic nucleus of the Siberian hamster. Eur J Neurosci 12: 2865-2870, 2000.

315. Meyer-Bernstein EL, Morin LP. Differential serotonergic innervation of the suprachiasmatic nucleus and the intergeniculate leaflet and its role in circadian rhythm modulation. J Neurosci 16: 2097-2111, 1996.
316. Meyer-Spasche A, Piggins HD. Vasoactive intestinal polypeptide phase-advances the rat suprachiasmatic nuclei circadian pacemaker in vitro via protein kinase A and mitogen-activated protein kinase. Neurosci Lett 358: 91-94, 2004.

317. Michel S, Clark JP, Ding JM, Colwell CS. Brain-derived neurotrophic factor and neurotrophin receptors modulate glutamateinduced phase shifts of the suprachiasmatic nucleus. Eur J Neurosci 24: 1109-1116, 2006.

318. Michel S, Colwell CS. Cellular communication and coupling within the suprachiasmatic nucleus. Chronobiol Int 18: 579-600, 2001.

319. Mikkelsen JD, Larsen PJ, Ebling FJ. Distribution of $N$-methyl D-aspartate (NMDA) receptor mRNAs in the rat suprachiasmatic nucleus. Brain Res 632: 329-333, 1993.

320. Minors DS, Waterhouse JM. Masking in humans: the problem and some attempts to solve it. Chronobiol Int 6: 29-53, 1989

321. Minors DS, Waterhouse JM, Wirz-Justice A. A human phaseresponse curve to light. Neurosci Lett 133: 36-40, 1991.

322. Mintz EM, Albers HE. Microinjection of NMDA into the SCN region mimics the phase shifting effect of light in hamsters. Brain Res 758: 245-249, 1997.

323. Mintz EM, Gillespie CF, Marvel CL, Huhman KL, Albers HE. Serotonergic regulation of circadian rhythms in Syrian hamsters. Neuroscience 79: 563-569, 1997.

324. Mintz EM, Marvel CL, Gillespie CF, Price KM, Albers HE. Activation of NMDA receptors in the suprachiasmatic nucleus produces light-like phase shifts of the circadian clock in vivo. $J$ Neurosci 19: 5124-5130, 1999.

325. Mishima K, Tozawa T, Satoh K, Saitoh H, Mishima Y. The $3111 \mathrm{~T} / \mathrm{C}$ polymorphism of hClock is associated with evening preference and delayed sleep timing in a Japanese population sample. Am J Med Genet B Neuropsychiatr Genet 133B: 101-104, 2005.

326. Mistlberger RE, Bossert JM, Holmes MM, Marchant EG. Serotonin and feedback effects of behavioral activity on circadian rhythms in mice. Behav Brain Res 96: 93-99, 1998.

327. Mistlberger RE, Skene DJ. Nonphotic entrainment in humans? $J$ Biol Rhythms 20: 339-352, 2005.

328. Mistlberger RE, Skene DJ. Social influences on mammalian circadian rhythms: animal and human studies. Biol Rev Camb Philos Soc 79: 533-556, 2004.

329. Miyake S, Sumi Y, Yan L, Takekida S, Fukuyama T, Ishida Y, Yamaguchi S, Yagita K, Okamura H. Phase-dependent responses of Per1 and Per2 genes to a light-stimulus in the suprachiasmatic nucleus of the rat. Neurosci Lett 294: 41-44, 2000.

330. Miyamoto Y, Sancar A. Vitamin $\mathrm{B}_{2}$-based blue-light photoreceptors in the retinohypothalamic tract as the photoactive pigments for setting the circadian clock in mammals. Proc Natl Acad Sci USA 95: 6097-6102, 1998.

331. Moga MM. Delayed loss of p75 neurotrophin receptor-immunoreactivity in the rat suprachiasmatic nucleus and intergeniculate leaflet after binocular enucleation. Neurosci Lett 253: 187-190, 1998.

332. Moga MM, Moore RY. Organization of neural inputs to the suprachiasmatic nucleus in the rat. J Comp Neurol 389: 508-534, 1997.

333. Moore-Ede MC. The 24 Hour Society: The Risks, Costs and Challenges of a World that Never Stops. London: Pitman, 1993.

334. Moore RY. Neural control of the pineal gland. Behav Brain Res 73: 125-130, 1996.

335. Moore RY. Retinohypothalamic projection in mammals: a comparative study. Brain Res 49: 403-409, 1973.

336. Moore RY, Lenn NJ. A retinohypothalamic projection in the rat. $J$ Comp Neurol 146: 1-14, 1972.

337. Moore RY, Speh JC, Leak RK. Suprachiasmatic nucleus organization. Cell Tissue Res 309: 89-98, 2002.

338. Morgenthaler TI, Lee-Chiong T, Alessi C, Friedman L, Aurora RN, Boehlecke B, Brown T, Chesson AL Jr, Kapur V, Maganti R, Owens J, Pancer J, Swick TJ, Zak R. Practice parameters for the clinical evaluation and treatment of circadian rhythm sleep disorders. An American Academy of Sleep Medicine report. Sleep 30: 1445-1459, 2007.

339. Morin LP. The circadian visual system. Brain Res 19: 102-127, 1994. 
340. Morin LP. SCN organization reconsidered. J Biol Rhythms 22: 3-13, 2007.

341. Morin LP, Allen CN. The circadian visual system, 2005. Brain Res Rev 51: 1-60, 2006.

342. Morin LP, Blanchard JH, Provencio I. Retinal ganglion cell projections to the hamster suprachiasmatic nucleus, intergeniculate leaflet, and visual midbrain: bifurcation and melanopsin immunoreactivity. J Comp Neurol 465: 401-416, 2003.

343. Moriya T, Horikawa K, Akiyama M, Shibata S. Correlative association between $N$-methyl-D-aspartate receptor-mediated expression of period genes in the suprachiasmatic nucleus and phase shifts in behavior with photic entrainment of clock in hamsters. Mol Pharmacol 58: 1554-1562, 2000.

344. Moriya T, Yoshinobu Y, Kouzu Y, Katoh A, Gomi H, Ikeda M, Yoshioka T, Itohara S, Shibata S. Involvement of glial fibrillary acidic protein (GFAP) expressed in astroglial cells in circadian rhythm under constant lighting conditions in mice. J Neurosci Res 60: 212-218, 2000.

345. Motzkus D, Loumi S, Cadenas C, Vinson C, Forssmann WG, Maronde E. Activation of human period-1 by PKA or CLOCK/ BMAL1 is conferred by separate signal transduction pathways. Chronobiol Int 24: 783-792, 2007.

346. Mrosovsky N. In praise of masking: behavioural responses of retinally degenerate mice to dim light. Chronobiol Int 11: 343-348, 1994.

347. Mrosovsky N. Phase response curves for social entrainment. $J$ Comp Physiol A Sens Neural Behav Physiol 162: 35-46, 1988.

348. Mrosovsky N, Foster RG, Salmon PA. Thresholds for masking responses to light in three strains of retinally degenerate mice. $J$ Comp Physiol A Sens Neural Behav Physiol 184: 423-428, 1999.

349. Mrosovsky N, Hattar S. Diurnal mice (Mus musculus) and other examples of temporal niche switching. J Comp Physiol A Sens Neural Behav Physiol 191: 1011-1024, 2005.

350. Mrosovsky N, Hattar S. Impaired masking responses to light in melanopsin-knockout mice. Chronobiol Int 20: 989-999, 2003.

351. Mrosovsky N, Redlin U, Roberts RB, Threadgill DW. Masking in waved-2 mice: EGF receptor control of locomotion questioned. Chronobiol Int 22: 963-974, 2005.

352. Mrosovsky N, Reebs SG, Honrado GI, Salmon PA. Behavioural entrainment of circadian rhythms. Experientia 45: 696-702, 1989.

353. Mrosovsky N, Salmon PA. A behavioural method for accelerating re-entrainment of rhythms to new light-dark cycles. Nature 330: 372-373, 1987.

354. Mrosovsky N, Salmon PA. Triazolam and phase-shifting acceleration re-evaluated. Chronobiol Int 7: 35-41, 1990.

355. Mrosovsky N, Thompson S. Negative and positive masking responses to light in retinal degenerate slow ( $r d s / r d s)$ mice during aging. Vision Res 48: 1270-1273, 2008.

356. Mrugala M, Zlomanczuk P, Jagota A, Schwartz WJ. Rhythmic multiunit neural activity in slices of hamster suprachiasmatic nucleus reflect prior photoperiod. Am J Physiol Regul Integr Comp Physiol 278: R987-R994, 2000.

357. Munekawa K, Tamada Y, Iijima N, Hayashi S, Ishihara A Inoue K, Tanaka M, Ibata Y. Development of astroglial elements in the suprachiasmatic nucleus of the rat: with special reference to the involvement of the optic nerve. Exp Neurol 166: 44-51, 2000.

358. Nahm SS, Farnell YZ, Griffith W, Earnest DJ. Circadian regulation and function of voltage-dependent calcium channels in the suprachiasmatic nucleus. J Neurosci 25: 9304-9308, 2005.

359. Naito E, Watanabe T, Tei H, Yoshimura T, Ebihara S. Reorganization of the suprachiasmatic nucleus coding for day length. $J$ Biol Rhythms 23: 140-149, 2008.

360. Nakahata Y, Grimaldi B, Sahar S, Hirayama J, Sassone-Corsi P. Signaling to the circadian clock: plasticity by chromatin remodeling. Curr Opin Cell Biol 19: 230-237, 2007.

361. Nakashima A, Kawamoto T, Honda KK, Ueshima T, Noshiro M, Iwata T, Fujimoto K, Kubo H, Honma S, Yorioka N, Kohno $\mathbf{N}$, Kato Y. DEC1 modulates the circadian phase of clock gene expression. Mol Cell Biol 28: 4080-4092, 2008.

362. Naruse Y, Oh-hashi K, Iijima N, Naruse M, Yoshioka H, Tanaka M. Circadian and light-induced transcription of clock gene Per1 depends on histone acetylation and deacetylation. Mol Cell Biol 24: 6278-6287, 2004.
363. Naum OG, Fernanda Rubio M, Golombek DA. Rhythmic variation in gamma-aminobutyric acid(A)-receptor subunit composition in the circadian system and median eminence of Syrian hamsters. Neurosci Lett 310: 178-182, 2001.

364. Negroni J, Nevo E, Cooper HM. Neuropeptidergic organization of the suprachiasmatic nucleus in the blind mole rat (Spalax ehrenbergi). Brain Res Bull 44: 633-639, 1997.

365. Nelson RJ, Zucker I. Photoperiodic control of reproduction in olfactory-bulbectomized rats. Neuroendocrinology 32: 266-271, 1981.

366. Nomura K, Takeuchi Y, Fukunaga K. MAP kinase additively activates the mouse Per1 gene promoter with CaM kinase II. Brain Res 1118: 25-33, 2006.

367. Nomura K, Takeuchi Y, Yamaguchi S, Okamura H, Fukunaga K. Involvement of calcium/calmodulin-dependent protein kinase II in the induction of mPer1. J Neurosci Res 72: 384-392, 2003.

368. O'Neill JS, Maywood ES, Chesham JE, Takahashi JS, Hastings MH. cAMP-dependent signaling as a core component of the mammalian circadian pacemaker. Science 320: 949-953, 2008.

369. Obrietan K, Impey S, Smith D, Athos J, Storm DR. Circadian regulation of cAMP response element-mediated gene expression in the suprachiasmatic nuclei. J Biol Chem 274: 17748-17756, 1999.

370. Obrietan K, Impey S, Storm DR. Light and circadian rhythmicity regulate MAP kinase activation in the suprachiasmatic nuclei. Nat Neurosci 1: 693-700, 1998.

371. Obrietan K, van den Pol AN. Neuropeptide Y depresses GABAmediated calcium transients in developing suprachiasmatic nucleus neurons: a novel form of calcium long-term depression. $J$ Neurosci 16: 3521-3533, 1996.

372. Ohta H, Yamazaki S, McMahon DG. Constant light desynchronizes mammalian clock neurons. Nat Neurosci 8: 267-269, 2005.

373. Okamura H. Suprachiasmatic nucleus clock time in the mammalian circadian system. Cold Spring Harb Symp Quant Biol 72: $551-556,2007$.

374. Okamura H, Miyake S, Sumi Y, Yamaguchi S, Yasui A, Muijtjens M, Hoeijmakers JH, van der Horst GT. Photic induction of mPer1 and mPer2 in cry-deficient mice lacking a biological clock. Science 286: 2531-2534, 1999.

375. Okamura H, Yamaguchi S, Yagita K. Molecular machinery of the circadian clock in mammals. Cell Tissue Res 309: 47-56, 2002.

376. Oster H, Werner C, Magnone MC, Mayser H, Feil R, Seeliger MW, Hofmann F, Albrecht U. cGMP-dependent protein kinase II modulates mPer1 and mPer2 gene induction and influences phase shifts of the circadian clock. Curr Biol 13: 725-733, 2003.

377. Ouyang Y, Andersson CR, Kondo T, Golden SS, Johnson CH. Resonating circadian clocks enhance fitness in cyanobacteria. Proc Natl Acad Sci USA 95: 8660-8664, 1998.

378. Palmer JD. The clocks controlling the tide-associated rhythms of intertidal animals. Bioessays 22: 32-37, 2000.

379. Panda S, Provencio I, Tu DC, Pires SS, Rollag MD, Castrucci AM, Pletcher MT, Sato TK, Wiltshire T, Andahazy M, Kay SA, Van Gelder RN, Hogenesch JB. Melanopsin is required for nonimage-forming photic responses in blind mice. Science 301: 525527, 2003.

380. Panda S, Sato TK, Castrucci AM, Rollag MD, DeGrip WJ, Hogenesch JB, Provencio I, Kay SA. Melanopsin (Opn4) requirement for normal light-induced circadian phase shifting. Science 298: 2213-2216, 2002.

381. Pandi-Perumal SR, Trakht I, Spence DW, Srinivasan V, Dagan Y, Cardinali DP. The roles of melatonin and light in the pathophysiology and treatment of circadian rhythm sleep disorders. Nat Clin Pract Neurol 4: 436-447, 2008.

382. Park D, Lee S, Jun K, Hong YM, Kim DY, Kim YI, Shin HS. Translation of clock rhythmicity into neural firing in suprachiasmatic nucleus requires mGluR-PLCbeta4 signaling. Nat Neurosci 6: 337-338, 2003.

383. Paul KN, Fukuhara C, Karom M, Tosini G, Albers HE. AMPA/ kainate receptor antagonist DNQX blocks the acute increase of Per2 mRNA levels in most but not all areas of the SCN. Brain Res 139: 129-136, 2005.

383a.Paz O. Carta de creencia. In: Obra Poética (1935-1988). Barcelona: Seix Barral, 1990. 
384. Pedrazzoli M, Louzada FM, Pereira DS, Benedito-Silva AA, Lopez AR, Martynhak BJ, Korczak AL, Koike Bdel V, Barbosa AA, D'Almeida V, Tufik S. Clock polymorphisms and circadian rhythms phenotypes in a sample of the Brazilian population. Chronobiol Int 24: 1-8, 2007.

385. Peytevin J, Aioun J, Chambille I. Neurons that express the AMPA receptor GluR2/3 subunits in suprachiasmatic nuclei of $\mathrm{Syr}-$ ian hamsters colocalize either vasoactive intestinal peptide, peptide histidine isoleucine or gastrin-releasing peptide. Cell Tissue Res 300: 345-359, 2000.

386. Pickard GE, Ralph MR, Menaker M. The intergeniculate leaflet partially mediates effects of light on circadian rhythms. J Biol Rhythms 2: 35-56, 1987.

387. Pierce ME, Besharse JC. Circadian regulation of retinomotor movements. I. Interaction of melatonin and dopamine in the control of cone length. J Gen Physiol 86: 671-689, 1985.

388. Pierce ME, Sheshberadaran H, Zhang Z, Fox LE, Applebury ML, Takahashi JS. Circadian regulation of iodopsin gene expression in embryonic photoreceptors in retinal cell culture. Neuron 10: 579-584, 1993.

389. Pittendrigh CS. Circadian systems: entrainment. In: Handbook of Behavioral Neurobiology: Biological Rhythms, edited by Aschoff J. New York: Plenum, 1981, vol. IV.

390. Pittendrigh CS. Temporal organization: reflections of a Darwinian clock-watcher. Annu Rev Physiol 55: 16-54, 1993.

391. Pittendrigh CS, Daan S. A functional analysis of circadian pacemakers in nocturnal rodents. V. Pacemaker structure: a clock for all seasons. J Comp Physiol 106: 333-355, 1976.

392. Pittendrigh CS, Daan S. A functional analysis of circadian pacemakers in nocturnal rodents. I. The stability and lability of spontaneous frequency. J Comp Physiol 106: 223-252, 1976.

393. Pittendrigh CS, Daan S. A functional analysis of circadian pacemakers in rodents. IV. Entrainment: pacemaker as clock. J Comp Physiol 106: 291-331, 1976.

394. Pizzio GA, Golombek DA. Photic regulation of map kinase phosphatases MKP1/2 and MKP3 in the hamster suprachiasmatic nuclei. J Mol Neurosci 34: 187-192, 2008.

395. Pizzio GA, Hainich EC, Ferreyra GA, Coso OA, Golombek DA. Circadian and photic regulation of ERK, JNK and p38 in the hamster SCN. Neuroreport 14: 1417-1419, 2003.

396. Pizzio GA, Hainich EC, Plano SA, Ralph MR, Golombek DA. Nerve growth factor-induced circadian phase shifts and MAP kinase activation in the hamster suprachiasmatic nuclei. Eur J Neurosci 22: 665-671, 2005.

397. Plano SA, Agostino PV, Golombek DA. Extracellular nitric oxide signaling in the hamster biological clock. FEBS Lett 581: 5500 5504, 2007.

398. Preitner N, Damiola F, Lopez-Molina L, Zakany J, Duboule D, Albrecht U, Schibler U. The orphan nuclear receptor REV-ERBalpha controls circadian transcription within the positive limb of the mammalian circadian oscillator. Cell 110: 251-260, 2002.

399. Prolo LM, Takahashi JS, Herzog ED. Circadian rhythm generation and entrainment in astrocytes. J Neurosci 25: 404-408, 2005.

400. Prosser RA. Serotonin phase-shifts the mouse suprachiasmatic circadian clock in vitro. Brain Res 966: 110-115, 2003.

401. Prosser RA, Dean RR, Edgar DM, Heller HC, Miller JD. Serotonin and the mammalian circadian system. I. In vitro phase shifts by serotonergic agonists and antagonists. J Biol Rhythms 8: 1-16, 1993.

402. Prosser RA, Gillette MU. Cyclic changes in cAMP concentration and phosphodiesterase activity in a mammalian circadian clock studied in vitro. Brain Res 568: 185-192, 1991.

403. Prosser RA, Gillette MU. The mammalian circadian clock in the suprachiasmatic nuclei is reset in vitro by cAMP. $J$ Neurosci 9 : 1073-1081, 1989.

404. Prosser RA, McArthur AJ, Gillette MU. cGMP induces phase shifts of a mammalian circadian pacemaker at night, in antiphase to cAMP effects. Proc Natl Acad Sci USA 86: 6812-6815, 1989.

405. Provencio I, Rollag MD, Castrucci AM. Photoreceptive net in the mammalian retina. This mesh of cells may explain how some blind mice can still tell day from night. Nature 415: 493, 2002.
406. Ptacek LJ, Jones CR, Fu YH. Novel insights from genetic and molecular characterization of the human clock. Cold Spring Harb Symp Quant Biol 72: 273-277, 2007.

407. Ralph MR, Hurd MW, Takeuchi J, Melo L, Mathur A, Golombek DA. Regulation and integration in the mammalian circadian system. Prog Brain Res 111: 191-203, 1996.

408. Ralph MR, Menaker M. GABA regulation of circadian responses to light. I. Involvement of $\mathrm{GABA}_{\mathrm{A}}$-benzodiazepine and $\mathrm{GABA}_{\mathrm{B}}$ receptors. J Neurosci 9: 2858-2865, 1989.

409. Ralph MR, Menaker M. A mutation of the circadian system in golden hamsters. Science 241: 1225-1227, 1988.

410. Redlin U, Mrosovsky N. Masking of locomotor activity in hamsters. J Comp Physiol A Sens Neural Behav Physiol 184: 429-437, 1999.

411. Reebs SG, Mrosovsky N. Effects of induced wheel running on the circadian activity rhythms of Syrian hamsters: entrainment and phase response curve. J Biol Rhythms 4: 39-48, 1989.

412. Reppert SM, Weaver DR. Coordination of circadian timing in mammals. Nature 418: 935-941, 2002.

413. Reppert SM, Weaver DR. Molecular analysis of mammalian circadian rhythms. Annu Rev Physiol 63: 647-676, 2001.

414. Roenneberg T, Daan S, Merrow M. The art of entrainment. J Biol Rhythms 18: 183-194, 2003.

415. Roenneberg T, Merrow M. Circadian clocks: the fall and rise of physiology. Nat Rev Mol Cell Biol 6: 965-971, 2005.

416. Rohling J, Meijer JH, VanderLeest HT, Admiraal J. Phase differences between SCN neurons and their role in photoperiodic encoding; a simulation of ensemble patterns using recorded single unit electrical activity patterns. J Physiol 100: 261-270, 2006.

417. Rohling J, Wolters L, Meijer JH. Simulation of day-length encoding in the SCN: from single-cell to tissue-level organization. $J$ Biol Rhythms 21: 301-313, 2006.

418. Romijn HJ, Sluiter AA, Pool CW, Wortel J, Buijs RM. Differences in colocalization between Fos and PHI, GRP, VIP and VP in neurons of the rat suprachiasmatic nucleus after a light stimulus during the phase delay versus the phase advance period of the night. J Comp Neurol 372: 1-8, 1996.

419. Ruby NF, Brennan TJ, Xie X, Cao V, Franken P, Heller HC, O'Hara BF. Role of melanopsin in circadian responses to light. Science 298: 2211-2213, 2002.

420. Rusak B, Boulos Z. Pathways for photic entrainment of mammalian circadian rhythms. Photochem Photobiol 34: 267-273, 1981.

421. Rusak B, Meijer JH, Harrington ME. Hamster circadian rhythms are phase-shifted by electrical stimulation of the geniculo-hypothalamic tract. Brain Res 493: 283-291, 1989.

422. Sack RL, Auckley D, Auger RR, Carskadon MA, Wright KP Jr, Vitiello MV, Zhdanova IV. Circadian rhythm sleep disorders. Part I, basic principles, shift work and jet lag disorders. An American Academy of Sleep Medicine review. Sleep 30: 1460-1483, 2007.

423. Sack RL, Brandes RW, Kendall AR, Lewy AJ. Entrainment of free-running circadian rhythms by melatonin in blind people. $N$ Engl J Med 343: 1070-1077, 2000.

424. Sack RL, Lewy AJ, Blood ML, Keith LD, Nakagawa H. Circadian rhythm abnormalities in totally blind people: incidence and clinical significance. J Clin Endocrinol Metab 75: 127-134, 1992.

425. Schaap J, Albus H, VanderLeest HT, Eilers PH, Detari L, Meijer JH. Heterogeneity of rhythmic suprachiasmatic nucleus neurons: implications for circadian waveform and photoperiodic encoding. Proc Natl Acad Sci USA 100: 15994-15999, 2003.

426. Schaap J, Meijer JH. Opposing effects of behavioural activity and light on neurons of the suprachiasmatic nucleus. Eur J Neurosci 13: 1955-1962, 2001.

427. Schaap J, Pennartz CM, Meijer JH. Electrophysiology of the circadian pacemaker in mammals. Chronobiol Int 20: 171-188, 2003.

428. Schibler U. Circadian time keeping: the daily ups and downs of genes, cells, and organisms. Prog Brain Res 153: 271-282, 2006.

429. Schurov IL, McNulty S, Best JD, Sloper PJ, Hastings MH. Glutamatergic induction of CREB phosphorylation and Fos expression in primary cultures of the suprachiasmatic hypothalamus in vitro is mediated by co-ordinate activity of NMDA and nonNMDA receptors. J Neuroendocrinol 11: 43-51, 1999. 
430. Schwartz MD, Wotus C, Liu T, Friesen WO, Borjigin J, Oda GA, de la Iglesia HO. Dissociation of circadian and light inhibition of melatonin release through forced desynchronization in the rat. Proc Natl Acad Sci USA 106: 17540-17545, 2009.

431. Schwartz WJ, Aronin N, Sassone-Corsi P. Photoinducible and rhythmic ICER-CREM immunoreactivity in the rat suprachiasmatic nucleus. Neurosci Lett 385: 87-91, 2005.

432. Schwartz WJ, Gross RA, Morton MT. The suprachiasmatic nuclei contain a tetrodotoxin-resistant circadian pacemaker. Proc Natl Acad Sci USA 84: 1694-1698, 1987.

433. Shearman LP, Sriram S, Weaver DR, Maywood ES, Chaves I, Zheng B, Kume K, Lee CC, van der Horst GT, Hastings MH, Reppert SM. Interacting molecular loops in the mammalian circadian clock. Science 288: 1013-1019, 2000.

434. Shearman LP, Zylka MJ, Weaver DR, Kolakowski LF Jr, Reppert SM. Two period homologs: circadian expression and photic regulation in the suprachiasmatic nuclei. Neuron 19: 1261-1269, 1997.

435. Shen S, Spratt C, Sheward WJ, Kallo I, West K, Morrison CF, Coen CW, Marston HM, Harmar AJ. Overexpression of the human VPAC2 receptor in the suprachiasmatic nucleus alters the circadian phenotype of mice. Proc Natl Acad Sci USA 97: 1157511580,2000

436. Shibata S, Moore RY. Calmodulin inhibitors produce phase shifts of circadian rhythms in vivo and in vitro. J Biol Rhythms 9: 27-41, 1994.

437. Shibata S, Moore RY. Neuropeptide Y and optic chiasm stimulation affect suprachiasmatic nucleus circadian function in vitro. Brain Res 615: 95-100, 1993.

438. Shigeyoshi Y, Taguchi K, Yamamoto S, Takekida S, Yan L, Tei H, Moriya T, Shibata S, Loros JJ, Dunlap JC, Okamura H. Light-induced resetting of a mammalian circadian clock is associated with rapid induction of the mPer1 transcript. Cell 91: 10431053, 1997.

439. Shimomura K, Kornhauser JM, Wisor JP, Umezu T, Yamazaki S, Ihara NL, Takahashi JS, Menaker M. Circadian behavior and plasticity of light-induced c-fos expression in SCN of tau mutant hamsters. J Biol Rhythms 13: 305-314, 1998.

440. Shimomura K, Menaker M. Light-induced phase shifts in tau mutant hamsters. J Biol Rhythms 9: 97-110, 1994.

441. Shirakawa T, Honma S, Katsuno Y, Oguchi H, Honma KI. Synchronization of circadian firing rhythms in cultured rat suprachiasmatic neurons. Eur J Neurosci 12: 2833-2838, 2000.

442. Siepka SM, Takahashi JS. Forward genetic screens to identify circadian rhythm mutants in mice. Methods Enzymol 393: 219-229, 2005.

443. Siepka SM, Yoo SH, Park J, Lee C, Takahashi JS. Genetics and neurobiology of circadian clocks in mammals. Cold Spring Harb Symp Quant Biol 72: 251-259, 2007.

444. Silver R, LeSauter J. Efferent signals of the suprachiasmatic nucleus. J Biol Rhythms 8 Suppl: S89-92, 1993.

445. Silver R, LeSauter J, Tresco PA, Lehman MN. A diffusible coupling signal from the transplanted suprachiasmatic nucleus controlling circadian locomotor rhythms. Nature 382: 810-813, 1996.

446. Sollars PJ, Ogilvie MD, Simpson AM, Pickard GE. Photic entrainment is altered in the $5-\mathrm{HT}_{1 \mathrm{~B}}$ receptor knockout mouse. $J$ Biol Rhythms 21: 21-32, 2006.

447. Sollars PJ, Simpson AM, Ogilvie MD, Pickard GE. Light-induced Fos expression is attenuated in the suprachiasmatic nucleus of serotonin 1B receptor knockout mice. Neurosci Lett 401: 209213, 2006.

448. Spoelstra K, Albrecht U, van der Horst GT, Brauer V, Daan S. Phase responses to light pulses in mice lacking functional per or cry genes. J Biol Rhythms 19: 518-529, 2004

449. Stehle JH, Pfeffer M, Kuhn R, Korf HW. Light-induced expression of transcription factor ICER (inducible cAMP early repressor) in rat suprachiasmatic nucleus is phase-restricted. Neurosci Lett 217: 169-172, 1996

450. Tabandeh H, Lockley SW, Buttery R, Skene DJ, Defrance R, Arendt J, Bird AC. Disturbance of sleep in blindness. Am J Ophthalmol 126: 707-712, 1998
451. Takahashi JS. Finding new clock components: past and future. $J$ Biol Rhythms 19: 339-347, 2004.

452. Takahashi JS, DeCoursey PJ, Bauman L, Menaker M. Spectral sensitivity of a novel photoreceptive system mediating entrainment of mammalian circadian rhythms. Nature 308: 186-188, 1984.

453. Takahashi JS, Hong HK, Ko CH, McDearmon EL. The genetics of mammalian circadian order and disorder: implications for physiology and disease. Nat Rev Genet 9: 764-775, 2008.

454. Takahashi JS, Shimomura K, Kumar V. Searching for genes underlying behavior: lessons from circadian rhythms. Science 322: 909-912, 2008.

455. Takano A, Uchiyama M, Kajimura N, Mishima K, Inoue Y, Kamei Y, Kitajima T, Shibui K, Katoh M, Watanabe T, Hashimotodani Y, Nakajima T, Ozeki Y, Hori T, Yamada N, Toyoshima R, Ozaki N, Okawa M, Nagai K, Takahashi K, Isojima Y, Yamauchi T, Ebisawa T. A missense variation in human casein kinase I epsilon gene that induces functional alteration and shows an inverse association with circadian rhythm sleep disorders. Neuropsychopharmacology 29: 1901-1909, 2004.

456. Takeuchi J, Shannon W, Aronin N, Schwartz WJ. Compositional changes of AP-1 DNA-binding proteins are regulated by light in a mammalian circadian clock. Neuron 11: 825-836, 1993.

457. Takumi T, Matsubara C, Shigeyoshi Y, Taguchi K, Yagita K, Maebayashi Y, Sakakida Y, Okumura K, Takashima N, Okamura H. A new mammalian period gene predominantly expressed in the suprachiasmatic nucleus. Genes Cells 3: 167-176, 1998.

458. Tamaru T, Isojima Y, Yamada T, Okada M, Nagai K, Takamatsu K. Light and glutamate-induced degradation of the circadian oscillating protein BMAL1 during the mammalian clock resetting. $J$ Neurosci 20: 7525-7530, 2000.

459. Terman JS, Reme CE, Terman M. Rod outer segment disk shedding in rats with lesions of the suprachiasmatic nucleus. Brain Res 605: 256-264, 1993.

460. Terman M. Evolving applications of light therapy. Sleep Med Rev 11: 497-507, 2007.

461. Thapan K, Arendt J, Skene DJ. An action spectrum for melatonin suppression: evidence for a novel non-rod, non-cone photoreceptor system in humans. J Physiol 535: 261-267, 2001.

462. Thomas KB, Tigges M, Iuvone PM. Melatonin synthesis and circadian tryptophan hydroxylase activity in chicken retina following destruction of serotonin immunoreactive amacrine and bipolar cells by kainic acid. Brain Res 601: 303-307, 1993.

463. Thompson CL, Bowes Rickman C, Shaw SJ, Ebright JN, Kelly U, Sancar A, Rickman DW. Expression of the blue-light receptor cryptochrome in the human retina. Invest Ophthalmol Vis Sci 44: 4515-4521, 2003.

464. Thompson CL, Selby CP, Van Gelder RN, Blaner WS, Lee J, Quadro L, Lai K, Gottesman ME, Sancar A. Effect of vitamin A depletion on nonvisual phototransduction pathways in cryptochromeless mice. J Biol Rhythms 19: 504-517, 2004.

465. Thompson S, Mullins RF, Philp AR, Stone EM, Mrosovsky N. Divergent phenotypes of vision and accessory visual function in mice with visual cycle dysfunction (Rpe65 rd12) or retinal degeneration (rd/rd). Invest Ophthalmol Vis Sci 49: 2737-2742, 2008.

466. Thresher RJ, Vitaterna MH, Miyamoto Y, Kazantsev A, Hsu DS, Petit C, Selby CP, Dawut L, Smithies O, Takahashi JS, Sancar A. Role of mouse cryptochrome blue-light photoreceptor in circadian photoresponses. Science 282: 1490-1494, 1998.

467. Tischkau SA, Gallman EA, Buchanan GF, Gillette MU. Differential cAMP gating of glutamatergic signaling regulates long-term state changes in the suprachiasmatic circadian clock. J Neurosci 20: 7830-7837, 2000.

468. Tischkau SA, Mitchell JW, Pace LA, Barnes JW, Barnes JA, Gillette MU. Protein kinase G type II is required for night-to-day progression of the mammalian circadian clock. Neuron 43: 539549, 2004.

469. Tischkau SA, Mitchell JW, Tyan SH, Buchanan GF, Gillette MU. $\mathrm{Ca}^{2+} / \mathrm{cAMP}$ response element-binding protein (CREB)-dependent activation of Per1 is required for light-induced signaling in the suprachiasmatic nucleus circadian clock. J Biol Chem 278: 718$723,2003$. 
470. Tischkau SA, Weber ET, Abbott SM, Mitchell JW, Gillette MU. Circadian clock-controlled regulation of cGMP-protein kinase G in the nocturnal domain. J Neurosci 23: 7543-7550, 2003.

471. To TL, Henson MA, Herzog ED, Doyle FJ 3rd. A molecular model for intercellular synchronization in the mammalian circadian clock. Biophys J 92: 3792-3803, 2007.

472. Toh KL. Basic science review on circadian rhythm biology and circadian sleep disorders. Ann Acad Med Singapore 37: 662-668, 2008.

473. Toh KL, Jones CR, He Y, Eide EJ, Hinz WA, Virshup DM, Ptacek LJ, Fu YH. An hPer2 phosphorylation site mutation in familial advanced sleep phase syndrome. Science 291: 1040-1043, 2001.

474. Tosini G, Aguzzi J, Bullock NM, Liu C, Kasamatsu M. Effect of photoreceptor degeneration on circadian photoreception and freerunning period in the Royal College of Surgeons rat. Brain Res 1148: 76-82, 2007.

475. Tosini G, Fukuhara C. The mammalian retina as a clock. Cell Tissue Res 309: 119-126, 2002.

476. Tosini G, Menaker M. Circadian rhythms in cultured mammalian retina. Science 272: 419-421, 1996.

477. Travnickova-Bendova Z, Cermakian N, Reppert SM, SassoneCorsi P. Bimodal regulation of mPeriod promoters by CREBdependent signaling and CLOCK/BMAL1 activity. Proc Natl Acad Sci USA 99: 7728-7733, 2002

478. Turek FW. From circadian rhythms to clock genes in depression. Int Clin Psychopharmacol 22 Suppl 2: S1-8, 2007.

479. Turek FW, Losee-Olson S. A benzodiazepine used in the treatment of insomnia phase-shifts the mammalian circadian clock. Nature 321: 167-168, 1986.

480. Turek FW, Penev P, Zhang Y, Van Reeth O, Takahashi JS, Zee P. Alterations in the circadian system in advanced age. Ciba Found Symp 183: 212-234, 1995.

481. Turek FW, Van Reeth $\mathbf{O}$. Use of benzodiazepines to manipulate the circadian clock regulating behavioral and endocrine rhythms. Horm Res 31: 59-65, 1989.

482. Usui S. Gradual changes in environmental light intensity and entrainment of circadian rhythms. Brain Dev 22 Suppl 1: S61-64, 2000.

483. Van den Pol AN, Finkbeiner SM, Cornell-Bell AH. Calcium excitability and oscillations in suprachiasmatic nucleus neurons and glia in vitro. J Neurosci 12: 2648-2664, 1992.

484. Van den Pol AN, Tsujimoto KL. Neurotransmitters of the hypothalamic suprachiasmatic nucleus: immunocytochemical analysis of 25 neuronal antigens. Neuroscience 15: 1049-1086, 1985.

485. Van Gelder RN, Wee R, Lee JA, Tu DC. Reduced pupillary light responses in mice lacking cryptochromes. Science 299: 222, 2003.

486. Van Soest S, Westerveld A, de Jong PT, Bleeker-Wagemakers EM, Bergen AA. Retinitis pigmentosa: defined from a molecular point of view. Surv Ophthalmol 43: 321-334, 1999.

487. Van Someren EJ, Kessler A, Mirmiran M, Swaab DF. Indirect bright light improves circadian rest-activity rhythm disturbances in demented patients. Biol Psychiatry 41: 955-963, 1997.

488. VanderLeest HT, Houben T, Michel S, Deboer T, Albus H, Vansteensel MJ, Block GD, Meijer JH. Seasonal encoding by the circadian pacemaker of the SCN. Curr Biol 17: 468-473, 2007.

489. VanderLeest HT, Rohling JH, Michel S, Meijer JH. Phase shifting capacity of the circadian pacemaker determined by the SCN neuronal network organization. PLoS One 4: e4976, 2009.

490. VanNewkirk MR, Nanjan MB, Wang JJ, Mitchell P, Taylor HR, McCarty CA. The prevalence of age-related maculopathy: the visual impairment project. Ophthalmology 107: 1593-1600, 2000.

491. Vanselow K, Kramer A. Role of phosphorylation in the mammalian circadian clock. Cold Spring Harb Symp Quant Biol 72: 167$176,2007$.

492. Vindlacheruvu RR, Ebling FJ, Maywood ES, Hastings MH. Blockade of glutamatergic neurotransmission in the suprachiasmatic nucleus prevents cellular and behavioural responses of the circadian system to light. Eur J Neurosci 4: 673-679, 1992.

493. Virshup DM, Eide EJ, Forger DB, Gallego M, Harnish EV. Reversible protein phosphorylation regulates circadian rhythms. Cold Spring Harb Symp Quant Biol 72: 413-420, 2007.
494. Vitaterna MH, Ko CH, Chang AM, Buhr ED, Fruechte EM, Schook A, Antoch MP, Turek FW, Takahashi JS. The mouse Clock mutation reduces circadian pacemaker amplitude and enhances efficacy of resetting stimuli and phase-response curve amplitude. Proc Natl Acad Sci USA 103: 9327-9332, 2006.

495. Vitaterna MH, Takahashi JS, Turek FW. Overview of circadian rhythms. Alcohol Res Health 25: 85-93, 2001.

496. Von Gall C, Duffield GE, Hastings MH, Kopp MD, Dehghani F, Korf HW, Stehle JH. CREB in the mouse SCN: a molecular interface coding the phase-adjusting stimuli light, glutamate, PACAP, and melatonin for clockwork access. J Neurosci 18: 10389-10397, 1998.

497. Vosko AM, Schroeder A, Loh DH, Colwell CS. Vasoactive intestinal peptide and the mammalian circadian system. Gen Comp Endocrinol 152: 165-175, 2007.

498. Wagner HJ, Behrens UD, Zaunreiter M, Douglas RH. The circadian component of spinule dynamics in teleost retinal horizontal cells is dependent on the dopaminergic system. Vis Neurosci 9: 345-351, 1992.

499. Wakamatsu H, Takahashi S, Moriya T, Inouye ST, Okamura $\mathbf{H}$, Akiyama M, Shibata S. Additive effect of mPer1 and mPer2 antisense oligonucleotides on light-induced phase shift. Neuroreport 12: 127-131, 2001.

500. Wang H, Ko CH, Koletar MM, Ralph MR, Yeomans J. Casein kinase I epsilon gene transfer into the suprachiasmatic nucleus via electroporation lengthens circadian periods of tau mutant hamsters. Eur J Neurosci 25: 3359-3366, 2007.

501. Wang H, Morris JF. Presence of neuronal nitric oxide synthase in the suprachiasmatic nuclei of mouse and rat. Neuroscience 74 : 1059-1068, 1996.

502. Watanabe A, Ono M, Shibata S, Watanabe $\mathbf{S}$. Effect of a nitric oxide synthase inhibitor, $N$-nitro-L-arginine methylester, on lightinduced phase delay of circadian rhythm of wheel-running activity in golden hamsters. Neurosci Lett 192: 25-28, 1995.

503. Waterhouse J, Minors D, Folkard S, Owens D, Atkinson G, Macdonald I, Reilly T, Sytnik N, Tucker P. Light of domestic intensity produces phase shifts of the circadian oscillator in humans. Neurosci Lett 245: 97-100, 1998.

504. Weber ET, Gannon RL, Michel AM, Gillette MU, Rea MA. Nitric oxide synthase inhibitor blocks light-induced phase shifts of the circadian activity rhythm, but not c-fos expression in the suprachiasmatic nucleus of the Syrian hamster. Brain Res 692: 137$142,1995$.

505. Weber ET, Gannon RL, Rea MA. cGMP-dependent protein kinase inhibitor blocks light-induced phase advances of circadian rhythms in vivo. Neurosci Lett 197: 227-230, 1995.

506. Wee R, Van Gelder RN. Sleep disturbances in young subjects with visual dysfunction. Ophthalmology 111: 297-302, 2004

507. Weinert D, Freyberg S, Touitou Y, Djeridane Y, Waterhouse JM. The phasing of circadian rhythms in mice kept under normal or short photoperiods. Physiol Behav 84: 791-798, 2005.

508. Welsh DK, Logothetis DE, Meister M, Reppert SM. Individual neurons dissociated from rat suprachiasmatic nucleus express independently phased circadian firing rhythms. Neuron 14: 697-706, 1995.

509. Welsh JH, Osborne CM. Diurnal changes in the retina of the catfish. J Comp Neurol 66: 349-360, 1937.

510. Westrin A, Lam RW. Seasonal affective disorder: a clinical update. Ann Clin Psychiatry 19: 239-246, 2007.

511. Wever RA. The Circadian System of Man. Results of Experiments Under Temporal Isolation. New York: Springer-Verlag, 1979.

512. Winfree AT. Phase control of neural pacemakers. Science 197: 761-763, 1977.

513. Winn B, Whitaker D, Elliott DB, Phillips NJ. Factors affecting light-adapted pupil size in normal human subjects. Invest Ophthalmol Vis Sci 35: 1132-1137, 1994.

514. Witting W, Mirmiran M, Bos NP, Swaab DF. Effect of light intensity on diurnal sleep-wake distribution in young and old rats. Brain Res Bull 30: 157-162, 1993

515. Xu Y, Padiath QS, Shapiro RE, Jones CR, Wu SC, Saigoh N, Saigoh K, Ptacek LJ, Fu YH. Functional consequences of a CKIdelta mutation causing familial advanced sleep phase syndrome. Nature 434: 640-644, 2005. 
516. Yamada S, Takayama Y, Seki T, Okada M, Nagai K. Changes in L1 and NCAM expression in the rat suprachiasmatic nucleus during growth and after orbital enucleation. Brain Res 143: 189-198, 2003.

517. Yamaguchi S, Isejima H, Matsuo T, Okura R, Yagita K, Kobayashi M, Okamura H. Synchronization of cellular clocks in the suprachiasmatic nucleus. Science 302: 1408-1412, 2003.

518. Yamazaki S, Alones V, Menaker M. Interaction of the retina with suprachiasmatic pacemakers in the control of circadian behavior. $J$ Biol Rhythms 17: 315-329, 2002.

519. Yan L, Karatsoreos I, Lesauter J, Welsh DK, Kay S, Foley D, Silver R. Exploring spatiotemporal organization of SCN circuits. Cold Spring Harb Symp Quant Biol 72: 527-541, 2007.

520. Yan L, Okamura H. Gradients in the circadian expression of Per1 and Per2 genes in the rat suprachiasmatic nucleus. Eur J Neurosci 15: 1153-1162, 2002.

521. Yan L, Silver R. Differential induction and localization of mPer1 and mPer2 during advancing and delaying phase shifts. Eur $J$ Neurosci 16: 1531-1540, 2002.

522. Yan L, Silver R. Resetting the brain clock: time course and localization of mPER1 and mPER2 protein expression in suprachiasmatic nuclei during phase shifts. Eur J Neurosci 19: 1105-1109, 2004.

523. Yan L, Takekida S, Shigeyoshi Y, Okamura H. Per1 and Per2 gene expression in the rat suprachiasmatic nucleus: circadian profile and the compartment-specific response to light. Neuroscience 94: 141-150, 1999.

524. Yannielli P, Harrington ME. Let there be "more" light: enhancement of light actions on the circadian system through non-photic pathways. Prog Neurobiol 74: 59-76, 2004.

525. Yannielli PC, Harrington ME. Neuropeptide $Y$ in the mammalian circadian system: effects on light-induced circadian responses. Peptides 22: 547-556, 2001.

526. Yokota S, Yamamoto M, Moriya T, Akiyama M, Fukunaga K, Miyamoto E, Shibata S. Involvement of calcium-calmodulin protein kinase but not mitogen-activated protein kinase in light-induced phase delays and Per gene expression in the suprachiasmatic nucleus of the hamster. J Neurochem 77: 618-627, 2001.

527. Yokota SI, Horikawa K, Akiyama M, Moriya T, Ebihara S, Komuro G, Ohta T, Shibata S. Inhibitory action of brotizolam on circadian and light-induced per1 and per2 expression in the hamster suprachiasmatic nucleus. Br J Pharmacol 131: 1739-1747, 2000 .
528. Yoshimura T, Ebihara S. Spectral sensitivity of photoreceptors mediating phase-shifts of circadian rhythms in retinally degenerate CBA/J (rd/rd) and normal CBA/N (+/+) mice. J Comp Physiol A Sens Neural Behav Physiol 178: 797-802, 1996.

529. Yujnovsky I, Hirayama J, Doi M, Borrelli E, Sassone-Corsi P. Signaling mediated by the dopamine D2 receptor potentiates circadian regulation by CLOCK:BMAL1. Proc Natl Acad Sci USA 103: 6386-6391, 2006

530. Zambon AC, Zhang L, Minovitsky S, Kanter JR, Prabhakar S, Salomonis N, Vranizan K, Dubchak I, Conklin BR, Insel PA. Gene expression patterns define key transcriptional events in cellcycle regulation by cAMP and protein kinase A. Proc Natl Acad Sci USA 102: 8561-8566, 2005.

531. Zatz M, Herkenham MA. Intraventricular carbachol mimics the phase-shifting effect of light on the circadian rhythm of wheelrunning activity. Brain Res 212: 234-238, 1981.

532. Zhang L, Kolaj M, Renaud LP. Suprachiasmatic nucleus communicates with anterior thalamic paraventricular nucleus neurons via rapid glutamatergic and GABAergic neurotransmission: state-dependent response patterns observed in vitro. Neuroscience 141: 2059-2066, 2006.

533. Zhang Y, Kornhauser JM, Zee PC, Mayo KE, Takahashi JS, Turek FW. Effects of aging on light-induced phase-shifting of circadian behavioral rhythms, fos expression and CREB phosphorylation in the hamster suprachiasmatic nucleus. Neuroscience 70: 951-961, 1996.

534. Zhang Y, Takahashi JS, Turek FW. Critical period for cycloheximide blockade of light-induced phase advances of the circadian locomotor activity rhythm in golden hamsters. Brain Res 740: 285-290, 1996

535. Zheng B, Albrecht U, Kaasik K, Sage M, Lu W, Vaishnav S, Li Q, Sun ZS, Eichele G, Bradley A, Lee CC. Nonredundant roles of the mPer1 and mPer2 genes in the mammalian circadian clock. Cell 105: 683-694, 2001.

536. Zhou H, Zarubin T, Ji Z, Min Z, Zhu W, Downey JS, Lin S, Han J. Frequency and distribution of AP-1 sites in the human genome. DNA Res 12: 139-150, 2005.

537. Zhou QY, Cheng MY. Prokineticin 2 and circadian clock output. FEBS Lett 272: 5703-5709, 2005.

538. Zylka MJ, Shearman LP, Weaver DR, Reppert SM. Three period homologs in mammals: differential light responses in the suprachiasmatic circadian clock and oscillating transcripts outside of brain. Neuron 20: 1103-1110, 1998. 


\section{Diego A. Golombek and Ruth E. Rosenstein}

Physiol Rev 90:1063-1102, 2010. doi:10.1152/physrev.00009.2009

You might find this additional information useful...

This article cites 532 articles, 180 of which you can access free at:

http://physrev.physiology.org/cgi/content/full/90/3/1063\#BIBL

Medline items on this article's topics can be found at http://highwire.stanford.edu/lists/artbytopic.dtl on the following topics:

Biochemistry .. Aspartate

Neuroscience .. Glutamate

Biochemistry .. Polypeptides

Genetics .. Clock Genes

Veterinary Science .. Suprachiasmatic Nuclei

Physiology .. Chronobiology

Updated information and services including high-resolution figures, can be found at:

http://physrev.physiology.org/cgi/content/full/90/3/1063

Additional material and information about Physiological Reviews can be found at: http://www.the-aps.org/publications/prv

This information is current as of August 6, 2010 . 